\title{
PLANEJAMENTO DO USO SUSTENTÁVEL DA TERRA EM MICROBACIAS HIDROGRÁFICAS: \\ UMA ABORDAGEM DE PROGRAMAÇÃO POR METAS
}

\section{LUÍS ALBERTO AMBRÓSIO}

Engenheiro Agrônomo

\author{
Orientador: Prof. Titular FERNANDO CURI PERES \\ Coorientador: PqC. Dr. PEDRO LUIZ DONZELI
}

\begin{abstract}
Tese apresentada à Escola Superior de Agricultura "Luiz de Queiroz", Universidade de São Paulo, para obtenção do título de Doutor em Ciências, Área de Concentração: Economia Aplicada.
\end{abstract}

\section{PIRACICABA}

Estado de São Paulo - Brasil

Maio - 1997 


\section{Dados Internacionais de catalogação na Publicação (CIP) DIVISÃO DE BIBLIOTECA E DOCUMENTAÇĀO - Campus "LUiz de Queiroz"/USP}

\section{Ambrósio, Luis Alberto}

Planejamento do uso sustentável da terra em microbacias hidrográficas: uma abordagem de programaçāo por metas / Luis Alberto Ambrósio. - Piracicaba, 1997.

161 p. : il.

Tese (doutorado) - Escola Superior de Agricultura Luiz de Queiroz, 1997.

Bibliografia.

1. Agricultura sustentável 2. Conservaçāo do solo 3. Erosāo do solo 4. Microbacia hidrográfica 5. Programação linear 6. Uso do solo I. Título

CDD 333.7313 


\section{PLANEJAMENTO DO USO SUSTENTÁVEL DA TERRA EM MICROBACIAS HIDROGRÁFICAS: UMA ABORDAGEM DE PROGRAMAÇĀO POR METAS}

\section{LUÍS ALBERTO AMBRÓSIO}

Aprovada em: 28.05.1997

Comissão julgadora:

Prof. Titular Fernando Curi Peres

ESALQ/USP

Prof. Associado José Vicente Caixeta Filho ESALQ/USP

Prof $^{\mathrm{a}}$. Dr ${ }^{\mathrm{a}}$. Zilda Paes Barros de Mattos ESALQ/USP

Prof $^{\underline{a}}$. Dr ${ }^{\underline{a}}$. Nídia Nacib Pontuschka FE/USP

PqC Dr. Francisco Lombardi Neto IAC/S.A.A.

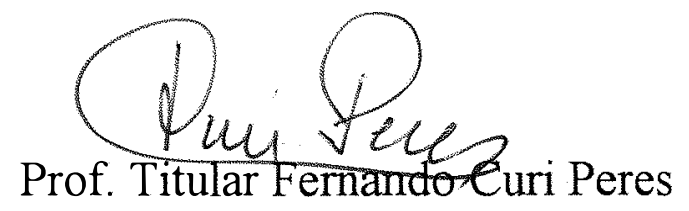

Orientador 
DEDICATÓRIA

DEDICO ESTA TESE

A MARZÉ,

CAMILI,

BETINHO

e

MACHEL,

meus grandes amores. 


\section{AGRADECIMENTOS}

Agradeço ao Prof. Fernando Curi Peres, do Departamento de Economia e Sociologia Rural da ESALQ/USP, pela orientação na elaboração deste trabalho de tese que disponibiliza um método de planejamento agrícola aplicável ao Programa Estadual de Microbacias Hidrográficas e que me conferiu o meu mais alto título acadêmico; pela orientação na escolha de disciplinas de pós-graduação que consolidaram minha formação acadêmica; pelas oportunidades de trabalho com pequenos produtores rurais nos programas que coordenou: Programa Kellogg/NACE-DRI que realizou trabalhos e tornou possível a extensão rural das Escolas Técnicas Agrícolas do Estado de São Paulo voltada para pequenos produtores rurais; Programa LIDERUSP que motivou dezenas de líderes rurais, com diversificada formação ideológica, a trabalharem em conjunto em prol do Desenvolvimento da Agricultura; Programa SENAR/FEALQ que assessorou dezenas de sindicatos rurais na realização de cursos de capacitação profissional de trabalhadores rurais; Programa UNIR que consolidou talvez a maior experiência da USP no desenvolvimento comunitário em dois municípios pobres do Estado de São Paulo: Vera Cruz e Espírito Santo do Turvo; pela oportunidade de interagir com professores da Faculdade de Saúde Pública da USP, Faculdade de Educação da USP e da ESALQ durante a elaboração do Projeto de Pesquisa Temático da FAPESP sobre educação ambiental e pela amizade cultivada com respeito e confiança.

Ao Pesquisador Científico Dr. Pedro Donzeli, da Seção de Fotointerpretação do Instituto Agronômico de Campinas, coorientador desta tese, meus agradecimentos pelas sugestões referentes ao uso do Sistema de Informações Geográficas, pela realização do planejamento da microbacia hidrográfica da Água F, Vera Cruz e pelo incentivo para incorporação de parâmetros econômicos no planejamento de microbacias hidrográficas. 
Ao Pesquisador Científico Dr. Francisco Lombardi Neto, da Seção de Fotointerpretação do Instituto Agronômico de Campinas, meus agradecimentos pela disponibilização de recomendações conservacionista para a microbacia da Água F e pelas inúmeras leituras deste trabalho e pela participação na Banca de Tese.

Meus agradecimentos ao Prof. José Vicente Caixeta Filho, do Departamento de Economia e Sociologia da ESALQ/USP, pela participação na Banca de Tese e pelas sugestões apresentadas na finalização deste trabalho.

Meus agradecimentos à Profe. Zilda Paes Barros de Mattos, do Departamento de Economia e Sociologia da ESALQ/USP, pela participação na Banca de Tese e pelas sugestões apresentadas na finalização deste trabalho.

Meus agradecimentos à Prof . Nídia Nacib Pontuschka, da Faculdade de Educação da USP, pela participação na Banca de Tese e pelas sugestões apresentadas na finalização deste trabalho.

Meus agradecimentos ao Engenheiro Agrônomo Reinaldo Oléa Corrêa da CATI da Dira de Marília, pela disponibilização de informações sobre os sistemas de cultivos recomendáveis para a região de Marília.

Meus agradecimentos à $\mathrm{PqC}$. Malimiria Norico Otani, do Instituto de Economia Agrícola, pela disponibilização das informações cadastrais das propriedades da Microbacia Hidrográfica da Água F, Vera Cruz.

Meus agradecimentos ao $\mathrm{PqC}$ Hiroshige Okawa, do Instituto de Economia Agrícola, pela disponibilização de informações de custos operacionais para as culturas na região de Marília.

Meus agradecimentos ao PqC. Nilberto Bernardo Soares, da Seção de Fruticultura Tropical do Instituto Agronômico de Campinas, pela disponibilização das informações dos sistemas de cultivos de frutíferas recomendáveis para a região da Alta Paulista.

Meus agradecimentos ao PqC. Paulo de Souza Gonçalves, do Programa de Seringueira do Instituto Agronômico de Campinas, pela disponibilização das informações do sistema de cultivo de seringueira para a região de Marília. 
Meus agradecimentos aos Pesquisadores Científicos José Antonio Quaggio e Bernardo van Raij, da Seção de Fertilidade do Solo e Nutrição de Plantas do Instituto Agronômico de Campinas, pelas análises de solo e orientação para recomendação de calagem e fertilizantes.

Meus agradecimentos à $\mathrm{PqC}$ Maria Helena de A. Melo, da Seção de Climatologia do Instituto Agronômico de Campinas, pelas informações sobre dias trabalháveis com trator na Microbacia Hidrográfica da Água F, Vera Cruz.

Meus agradecimentos ao $\mathrm{PqC}$ Irineu Arcaro Junior, do Instituto de Zootecnia de Nova Odessa, pela disponibilização de informações sobre os sistemas manejo de gado de leite e corte.

Meus agradecimentos ao Prof. Luis Carlos Moreno Canedo, da Escola Técnica Agrícola de Vera Cruz, pelo apoio e pela apresentação dos estagiários que realizaram as amostras de solos, nas propriedades da microbacia hidrográfica da Água F, Vera Cruz.

Meus agradecimentos ao Engenheiro Agrônomo Francisco Irineu Menin da Cooperativa dos Cafeicultores de Vera Cruz, pela disponibilização dos preços locais de insumos agrícolas e pelas informações sobre a cultura do café.

Meus agradecimentos aos Professores do Curso de Pós-graduação em Economia Aplicada, do Departamento de Economia e Sociologia Rural da ESALQ, pelos ensinamentos, pelo incentivo e pela dedicação aos alunos.

Meus agradecimentos aos Colegas de Turma do Curso de Pósgraduação em Economia Aplicada da ESALQ, pelo companheirismo cultivado ao longo do curso.

Meus agradecimentos aos Funcionários do Departamento de Economia e Sociologia da ESALQ: Cristiane Cipriano, Elenice Cazalatina de Mattos, Helena Aparecida Cardoso de Oliveira, Luciane Cristina Cipriano, Márcia Maria Beltrame Correia, Maria Angélica Amador Oliveira e Maria Aparecida Maielli Travalini, pela atenção, apoio e colaboração prestadas ao longo do curso. 
Meus agradecimentos à Fundação W. Kellogg, via Programa UNIR, que facilitou os contatos com os pequenos produtores da Microbacias Hidrográfica da Água F, Vera Cruz.

Meus agradecimentos à Fundação de Amparo à Pesquisa do Estado de São Paulo - FAPESP pelo financiamento das atividades de pesquisa.

Meus agradecimentos à CAPES pela concesão de bolsa de doutorado.

Meus agradecimentos à Diretoria do Instituto Agronômico de Campinas pelo apoio e pelas facilidades fornecidas ao longo de todo o curso de doutorado.

Meus agradecimentos aos colegas de trabalho da Seção de Técnica Experimental e Cálculo do Instituto Agronômico de Campinas, Pesquisadores Científicos Toshio Igue, Violeta Nagai, Armando Conagin, Luiz Eugênio Coelho Miranda, Ana Maria Futino pelo apoio e incentivo ao longo de todo o curso de doutorado.

Meus agradecimentos aos PRODUTORES RURAIS da Microbacia Hidrográfica da Água F, Vera Cruz, por disponibilizarem seus preciosos tempos e por confidenciarem sobre seus trabalhos e propriedades. 


\section{SUMÁRIO}

Página

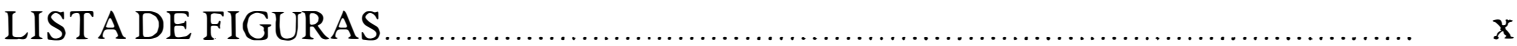

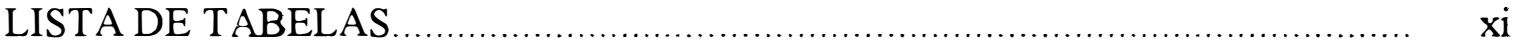

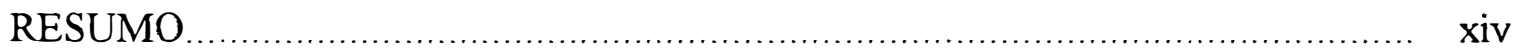

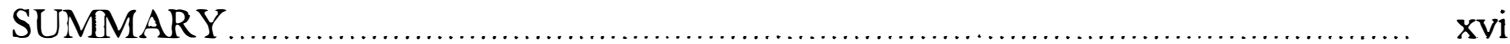

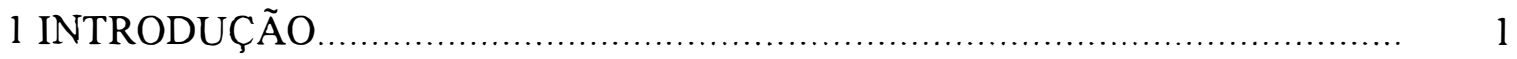

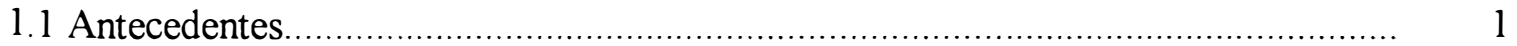

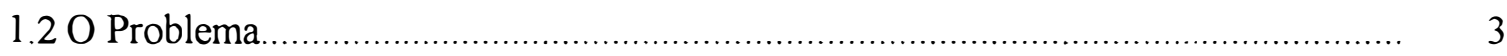

1.3 Objetivos

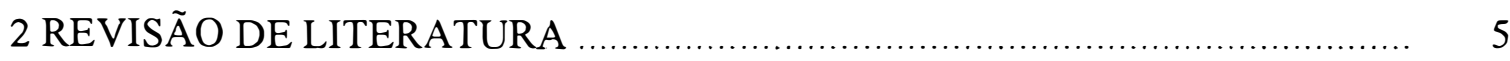

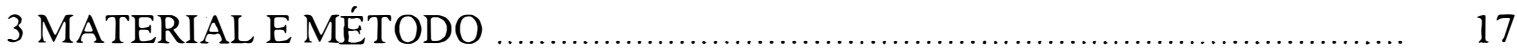

3.1 Modelo conceitual de sistema de produção........................................... 17

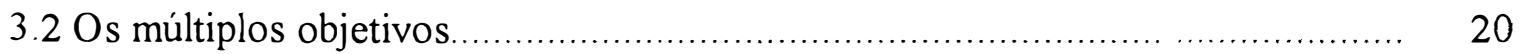

3.3 As atividades e as restrições...................................................... 24

3.4 A programação por metas lexicográficas............................................. 25

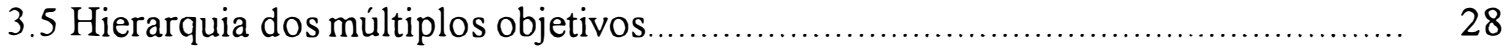

3.6 Sistema de Informações Geográficas aplicado no planejamento da

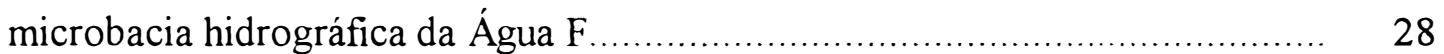

3.7 Método de Planejamento do Uso Sustentável da Terra.............................. 32

3.8 Microbacia hidrográfica da Água F, Vera Cruz......................................... 34

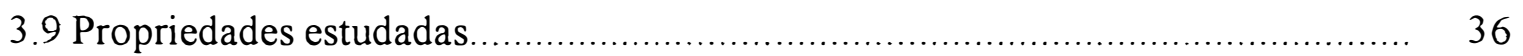

3. 10 Construção de cenários para otimização dos múltiplos objetivos.................. 41

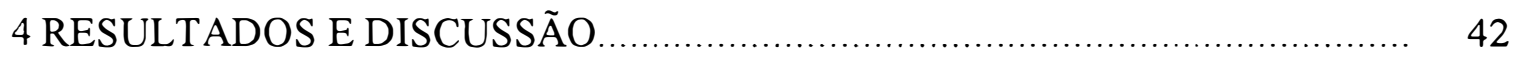

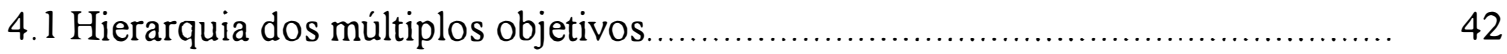


4.2 Otimização dos objetivos

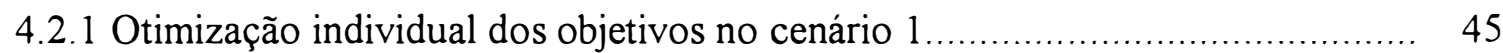

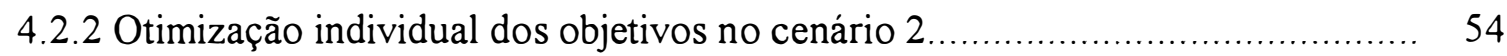

4.2.3 Comparação das atividades selecionadas na otimização individual dos objetivos nos cenários 1 e 2 .

4.3 Otimização lexicográfica dos múltiplos objetivos. 64

4.4 Discussão do impacto do planejamento do uso sustentável da terra nos sistemas de produção 71

5 CONCLUSÕES 76

REFERÊNCIAS BIBLIOGRÁFICAS 78

APÊNDICE 1 - PROGRAMAÇÃO MULTICRITÉRIO: UM INSTRUMENTO PARA PLANEJAMENTO AGRÍCOLA 86 APÊNDICE 2 - EQUAÇÕES DAS FUNÇÕES OBJETIVOS, METAS E RESTRIÇÕES 


\section{LISTA DE FIGURAS}

Página

1 Diagrama simplificado de um sistema aberto................................................ 18

2 Diagrama do atributo hierárquico do sistema agrícola.................................... 18

3 Diagrama simplificado do sistema de produção agrícola, com as interações entre os subsistemas de cultivo, criação, florestal, quintal, recursos naturais, financeiro, recursos materiais e familiar

4 Carta da capacidade de uso sustentável da terra, limites das propriedades e plano hídrico da microbacia hidrográfica da Água F, Vera Cruz, 1996.

5 Fluxograma do Planejamento do Uso Sustentável da Terra em Microbacias Hidrográficas.

6 Cartão que ilustra o objetivo de minimizar o uso de defensivos agrícolas. 140

7 Cartão que ilustra o objetivo de maximizar o lucro

8 Cartão que ilustra o objetivo de minimizar a estacionalidade do fluxo de caixa.... 142

9 Cartão que ilustra o objetivo de maximizar o uso da mão-de-obra permanente.... 143

10 Cartão que ilustra o objetivo de maximizar a produção de alimentos básicos. 144

11 Cartão que ilustra o objetivo de minimizar a estacionalidade do uso da mão-de-obra 


\section{LISTA DE TABELAS}

Página

1 Atividades recomendadas por classe de capacidade de uso sustentável da terra, para a microbacia hidrográfica da Água F, Vera Cruz, 1996.

2 Uso da terra, microbacia hidrográfica da Água F, Vera Cruz, 1991 35

3 Disponibilidade de recursos de capital, trator, mão-de-obra familiar e residente em 6 propriedades da microbacia da Água F, Vera Cruz, 1994.

4 Total mensal de horas trabalháveis com trator na microbacia hidrográfica da Água F, Vera Cruz. 38

5 Uso atual do solo, atividades em ha, em 6 propriedades da microbacia hidrográfica da Água F, Vera Cruz, 1994.

6 Áreas, em hectares, das classes de capacidade de uso sustentável da terra, em 6 propriedades da microbacia hidrográfica da Água F, Vera Cruz, 1996.

7 Hierarquia dos múltiplos objetivos dos tomadores de decisão em 6 propriedades da microbacia hidrográfica da Água F, Vera Cruz, 1996.

8 Valores calculados para o uso de defensivos químicos, lucro, estacionalidade do fluxo de caixa, uso da mão-de-obra permanente, produção de alimentos básicos, estacionalidade do uso da mão-de-obra, considerando o uso atual da terra, em 6 propriedades da microbacia hidrográfica da Água F, Vera Cruz, 1996... 43

9 Atividades selecionadas pela otimização individual dos objetivos, cenário 1 , da propriedade P1, microbacia hidrográfica da Água F, Vera Cruz, 1996 46

10 Atividades selecionadas pela otimização individual dos objetivos, cenário 1 , da propriedade P2, microbacia hidrográfica da Água F, Vera Cruz, 1996. 
11 Atividades selecionadas pela otimização individual dos objetivos, cenário 1, da propriedade P3, microbacia hidrográfica da Água F, Vera Cruz, 1996

12 Atividades selecionadas pela otimização individual dos objetivos, cenário 1 , da propriedade P4, microbacia hidrográfica da Água F, Vera Cruz, 1996.

13 Atividades selecionadas pela otimização individual dos objetivos, cenário 1 , da propriedade P5, microbacia hidrográfica da Água F, Vera Cruz, 1996.

14 Atividades selecionadas pela otimização individual dos objetivos, cenário 1 , da propriedade P6, microbacia hidrográfica da Água F, Vera Cruz, 1996.

15 Atividades selecionadas pela otimização individual dos objetivos, cenário 2, da propriedade P1, microbacia hidrográfica da Água F, Vera Cruz, 1996.

16 Atividades selecionadas pela otimização individual dos objetivos, cenário 2 , da propriedade P2, microbacia hidrográfica da Água F, Vera Cruz, 1996. 56

17 Atividades selecionadas pela otimização individual dos objetivos, cenário 2, da propriedade P3, microbacia hidrográfica da Água F, Vera Cruz, 1996.

18 Atividades selecionadas pela otimização individual dos objetivos, cenário 2, da propriedade P4, microbacia hidrográfica da Água F, Vera Cruz, 1996.

19 Atividades selecionadas pela otimização individual dos objetivos, cenário 2 , da propriedade P5, microbacia hidrográfica da Água F, Vera Cruz, 1996.

20 Atividades selecionadas pela otimização individual dos objetivos, cenário 2 , da propriedade P6, microbacia hidrográfica da Água F, Vera Cruz, 1996.

21 Atividades selecionadas pela otimização lexicográfica dos objetivos, cenário 1 , para cada gleba das 6 propriedades da microbacia hidrográfica da Água F, Vera Cruz, 1996.

22 Atividades selecionadas pela otimização lexicográfica dos objetivos, cenário 2 , para cada gleba das 6 propriedades da microbacia hidrográfica da Água F, Vera Cruz, 1996.

23 Valores alcançados pela otimização lexicográfica dos objetivos, nos cenários

1 e 2 e valores atuais para 6 propriedades da microbacia hidrográfica da Água F, Vera Cruz, 1996 
24 Uso dos recursos de mão-de-obra (familiar, residente e eventual) e de trator (uso próprio, aluguel e contratação) resultantes da otimização lexicográfica dos objetivos, em 6 propriedades da microbacia hidrográfica da Água F, Vera Cruz, 1996 


\title{
PLANEJAMENTO DO USO SUSTENTÁVEL DA TERRA EM MICROBACIAS HIDROGRÁFICAS: UMA ABORDAGEM DE PROGRAMAÇÃO POR METAS
}

\author{
Autor: LUÍS ALBERTO AMBRÓSIO \\ Orientador: Prof. Titular FERNANDO CURI PERES
}

\section{RESUMO}

O Programa Estadual de Microbacias Hidrográficas de São Paulo (PEMBH) foi concebido com múltiplos objetivos a serem otimizados com atividades em conformidade com a Capacidade de Uso Sustentável da Terra (CUST). A implementação destas atividades depende dos interesses e das possibilidades dos agricultores da microbacia. O trabalho apresenta um método para Planejamento do Uso Sustentável da Terra (PUST) em Microbacias Hidrográficas, com base na proposta conservacionista do Instituto Agronômico de Campinas. A otimização dos objetivos (minimizar a erosão do solo, minimizar o uso de defensivos químicos, maximizar a produção de alimentos básicos, maximizar a margem bruta, minimizar a estacionalidade da renda, maximizar o uso da mão-de-obra fixa e minimizar a estacionalidade do uso da mão-de-obra) sujeita às restrições de disponibilidade de máquinas, mão-de-obra permanente e capital e usando a programação por metas lexicográficas (PML), selecionou determinados usos para as terras das propriedades. A adoção das alternativas selecionadas afetaria diferentemente os sistemas de produção em termos de mudanças no "layout" das glebas, racionalizando o uso da mão-de-obra, de máquinas e de defensivos químicos, mantendo ou aumentando a renda e a produção de alimentos básicos e promovendo a conservação dos solos. O PUST, por considerar os múltiplos objetivos hierarquizados pelos tomadores de decisão, produz recomendações mais aceitáveis pelos 
produtores rurais. Portanto, pode ser usado no Programa Estadual de Microbacias Hidrográficas.

PALAVRA CHAVE: Planejamento Multi-objetivo, Microbacia Hidrográfica, Sistemas de Produção, Programação por Metas Lexicográficas. 


\title{
PLANNING FOR SUSTAINABLE WATERSHED SOIL USE: A GOAL PROGRAMMING APPROACH.
}

\author{
Author: LUÍS ALBERTO AMBRÓSIO \\ Adviser: Prof. FERNANDO CURI PERES
}

\section{SUMMARY}

The São Paulo State Watershed Program (PEMBH) was drawn with multiple objectives to be optimized through planning of sustainable agricultural activities. Important dimensions that must be considered in implementing the PEMBH are farmer's specific objectives and farm restrictions. This work presented a method for Planning Land Use (PLU) in a sustainable way, using Lexicographic Goal Programming to plan the mix of activities for each farm. These objectives were: minimization of runoff effects, pesticide use, seasonal income variability, and seasonal demand for labor; and maximization of farm gross margin, basic staple production, and resident labor use. The optimization process pointed to activities that affected the farm system (labor, machinery, and pesticides use, crop layout, gross margins, staple production, and soil conservation) in different ways. More acceptable solutions to farmers' multiple objectives were suggested through PLU.

KEY WORDS: Multi-objective Agricultural Programming, Watershed, Agricultural System, Goal Programming. 


\section{PLANEJAMENTO DO USO SUSTENTÁVEL DA TERRA EM \\ MICROBACIAS HIDROGRÁFICAS: \\ UMA ABORDAGEM DE PROGRAMAÇÃO POR METAS}

\section{NTRODUÇÃO}

\subsection{Antecedentes}

Docentes da Escola Superior de Agricultura "Luiz de Queiroz" junto com professores de seis escolas agrotécnicas do Estado de São Paulo (ETAS) implantaram um programa de desenvolvimento de comunidades rurais, chamado Programa de Desenvolvimento Rural Integrado (DRI), centrado no trabalho de extensão rural das ETAS. O DRI, financiado pela Fundação W. K. Kellogg, propiciou treinamento aos professores das ETAS e estágios na universidade para alunos dessas escolas. Também foi implementado um programa de lideranças rurais com o propósito de recuperar a auto-estima das populações locais e de criar parcerias entre comunidades e instituições.

O Projeto DRI foi integrado por seis municípios do Estado de São Paulo, dentre os quais o de Vera Cruz. Em continuidade ao DRI vem sendo implementado um novo projeto, denominado "Uma Nova Iniciativa em Desenvolvimento Rural" (UNIR), com características diferentes do DRI, integrando as áreas de educação, saúde e agricultura, mantendo a ênfase no desenvolvimento rural.

O Projeto UNIR vem promovendo uma atuação conjunta interinstitucional e interdisciplinar abrangendo a Universidade de São Paulo, as comunidades e as instituições dos municípios de Vera Cruz e Espírito Santo do Turvo. Sua finalidade é aumentar a capacidade de organização dos pequenos produtores e trabalhadores rurais e contribuir para melhorar suas rendas e condições de vida, capacitar as instituições locais a elevar a qualidade dos serviços prestados e qualificar professores e estudantes a buscarem a superação de problemas 
sociais, políticos e econômicos das famílias de pequenos produtores e trabalhadores rurais. $\mathrm{O}$ Instituto Agronômico de Campinas (IAC) é uma das instituições alvo do UNIR a qual vem atuando, no município de Vera Cruz, através do Programa Estadual de Microbacias Hidrográficas (PEMBH).

O Programa Estadual de Microbacias Hidrográficas foi criado pela Secretaria de Agricultura e Abastecimento do Estado de São Paulo, em 1992, para controlar a erosão hídrica do solo minimizando seus efeitos na deterioração do ambiente e no assoreamento dos cursos e espelhos d'água. O PEMBH define a microbacia hidrográfica como uma área fisiográfica drenada por um curso d'água ou por um sistema de cursos d'água conectados e que convergem, direta ou indiretamente, para um leito ou para um espelho d'água, constituindo uma unidade ideal para o planejamento integrado do manejo dos recursos naturais. A proposta do PEMBH é implementar trabalhos de manejo do solo e da água, na microbacia, com uma visão holística, isto é, do aproveitamento integrado dos recursos naturais: solo, água, flora e fauna. Assim, o trabalho conservacionista do PEMBH ultrapassa os limites físicos das propriedades agrícolas contidas na microbacia, diferenciando-se, desta forma de outros trabalhos conservacionistas com ações isoladas numa propriedade agricola.

O PEMBH pretende integrar os interesses de todos os segmentos da sociedade em termos de abastecimento, saneamento, habitação, lazer, preservação do ambiente, produtividade, elevação da renda e bem-estar de toda a comunidade (Lombardi Neto, 1993). A Microbacia Hidrográfica da Água $\mathbf{F}{ }^{1}$ de Vera Cruz foi selecionada, pela Comissão Estadual de Pesquisa e Extensão, como uma das microbacias pilotos, onde se desenvolveriam as pesquisas agronômicas e conservacionistas que geram tecnologia para servir de base ao PEMBH.

O problema deste trabalho de tese surgiu do esforço do UNIR para promover parcerias entre a Universidade de São Paulo, a comunidade de Vera Cruz e o Instituto Agronômico de Campinas. Esse problema está relacionado com o PEMBH e com a obtenção de alternativas de uso da terra para pequenos produtores rurais.

${ }^{1}$ Água F é a denominação cartográfica do córrego afluente do Rio do Peixe, localizado nas coordenadas geográficas: Latitude Sul $22^{\circ} 15^{\prime}$ a $22^{\circ} 18^{\prime}$ e Latitude Oeste $49^{\circ} 47^{\prime}$ a $49^{\circ} 51^{\prime}$. 


\subsection{O Problema}

A consecução dos propósitos do PEMBH, em especial na adoção de técnicas conservacionistas e de alternativas de uso da terra ${ }^{2}$, depende dos interesses e das possibilidades das empresas agrícolas contidas na microbacia, bem como dos interesses da comunidade. Para tanto, o PEMBH deve atender múltiplos objetivos: minimizar a erosão do solo, minimizar o uso de defensivos químicos, maximizar a produção de alimentos básicos, maximizar a receita líquida, minimizar a estacionalidade da renda, minimizar risco, maximizar o uso da mão-de-obra permanente (familiar e residente), minimizar a estacionalidade do uso da mão-de-obra e maximizar a produção de alimentos para autoconsumo. Um aspecto a ser aprofundado no âmbito do PEMBH refere-se à obtenção de alternativas de uso do solo que otimizem os múltiplos objetivos e permitam a implementação de trabalhos de conservação do solo com observância da Capacidade de Uso Sustentável da Terra (CUST), na propriedade agrícola.

Não se encontra na literatura um método desenvolvido para selecionar atividades planejadas para propriedades agrícolas, no contexto de microbacias hidrográficas, que considere a otimização simultânea de múltiplos objetivos conflitantes. Neste trabalho, é proposto um método, denominado Planejamento do Uso Sustentável da Terra (PUST), baseado na proposta conservacionista do Instituto Agronômico de Campinas (IAC), que enfatiza o manejo do solo em termos de fertilidade, mecanização, drenagem e cobertura vegetal, além de usar variáveis físicas do solo, para definir as classes de capacidade de uso sustentável da terra.

O PUST, além de possibilitar a obtenção de alternativas de uso da terra, também possibilita o conhecimento, "ex-ante", do impacto da adoção dessas alternativas nos sistemas de produção, em especial, na produção, na renda líquida, no uso da mão-de-obra e no uso de defensivos químicos, para cada propriedade da microbacia hidrográfica. A complexidade do PUST requer a construção de um modelo de sistema de produção, com

\footnotetext{
${ }^{2}$ O termo terra se refere ao espaço superficial e o termo solo se refere ao corpo com caraterísticas edafológicas e pedológicas.
} 
enfoque sistêmico, que tome explícito o modo como o proprietário toma decisões na adoção de tecnologias e na escolha das atividades implementadas em diferentes glebas (parcelas) de terra. Na literatura, a resolução de problemas que envolvem múltiplos objetivos são tratados de forma apropriada pelos modelos de programação multicritério de tomada de decisão ("Multiple Criteria Decision Making" - MCDM). Dentre estes modelos, a Programação por Metas Lexicográficas (PML) tem sido usada no planejamento agrícola. A comparação do uso atual da terra com o uso ótimo, obtido através da PML e tendo como restrição a CUST, pode permitir a avaliação do impacto do PUST nos sistemas de produção de uma microbacia hidrográfica.

Em síntese, a hipótese básica testada é de que a implementação do Planejamento do Uso Sustentável da Terra afeta, com intensidades diferentes, as otimizações dos múltiplos objetivos relacionados com as empresas agrícolas (sistemas de produção agrícola ou "farm systems"), no contexto de microbacias hidrográficas.

A importância desta pesquisa está em testar um método para auxiliar a escolha de alternativas para o uso sustentável da terra de propriedades agrícolas que participarem do Programa Estadual de Microbacias Hidrográficas, o qual pretende estabelecer trabalhos conservacionistas em mil e quinhentas microbacias no Estado de São Paulo.

\subsection{Objetivos}

\section{Objetivo geral:}

Propor um método para planejamento do uso sustentável da terra, nos sistemas de produção de uma microbacia hidrográfica.

\section{Objetivos específicos:}

(1) Testar o método de programação multicritério, conhecido como Programação por Metas Lexicográficas, para selecionar alternativas de uso da terra que otimizem os múltiplos objetivos do PEMBH, sujeitos às restrições do planejamento do uso sustentável da terra.

(2) Obter alternativas de explorações agropastoris que possam ser adotadas pelos produtores da microbacia hidrográfica da Água F em Vera Cruz, São Paulo. 


\section{REVISÃO DE LITERATURA}

"A degradação do solo insere-se no conjunto dos problemas do meio ambiente e dos recursos naturais, que só serão equacionados em termos de planejamento global. Para proteger e conservar a Natureza é preciso conhecê-la. Isto envolve todas as esferas sociais, desde as instituições governamentais, os profissionais e cientistas, as faculdades e demais escolas, estendendo-se à toda a comunidade" (Lombardi Neto, 1993, p.24).

Pretende-se, nesta revisão de literatura: (1) mostrar como vem sendo estudado o planejamento do uso sustentável da terra, do ponto de vista conservacionista, em microbacias hidrográficas e explicitar os objetivos do PEMBH; (2) mostrar, usando o enfoque sistêmico, como o tomador de decisão da empresa agrícola considera múltiplos objetivos na adoção de tecnologias, em especial de práticas recomendadas pelo planejamento do uso sustentável da terra e (3) discutir a adequação do método de Programação por Metas Lexicográficas para determinar o impacto do planejamento do uso sustentável da terra e selecionar alternativas de exploração econômica para os sistemas de produção em microbacias hidrográficas.

No Estado de São Paulo, a degradação dos recursos naturais, principalmente do solo e da água, atingiu níveis críticos que se refletem na deterioração do ambiente, no assoreamento e na poluição dos cursos e espelhos d'água, com prejuízos para a saúde humana e animal, na destruição de estradas, pontes e bueiros, na geração de energia elétrica, na disponibilidade de água para irrigação e abastecimento, na redução da produtividade agrícola, na diminuição da renda líquida e, conseqüentemente, no empobrecimento do meio rural. Para controlar a erosão hídrica e minimizar os seus efeitos, criou-se o Programa Estadual de Microbacias Hidrográficas (Lombardi Neto, 1993). 
O sistema hidrográfico apresenta uma grande diferenciação de formas, tamanhos e densidades, determinada por inúmeros fatores ecológicos. Em vista disto, a unidade espacial mínima de delimitação do sistema hidrográfico deve ser identificada, obedecendo rigidamente a lógica da dinâmica e da conformação da rede fluvial à qual está ligada. Para fins conservacionistas de aplicação de um plano de manejo de solo e água, a unidade espacial mínima delimitada - microbacia hidrográfica - deve ter uma área que varia de 1000 a 5000 hectares. Esta área possibilita um planejamento global dos problemas do ambiente e dos recursos naturais, atingindo as esferas social, política, econômica e educacional. A proposta do PEMBH é implementar trabalhos de manejo do solo e da água na microbacia, com uma visão holística, isto é, do aproveitamento integrado dos recursos naturais: solo, água, flora e fauna. Assim, o trabalho conservacionista do PEMBH ultrapassa os limites fisicos das propriedades agrícolas contidas na microbacia. Desta forma, diferencia-se de outros trabalhos conservacionistas que propõem projetos isolados de conservação do solo dentro dos limites de uma propriedade agricola (Lombardi Neto, 1993). A consecução dos propósitos do PEMBH deve atender múltiplos objetivos que, neste trabalho, são classificados em dois grupos:

I. Buscar melhor estrutura organizacional, através:

(1) do estabelecimento das condições para o uso sustentável do solo e da água, na microbacia;

(2) da racionalização do uso dos recursos materiais, financeiros e de pessoal em âmbito federal, estadual e municipal, compatibilizando e otimizando sua utilização;

(3) da maximização das rendas municipais e comunitárias, através da minimização de custos de administração, de manutenção de estradas, de obras de arte, de controle da poluição etc;

(4) do incentivo à organização associativa dos produtores rurais, visando a solução de seus problemas comuns;

(5) do estímulo ao planejamento, à organização e à comercialização da produção municipal, sobretudo dos alimentos básicos;

(6) da promoção de ações comunitárias visando a obtenção de beneficios nas áreas de produção, comercialização, saúde, educação, transporte, comunicação etc. 
II. Buscar a sustentabilidade dos sistemas de produção, através:

(1) do manejo adequado dos recursos naturais renováveis, solo e água;

(2) da redução dos processos de degradação do solo causados pela erosão, garantindo maior disponibilidade e melhor qualidade de água para usos múltiplos;

(3) da diminuição dos riscos causados por fatores climáticos, biológicos e mercadológicos;

(4) do incremento à produção e à produtividade agropastoris;

(5) da obtenção de novas alternativas de exploração econômica para as propriedades agrícolas;

(6) da contribuição para o processo de fixação do homem no campo.

Esta classificação se faz necessária para explicitar a hipótese básica a ser testada neste trabalho. Os objetivos do primeiro grupo abrangem interesses gerais da comunidade e seus custos e beneficios são sociais. Por outro lado, a consecução dos objetivos do segundo grupo está essencialmente relacionada com os interesses e com as possibilidades, ou seja, com as vantagens comparativas das empresas agrícolas contidas na microbacia, embora também sejam de interesse geral da comunidade. A implementação do planejamento integrado dos recursos naturais da microbacia depende do grau de satisfação dos interesses do tomador de decisão das empresas agrícolas, consideradas isoladamente. Assim, a adoção do planejamento do $\mathrm{PEMBH}$, pelas empresas agrícolas, pressupõe que cada propriedade deve: investir em obras de conservação do solo; destinar áreas para reflorestamento e mata ciliar; modificar o "layout" (arranjo) das parcelas de cultivo e pastagens conforme novos contornos conservacionistas; diversificar as atividades de produção; usar insumos agrícolas de forma racional; diminuir a estacionalidade do uso da mão-de-obra ao longo do ano; gerar renda familiar no mínimo igual a renda urbana de atração e maximizar o lucro da propriedade agrícola. Neste aspecto, identificam-se objetivos conflitantes (por exemplo, a maximização do lucro requer o uso intensivo de tecnologia e isto é conflitante com a minimização o uso de defensivos) isto é, a plena consecução de determinados objetivos só será possivel em detrimento de outros.

As microbacias hidrográficas formam um sistema geográfico uniforme em vários aspectos edáficos e climáticos. Entretanto, existem variações nos tipos, texturas e 
declividade dos solos determinando a existência de glebas de terra com capacidades de uso sustentável do solo diferentes, que devem ser consideradas nos trabalhos de conservação do solo e na escolha de atividades agropastoris. A rigor, os trabalhos de conservação dos solos devem cobrir toda área da microbacia de forma contínua e ultrapassar os marcos das divisas das propriedades agricolas, para terem eficácia na minimização das perdas de solo. No planejamento de microbacias hidrográficas há dois aspectos importantes relacionados com o "layout" das atividades agropastoris, ou seja, com a disposição das parcelas (glebas) de terra destinadas às culturas, pastos e florestas. O primeiro é o Uso Atual da Terra que descreve o tipo de exploração em uso e, conseqüentemente, se refere à disposição das parcelas de culturas, pastos e florestas praticada pelos proprietários das terras em função de suas preferências. O segundo é a Capacidade de Uso Sustentável da Terra, que se refere ao uso adequado das glebas de terra, determinada com o uso de parâmetros de potencial de erosão e de manejo do solo. Assim, é possivel (de certa forma comprovável pela presença de erosão do solo) que numa propriedade agricola, o Uso Atual da Terra não esteja de acordo com a Capacidade de Uso Sustentável. Então, recomenda-se modificar o "layout" das atividades agropastoris em determinadas parcelas ou glebas de terra.

Um aspecto a ser aprofundado no âmbito do $\mathrm{PEMBH}$ refere-se à adoção das recomendações técnicas planejadas nos trabalhos de microbacias, especificamente na implementação de trabalhos de conservação do solo com observância da Capacidade de Uso Sustentável e na implementação de atividades agropastoris. A adoção destas técnicas depende das preferências do produtor rural e é orientada pela racionalidade econômica. O produtor, ao decidir pela instalação de uma determinada atividade agropastoril numa parcela, que é subsistema de seu sistema de produção, considera vários objetivos: maximizar o lucro, minimizar o uso de insumos, minimizar os riscos e garantir a subsistência da família, conforme a disponibilidade de recursos financeiros, terra, máquinas e mão-de-obra.

O enfoque sistêmico é uma forma de materializar a visão holística na pesquisa agrícola, integrando disciplinas. A tecnologia agrícola que envolve aspectos da fisica, da química, da biologia, das ciências do comportamento humano e outros, é utilizada num contexto onde interagem fatores de produção, próprios ou adquiridos, condições edafoclimáticas variadas, produções vegetais e animais, microrganismos úteis e patológicos, 
insetos, pragas e ainda uma estrutura familiar intimamente associada ao processo produtivo, formando um todo extremamente complexo, que precisa ser gerido de forma coerente, colocando cada detalhe a serviço dos objetivos do sistema global (Nadall et al., 1992). Este enfoque pode ser aplicado para identificar e selecionar os múltiplos objetivos dos sistemas de produção e seus principais componentes, possibilitando a elaboração de modelos teóricos que representem esses sistemas (Ackoff \& Gupta, 1962). Seu uso, neste trabalho, é adequado, admitido que o problema estudado relaciona-se com o comportamento do sistema de produção agrícola como um todo, face às possíveis mudanças nos seus subsistemas, se o planejamento do uso sustentável da terra for adotado.

$\mathrm{Na}$ literatura de economia agrícola há vários trabalhos que discutem a hipótese do tomador de decisão estar motivado por múltiplos objetivos ou um simples objetivo de maximizar o lucro (Willis \& Perlack, 1980). A abordagem multi-objetivo mais comum envolve lucro, risco e subsistência (Brink \& McCarl, 1978 e Calkins, 1971). A adoção de tecnologias que afetem quaisquer dos subsistemas das propriedades agrícolas é avaliada pelo produtor rural sob os aspectos de lucro, risco e subsistência. Do mesmo modo, para a adoção de práticas conservacionistas e para a introdução de alternativas de exploração econômica devem ser considerados os múltiplos objetivos da empresa agrícola ou do sistema de produção.

Há exemplos, na literatura, de fracassos em planejamentos de propriedades agrícolas porque deixaram de considerar determinados objetivos dos agricultores. Panagides \& Ferreira (1972) relatam aumentos, na ordem de 30 a $300 \%$ na renda familiar de agricultores tradicionais da Zona da Mata, Minas Gerais, apenas com a adoção de novas tecnologias associadas à atividade de fruticultura. Entretanto, não foi possível incrementar projetos para introdução da fruticultura porque o modelo analítico usado não refletem os sistemas de produção do pequeno produtor, na região de estudo. A introdução de explorações perenes, as quais exigem um período razoável antes de produzir a primeira colheita, é um tipo de alteração que dificilmente seria suportado pelos pequenos produtores descapitalizados, sendo, portanto, necessário analisar esta introdução junto com outras alternativas, para atingir o objetivo de obter um fluxo de caixa estável, como por exemplo, o cultivo intercalar. 
Marss et al. (1976) relatam 36 projetos de introdução de pacotes tecnológicos agrícolas, em 11 países, que estavam sendo experimentados por pequenos produtores. A adoção de pacotes, conforme os autores, apresentaram as seguintes dificuldades: (a) diferenças de objetivos, porque os pacotes procuravam aumentar a produtividade enquanto que os pequenos produtores procuravam aumentar suas rendas; (b) os pacotes foram elaborados sobre a base de pesquisas para aumentar a produtividade de cultivos isolados, enquanto que os produtores buscavam um aumento da renda total obtida de todas as atividades combinadas; e (c) os pequenos produtores se preocupam com a estabilidade dos rendimentos obtidos, enquanto que as inovações técnicas, especialmente as que dependem de novas variedades, tendem a demandar alterações freqüentes a cada 5 ou 10 anos.

Um dos pressupostos da teoria econômica da produção é de que os empresários, tomadores de decisão, são agentes econômicos que se movem única e exclusivamente em busca da maximização do lucro. Uma crítica a este ponto de vista neoclássico, realizada por Simon (1955), sustenta que os tomadores de decisão, mais do que otimizar um objetivo, o lucro, tratam de alcançar um conjunto de múltiplos objetivos conflitantes, isto é, que não se podem otimizar simultaneamente. A Programação Multicritério tem sido desenvolvida como método aplicado ao planejamento sujeito às múltiplas metas e objetivos conflitantes. Os primeiros trabalhos sobre esse método foram efetuados por Kuhn \& Tucker (1951), Chames et al. (1955) e Charnes \& Cooper (1961). Posteriormente, os trabalhos de Ijiri (1965), Lee (1972), Ignizio (1976), Cohon (1978) e Zeleny (1973 e 1982) trouxeram novas contribuições, tornado a Programação Multicritério um método aplicável ao planejamento.

Para a escolha das técnicas algorítmicas da programação multicritério é necessário estabelecer as diferenças conceituais entre objetivos e metas. Romero \& Rehman (1983) esclarecem que os objetivos podem ser expressos como funções matemáticas das variáveis de decisão. Assim, por exemplo, maximizar o lucro, minimizar o risco e maximizar o uso da mão-de-obra permanente, constituem exemplos típicos de objetivos empresariais. Em geral, os objetivos tomam a forma: $\operatorname{Max} \mathrm{f}(\mathbf{x})$ ou $\operatorname{Min} \mathrm{f}(\mathbf{x})$, onde $\mathbf{x}$ é um vetor de variáveis de decisão. Para estabelecer o conceito de meta, os autores definem, previamente, o que se entende por nível de aspiração, que reflete um nível aceitável de ganho para um dos possíveis 
objetivos do tomador de decisão. Assim, por exemplo, se a empresa deseja um lucro de $\mathrm{R} \$ 100.000,00$ no ano, tem-se neste caso uma meta. De modo geral, as metas são expressas da forma $\mathrm{f}(\mathbf{x})>\mathbf{a} ; \mathrm{f}(\mathbf{x})<\mathbf{a}$ ou $\mathrm{f}(\mathbf{x})=\mathbf{a}$, onde a representa o valor do nivel de aspiração.

Os conceitos de metas e de restrições, embora tenham a mesma expressão matemática, diferenciam-se no significado atribuído ao segundo membro da equação. Assim, nas equações das metas, o segundo membro representa um nível de aspiração que o tomador de decisão quer alcançar, podendo não atingir este propósito. Nas equações das restrições, o segundo membro deve ser satisfeito para se obter uma solução possível. Em outras palavras, as metas permitem certas violações das equações, o que não é possível no domínio das restrições.

$\mathrm{Na}$ literatura que estuda o planejamento agrícola, tanto da empresa quanto do regional, é freqüente o uso de métodos de programação linear para otimizar um objetivo, em geral a maximização do lucro, expresso como uma função linear sujeita às restrições lineares de disponibilidade de recursos financeiros, mão-de-obra, máquinas etc. Essas restrições delimitam o campo de soluções possiveis que contém a solução que otimiza a função objetivo. A existência de recursos limitados condiciona a implementação de atividades agrícolas, resultando numa partição de conjunto de soluções possiveis e impossíveis de serem alcançadas. Uma vez conhecidas as soluções possiveis, ainda existe o problema de selecionar dentre elas as soluções preferidas pelos tomadores de decisão.

De modo geral, a tomada de decisão baseada em único objetivo não se ajusta adequadamente ao mundo real das empresas agrícolas, porque a resolução dos problemas reais está sujeita aos múltiplos objetivos, que na maioria das ocasiões apresentam conflitos entre si. Isso torna mais adequado o uso de métodos de Programação Multicritério como instrumento auxiliar na tomada de decisões para implementar atividades agrícolas, como mostram os trabalhos de Wheeler \& Russell (1977), Bartlett \& Clawson (1978), Hitchens et al. (1978), Flinn et al. (1980), Calatrava Requena (1980), Barnett et al. (1982), Romero \& Rehman (1984a, 1984b e 1985), Alonso \& Iruretagoyena (1986 e 1988), Bouzaher \& Mendoza (1987), Maino et al. (1987), Romero et al. (1987), El-Shishiny (1988), Arias (1989), Shakya \& Leuschner (1990), Coetzee et al. (1993), Piech \& Rehman (1993) e Millan $\&$ Berbel (1994). A seguir discute-se alguns destes trabalhos. 
Calatrava Requena (1980) discute o uso da programação multicritério como instrumento de análise de planejamentos agrícolas regionais. Apresenta de forma geral os fundamentos teóricos da programação multicritério, na época ainda pouco desenvolvidos. Conclui que este método é importante para planejamentos de atividades agrícolas que envolvem decisões do Estado e/ou da empresa privada.

Barnett et al. (1982) utilizaram o método de programação por metas ponderadas para selecionar alternativas tecnológicas para pequenos produtores. Os objetivos usados foram: (1) produzir alimentos em quantidade suficiente para a família, inclusive para o período de entressafra; (2) gastar menos em insumos e, conseqüentemente, diminuir a produção; (3) obter mais renda, a ser destinada à compra de animais; (4) organizar o trabalho para ter mais lazer; e (5) obter mais produção, gastando mais dinheiro com insumos. Concluíram que a programação por metas ponderadas não foi superior ao uso da programação linear com maximização do lucro, como método para selecionar alternativas tecnológicas. Esta conclusão foi questionada por Romero \& Rehman (1983) por suporem que as metas estabelecidas foram pessimistas.

Alonso \& Iruretagoyena (1986) trabalharam com programação por metas lexicográficas usando programação quadrática para selecionar alternativas agrícolas sob múltiplas metas em conflitos, sujeitas às restrições de ordem agronômica e comercial. As metas foram hierarquizadas conforme aspirações do planificador. Os dados foram obtidos de questionário em Córdoba, Espanha, contendo: margem bruta das atividades em \$/ha (mão-deobra fixa ou eventual foram consideradas custo variável); emprego de mão-de-obra anual em horas/ha; e distribuição do emprego de mão-de-obra/período que se divide conforme o ano agrícola. As metas consideradas foram: margem bruta; emprego de mão-de-obra e estacionalidade do uso de mão-de-obra. A estrutura de prioridades foi formada: (1) pelas restrições que são prioridades absolutas; (2) pela margem bruta, primeira prioridade; (3) pelo emprego da mão-de-obra, segunda prioridade; e (4) pela estacionalidade do uso de mão-deobra, terceira prioridade.

Romero et al. (1987) aplicaram o método Programação Compromisso (PC) para selecionar alternativas de exploração agrícola irrigada para uma cooperativa em Andaluzia, Espanha, considerando os objetivos de maximizar a oferta de emprego, minimizar 
a sazonalidade do emprego e maximizar o lucro. Concluíram que a PC é uma ferramenta útil para o planejamento agrícola e que este método não introduz dificuldades com relação a abordagem tradicional da programação linear.

Alonso \& Iruretagoyena (1988) compararam os resultados obtidos no planejamento de uma propriedade agrícola usando os métodos de programação multiobjetivos: Programação por Objetivos Ponderados (POP), Método das Restrições, "NonInferior Set Estimation" (NISE), Programação Compromisso (PC), "Step", e "Surrogate Worth Trade-off' (SWT). Os métodos NISE e POP que geram pontos extremos do conjunto de soluções eficientes, geraram a mesma curva de "trade-offs", sendo que o NISE precisou de menor número de interações para obter as soluções. As variáveis de decisão selecionadas foram as mesmas para os dois métodos. Este resultado coincide com o resultado obtido por Alonso \& Iruretagoyena (1986) onde se aplicou o método de programação por metas lexicográficas. Os métodos Programação Compromisso e STEP aproximam-se do conjunto de soluções eficientes, gerando somente aquelas que se situam a uma distância previamente definida do ponto ideal. Com o método das restrições foram geradas muito mais soluções do que o necessário para um caso real, isto, porque tais soluções eram necessárias para aplicar o método SWT. O SWT exigiu um número excessivo de interações para chegar a uma solução ótima. O SWT, por ser interativo, gera soluções não estáveis que variam com as decisões tomadas e se mostrou bastante sensível às variações em determinados objetivos. Houve grande variação nas variáveis decisórias selecionadas pelos métodos PC, Restrições, SWT e Step.

Arias (1989) realizou estudos comparativos das técnicas interativas de programação multicritério como instrumento para a tomada de decisão em planejamento agrícola. Os métodos comparados foram: STEM, "Ideal Desplazado", Geoffrion (GDF), Belenson-Kapur, Zionts-Wallenius, Steuer, SWT, Satisfação de Metas; Programação por Metas Interativas Seqüenciais (ISGP), Programação por Metas Múltiplas Interativas (IMGP) e Ponderações Recursivas. A característica comum desses métodos é a interação entre o analista e o tomador de decisão na busca de um posicionamento do tomador de decisão sobre uma dada solução possível apontada pelo modelo. Esse posicionamento do tomador de decisão é incorporado ao modelo em busca de nova solução a ser avaliada. Este ciclo se 
repete até que o tomador de decisão considere que a solução alcançada é satisfatória ou até que não se possa gerar novas soluções de acordo com suas preferências. $\mathrm{O}$ autor concluiu que qualquer um destes métodos apresenta soluções similares no campo dos objetivos e das variáveis de decisão. Apontou como vantagens do Método de Ponderações Recursivas: (1) requer do tomador de decisão uma informação de indicação, ou seja, que assinale qual ou quais objetivos não pretende melhorar. Isso evita, como ocorre em alguns métodos, a definição da quantidade de relaxação nos níveis alcançados pelos objetivos; (2) apresenta ao tomador de decisão uma única solução por interação para sua avaliação. Isto exige a resolução de uma única programação matemática, porque requer pouco trabalho por interação; (3) produz um mínimo de dificuldade operativa ao incrementar a quantidade de objetivos, restrições ou variáveis de decisão; (4) não solicita excessiva participação do tomador de decisão, sendo esta de fácil compreensão.

Shakya \& Leuschner (1990) usaram, no Nepal, o método de programação multi-objetivo com coeficientes de ponderação para selecionar altemativas de uso do solo em fazendas, considerando a integração dos subsistemas de cultivo, criação e florestal. Concluíram que o modelo foi útil para analisar o planejamento de uso do solo, coordenando múltiplos objetivos no tempo e espaço.

Piech \& Rehman (1993) testaram três métodos de Programação Multicritério: Programação por Metas (PM), Programação Multi-objetivo (PMO) e Programação Compromisso (PC) no planejamento de uma propriedade agrícola, na Inglaterra. Concluíram que, em termos de geração de informações, a Programação por Metas é inferior aos outros dois por apresentar apenas uma solução. A PM também apresenta o problema de obter e selecionar o peso associado aos objetivos e requer informações mais precisas do tomador de decisão tal como os valores pretendidos das metas. A PMO gera informações mais significativas ao tomador de decisão em comparação com os outros dois métodos. Entretanto, a PMO não é recomendada para resolução de problemas com muitas restrições e variáveis de decisão dadas as dificuldades computacionais e por gerar resultados com muitas soluções para serem escolhidas. A PC produz um conjunto de soluções eficientes que tendem a um ponto ideal e pode ser resolvida com programa computacional de programação linear. 
Analisando os trabalhos publicados, observa-se que ainda não existe um método consagrado de programação multicritério para aplicação no planejamento agrícola. Todos os trabalhos têm por objetivo testar dois ou mais métodos de programação multicritério. As razões que geram a busca de melhor método a ser aplicado, são:

(a) a programação multicritério tem um desenvolvimento metodológico recente e o surgimento de novos algoritmos e técnicas computacionais requerem suas experimentações no setor agrícola;

(b) a existência de diferentes modelos teóricos de empresas agrícolas, os quais definem objetivos especificos a serem otimizados;

(c) a incorporação de risco nos modelos;

(d) a diferença ambiental e politica dos meios onde estão inseridas as empresas agrícolas em estudo provocam abordagens específicas dos objetivos e restrições a serem consideradas no planejamento agrícola;

(e) a abrangência do planejamento regional e da propriedade agrícola, incorporando objetivos públicos e privados;

(f) a característica do modelo: estático ou dinâmico;

(g) o grau requerido de participação do tomador de decisão na fase de planejamento;

(h) a disponibilidade de informações sobre as preferências do tomador de decisão

As razões apresentadas mostram a necessidade de se testar métodos de programação multicritério para escolha de atividades agropastoris nos sistemas de produção, considerando os objetivos privados e as restrições das empresas agrícolas, concomitantemente aos objetivos do planejamento do uso sustentável da terra na microbacia hidrográfica, para as condições sócio-econômicas do Estado de São Paulo. A programação por metas lexicográficas é um método que exige poucas informações do tomador de decisão e permite a interação do analista com o produtor rural (através da construção de vários cenários de análise, que aproximam o modelo ao mundo real do produtor), o que facilita seu uso no planejamento de grande quantidade de microbacias. A 
Programação por Metas Lexicográficas pode ser resolvida com uso de programas computacionais de programação linear, usando a técnica de programação linear seqüencial, conforme Lee (1972). De modo geral, os trabalhos publicados mostram que os resultados obtidos por diferentes métodos são similares em relação ao conjunto de alternativas ótimas. Então, o método a ser testado para as condições das microbacias hidrográficas é aquele que apresenta maior facilidade operacional, ou seja, a programação por metas lexicográficas.

A hierarquização dos múltiplos objetivos, por parte do tomador de decisão, é fundamental para a execução do algoritmo da programação por metas lexicográficas. Harper \& Eastman (1980) analisaram a hierarquização de objetivos por 61 pequenos produtores rurais, em Novo México - EUA. Subdividindo os objetivos em dois conjuntos, que se constatou serem conflitantes, obtiveram a seguinte ordenação: (a) Objetivos para a unidade familiar (maximizar a qualidade de vida, maximizar a renda, maximizar a acumulação de bens materiais, maximizar o consumo e maximizar "status" e prestígio social) e (b) objetivos para as atividades agrícolas (melhorar a qualidade de vida derivada das operações agrícolas, evitar atividades não agrícolas, minimizar risco de perdas e prejuizos, obter mais lucro a cada ano, aumentar a produção de bens materiais na propriedade, cultivar mais áreas de terra e adquirir máquinas e construções novas). A prioridade da qualidade de vida derivada das operações agrícolas acima da maximização do lucro, indicou que a família é uma unidade de análise mais relevante do que as atividades agrícolas. A ordenação dos objetivos neste trabalho não foi correspondente à obtida em outro trabalho similar realizado em Oklahoma, por isto os autores não generalizaram os resultados para outros grupos de pequenos produtores. Estas conclusões mostram a necessidade da obtenção da hierarquização dos objetivos para cada produtor. 


\section{MATERIAL E MÉTODO}

O método usado é apresentado em cinco partes: (1) formulação do modelo teórico sistêmico de empresa agrícola, tendo como estrutura os subsistemas considerados na tomada de decisão para implementar atividades agropastoris e novas tecnologias que afetem os sistemas de produção; (2) definição dos múltiplos objetivos potenciais a serem otimizados no planejamento de atividades agropastoris; (3) descrição das atividades e restrições; (4) descrição do modelo de programação por metas lexicográficas e (5) proposta para Planejamento do Uso Sustentável da Terra. No que se refere a material, será feita uma descrição da microbacia hidrográfica da Água F em Vera Cruz.

\subsection{Modelo conceitual de sistema de produção}

O modelo conceitual de sistema de produção define a propriedade agrícola como unidade de produção. O modelo é caracterizado conforme os fundamentos da Teoria Geral dos Sistemas apresentados por Ackoff \& Gupta (1962) e Bertalanffy (1975). Conforme esta teoria, nos sistemas abertos, tais como os sistemas agrícolas, há quatro atributos básicos, como mostrado na Figura 1: limites, entradas, processos e saídas. Assim, têm-se os limites que delimitam o campo ou área de ação onde as entradas ("input") participam de processos, nos quais interagem os componentes do sistema, gerando as saídas ("output"). Assim, a unidade de produção agrícola é caracterizada como um sistema aberto pois recebe energia solar e insumos externos e exporta energia através de seus produtos e de perdas. Sistemas fechados, onde não há troca de materiais ou energia, praticamente não ocorrem na natureza. 


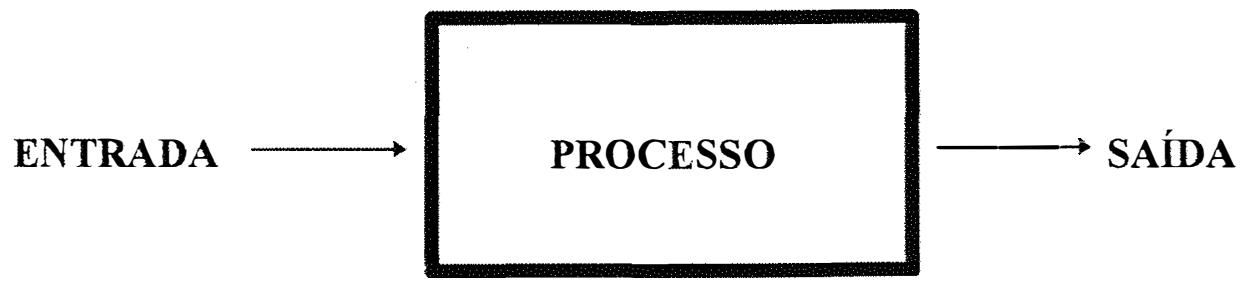

Figura 1 - Diagrama simplificado de um sistema aberto.

Outro atributo importante dos sistemas é o hierárquico, isto é, os sistemas existem dentro de outros sistemas, que por sua vez se dividem em subsistemas. Assim, no sistema agrícola, pode-se definir diversos níveis hierárquicos (Figura 2) tais como: as regiões tropicais, o continente, o país, o estado, a Divisão Regional Agrícola (DIRA), o município, a MICROBACIA HIDROGRÁFICA, a PROPRIEDADE AGRÍCOLA, a parcela de cultivo, a planta, o fruto, a célula.

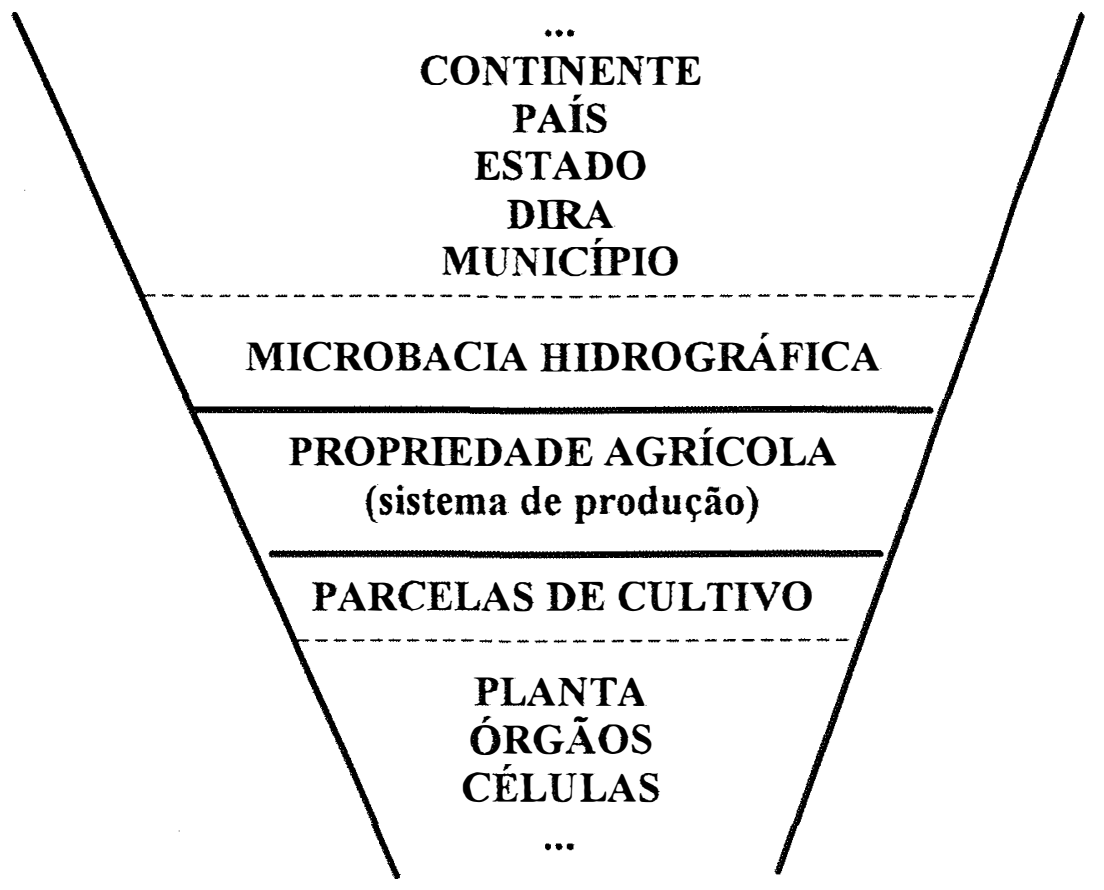

Figura 2 - Diagrama do atributo hierárquico do sistema agrícola. 
Cada um dos níveis da Figura 2 representa um sistema ou subsistema quando comparado com o sistema de nível hierárquico superior ou inferior. Este atributo é importante para delimitar os sistemas e subsistemas da microbacia hidrográfica. Assim, o município é a unidade onde devem ocorrer as principais ações de ordem organizacional do PEMBH. Por outro lado, a propriedade agrícola é a unidade onde ocorrem as principais atividades conservacionistas. O termo "sistema de produção agrícola" ("farm system") é mais apropriado para descrever a propriedade como um todo. Os termos sistema de cultivo, sistema de criação e sistema florestal são melhor usados para descreverem subsistemas do sistema de produção agrícola. Por sua vez, os sistemas de produção são subsistemas do sistema da microbacia hidrográfica.

O sistema de produção agrícola (Figura 3) cujo contorno físico é a propriedade, representa o campo onde ocorrem as ações do tomador de decisão, em especial as referentes à adoção das recomendações do planejamento do uso sustentável da terra proposto pelo PEMBH. É composto por subsistemas, que interagem entre si para atingirem os objetivos do proprietário, tomador de decisão, tais como: sistema de cultivo, sistema de criação, sistema florestal, sistema quintal, sistemas de recursos naturais (solo, água e clima), sistema familiar, sistema de recursos materiais (máquinas e infra-estrutura) e sistema financeiro. As interações entre estes subsistemas também afetam os objetivos públicos de geração de empregos e de preservação do ambiente.

Os subsistemas de cultivo, criação e florestal são compostos por atividades de produção destinadas à comercialização e ao autoconsumo e, fisicamente, são delimitados pelas parcelas ou glebas de terra. Novas alternativas de atividades, propostas pelo planejamento do uso sustentável do solo, competem com as atividades já instaladas (uso atual do solo), no uso de recursos materiais, financeiros e familiar. Cabe ao tomador de decisão a escolha entre as alternativas propostas conforme os seus objetivos. Por sua vez, o sistema da microbacia hidrográfica contém várias propriedades agrícolas que se constituem em subsistemas da microbacia. Assim, por exemplo, o objetivo público de minimização de perdas de solo deve ser otimizado concomitantemente aos objetivos privados. Esta formulação de modelo conceitual de sistema de produção permite considerar que para o produtor rural adotar as práticas conservacionistas, planejadas para 
a microbacia hidrográfica, estas devem otimizar tanto os objetivos públicos como os privados, sujeitos às restrições de ordem técnica e econômica de cada propriedade agrícola.

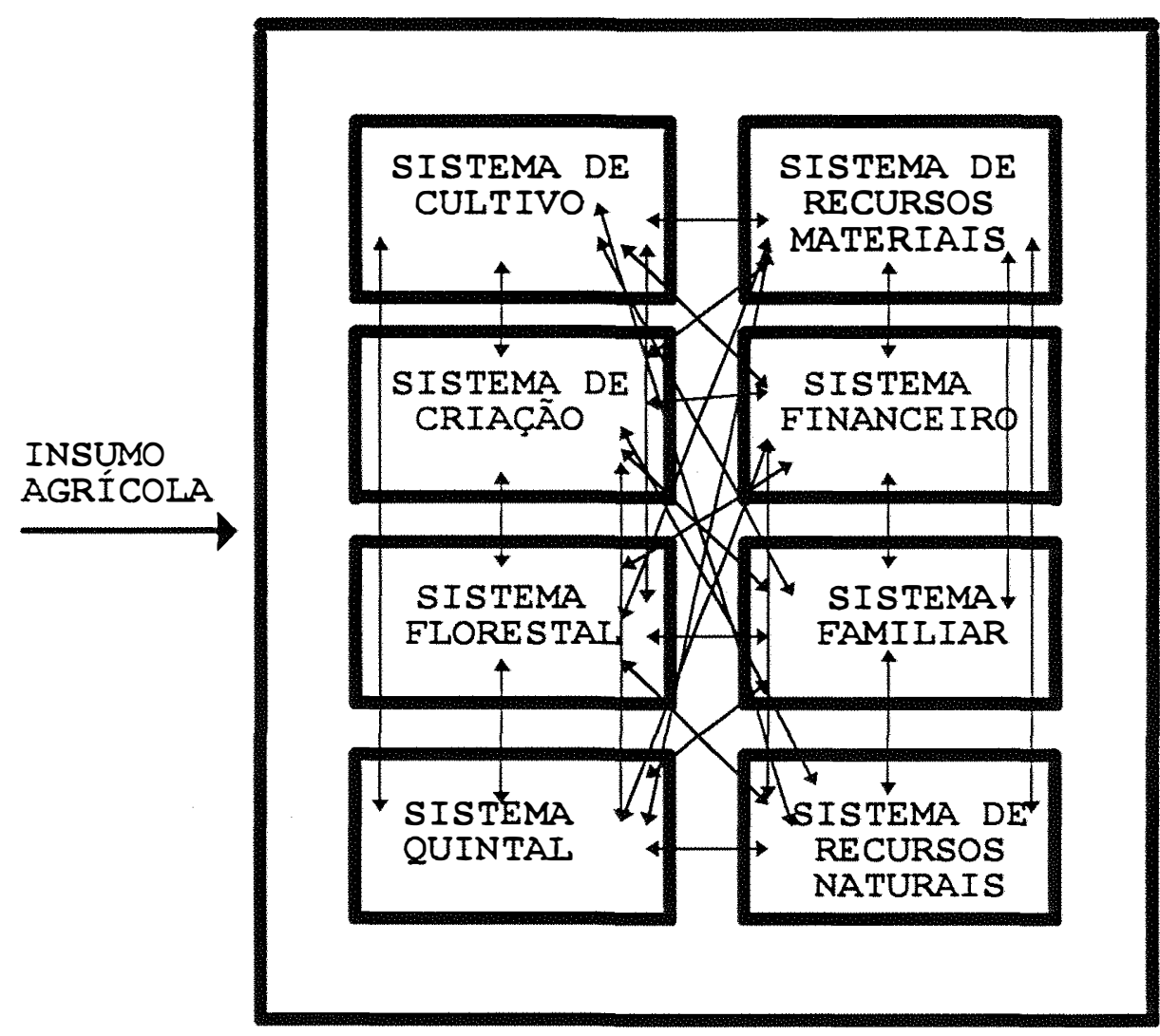

PRODUÇÃO AGRÍCOLA

Figura 3 - Diagrama simplificado do sistema de produção agrícola, com as interações entre os subsistemas de cultivo, criação, florestal, quintal, recursos naturais, financeiro, recursos materiais e familiar.

\subsection{Os múltiplos objetivos}

Os múltiplos objetivos do PEMBH, descritos por Lombardi Neto (1993), serão formulados a seguir com apresentação do modo de valoração adotado para cada objetivo. 
(A) Erosão do solo. A erosão do solo é determinada pela equação universal de perda de solo (EUPS), desenvolvida por Wischmeier \& Smith (1978):

\section{$\mathbf{A}=\mathbf{R} \times \mathbf{K} \times \mathbf{L S} \times \mathbf{C} \times \mathbf{P}$}

(equação 1)

onde,

$\mathbf{A}=$ perdas médias de solo, em $\mathrm{t} / \mathrm{ha}$.ano;

$\mathbf{R}=$ erosividade da chuva, em $\mathrm{MJ} / \mathrm{ha} \cdot \mathrm{mm} \cdot \mathrm{ha}$;

$\mathbf{K}=$ erodibilidade dos solos: intensidade de erosão por unidade de índice de erosão da chuva, para um solo específico que é mantido continuadamente sem cobertura, mas sofrendo as operações culturais normais, em um declive de $9 \%$ e comprimento de rampa de $25 \mathrm{~m}$;

$\mathbf{L S}=$ fator topográfico, ou seja, declividade e comprimento da encosta, uso e manejo do solo e prática conservacionista adotada;

$\mathbf{C}=$ fator de uso e manejo do solo;

$\mathbf{P}=$ fator de prática conservacionista;

A relação entre a perda média de solo e a tolerância de perda do solo fornece o risco de erosão, conforme a equação 2 :

$$
\mathbf{e}=\mathrm{A} / \mathrm{T}
$$

onde,

$\mathbf{e}=$ risco de erosão;

$\mathbf{A}=$ perdas médias de solo;

$\mathrm{T}=$ tolerância de perda de solo.

O uso das variáveis de fertilidade, drenagem, mecanização, profundidade e risco de erosão gera a Capacidade de Uso Sustentável da Terra (CUST). A CUST garante as perdas de solos dentro de limites aceitáveis, mantendo a sua produtividade ao longo dos anos, sem degradar o ambiente. Tendo em vista que o objetivo deste trabalho é de ter um planejamento do uso sustentável da terra para os sistemas de produção, não se 
permite a violação do uso planejado para as glebas das propriedades agrícolas. Portanto, a Capacidade do Uso Sustentável da Terra, sendo considerada como restrição, torna-se uma prioridade absoluta na otimização dos demais objetivos.

(B) Uso de defensivos químicos. Os defensivos químicos representam os inseticidas, fungicidas, nematicidas, formicidas, herbicidas, carrapaticidas, vermífugos etc, cujo uso indiscriminado causa impacto negativo no ambiente e na saúde humana. Por isso, seu uso deve ser minimizado. Para cada atividade, a quantidade de defensivos químicos é expressa pelo custo por hectare ou por unidade animal.

(C) Produção de alimentos básicos. É um objetivo fixado no âmbito do PEMBH tendo-se em vista a segurança alimentar da população. Pretende-se maximizar a produção de alimentos básicos, tais como: arroz, trigo, feijão, milho, mandioca, carne, leite etc. É medido pelo valor monetário bruto da produção recebido pelo produtor.

(D) Fixação do homem no campo. O objetivo de maximizar a fixação do homem no campo ou de minimizar a migração rural-urbana, será atingido com o oferecimento de alternativas de produção agropecuária com padrão tecnológico tal que maximizem a oferta de emprego permanente com remuneração de um e meio salários mínimos, como "proxis" da renda urbana de atração. Estas alternativas também devem minimizar a estacionalidade do uso da mão-de-obra permanente e eventual. A estacionalidade é medida pela somatória dos desvios absolutos do uso mensal da mão-deobra em relação à média anual e seu valor ótimo é igual a zero.

(E) Estacionalidade da renda. Supõe-se que o produtor prefira manter constante, tanto quanto for possível, a renda mensal da propriedade. A estacionalidade da renda é medida pela somatória dos desvios absolutos dos fluxos de caixa mensais em relação à média anual e seu valor ótimo é igual a zero.

(F) Margem Bruta. A maximização da margem bruta (usada como "proxis" da maximização do lucro) representa o interesse atual do proprietário, tomador de decisão, em usar um determinado manejo de solo em uma atividade agrícola. É determinada para cada sistema de cultivo, de criação e de manejo florestal a partir da receita bruta proporcionada, subtraídos os custos operacionais com máquinas, mão-deobra, defensivos químicos e outros insumos. Considerando a sustentabilidade dos 
sistemas de produção, interessa conhecer os impactos do Planejamento do Uso Sustentável da Terra, quando as atividades recomendadas atingem uma produção estável. Entretanto, as atividades de culturas permanentes, por exemplo a fruticultura, possuem três períodos com fluxos financeiros distintos: implantação do pomar no primeiro ano, formação dos 2 aos 4 anos e produção dos 5 aos 25 anos. Para que a margem bruta represente um ano estável típico, calcula-se a margem bruta anualizada multiplicando o valor da margem bruta presente (VMBP) pelo coeficiente de recuperação de capital $(k)$ (Peres, 1981). O coeficiente $\mathrm{k}$ é calculado por:

$$
k=\frac{i(1+i)^{t}}{(1+i)^{t}-1}
$$

onde,

$k=$ coeficiente de recuperação de capital

$i=$ taxa de desconto

$t=$ período

Há dois objetivos considerados importantes na decisão do agricultor na escolha de atividades produtivas: risco e autoconsumo. Neste estudo não se obteve dados sobre as variações nos preços dos produtos e insumos e sobre as variações na produção agrícola em função de fatores adversos, para a região de Vera Cruz. Um estudo sobre o autoconsumo na microbacia da Água F (Ambrósio et al., 1996) mostrou que o quintal é importante fonte de alimentação para as famílias rurais, mas que a familia usa apenas recursos marginais no subsistema quintal. Também Otani et al. (1994) mostraram que não há produção significativa para autoconsumo na Microbacia da Água F. Por isto, o objetivo de autoconsumo não é considerado neste estudo. 


\subsection{As atividades e as restrições}

As atividades, variáveis de decisão das funções objetivos, são representadas pelas alternativas de uso da terra para as parcelas de cultivo, criação e floresta, conforme o planejamento do uso sustentável da terra e pelo uso atual da terra. Também são consideradas outras atividades, tais como: uso de mão de obra familiar e residente contratada, prestação de serviço braçal da família para terceiros, aluguel de trator para terceiros, contratação de mão-de-obra eventual, contratação de trator, compra de milho para formulação de ração e transferências mês a mês de caixa e de milho produzido.

As estruturas dos custos operacionais e dos custos de implantação das alternativas de uso da terra são recomendadas pela Secretaria de Agricultura de São Paulo. As atividades de fruticultura (abacate, acerola, manga, mamão, tangerina, limão Taiti, maracujá e goiaba) foram propostas pelo Plano de Fruticultura da Alta Paulista (Soares, 1994). As atividades de pastagem de braquiária, capineira de Napier, pecuária de leite, pecuária de corte, eucalipto e seringueira são recomendadas pela Coordenadoria de Assistência Técnica Integral (CATI), DIRA de Marília. Todas as atividades em uso na microbacia foram consideradas com sistema de cultivo atual e com sistemas de cultivo melhorados conforme Pedro Júnior (1987). As culturas anuais (milho, feijão, amendoim e arroz de sequeiro) dos períodos das águas e da seca, são consideradas em três sistemas de cultivo: mecanizado ( $t$ ), tração animal (a) e operações manuais na colheita e capina (m). Todas as atividades seguem recomendações de adubação e calagem conforme Raij et al. (1996), com amostragem de solo em cada gleba. Isto atende às recomendações de manejo de fertilidade propostas pelo PUST.

As estruturas de custo operacional e de implantação de mata ciliar e de reserva florestal se baseiam em Toscano (1994). Nos custos das atividades recomendadas está incluído o custo médio de terraceamento cuja distância entre terraços é baseada em Lombardi Neto et al. (1994), porém com um custo uniforme por hectare para cada classe de CUST. Os preços dos insumos agrícolas são os praticados pela Cooperativa de Cafeicultores de Vera Cruz e os preços dos produtos agrícolas têm como fonte o 
Instituto de Economia Agrícola (IEA) e se referem à DIRA de Marília. Os preços de venda de leite e de animais de corte são os praticados pelos produtores da microbacia.

A otimização dos objetivos através da escolha de atividades de exploração agrícola, está sujeita às limitações de disponibilidade de terra (área e classe de uso sustentável do solo), mão-de-obra permanente (familiar e contratada) e eventual, capital e máquinas.

As restrições de disponibilidade de terra garantem o cumprimento das recomendações de uso do solo conforme a CUST. Para maior discussão sobre o uso sustentável da terra, ver Lombardi Neto (1996). As classes de Capacidade de Uso Sustentável da Terra presentes na microbacia da Água F, Vera Cruz, comportam as atividades apresentadas na Tabela 1.

Tabela 1 - Atividades recomendadas por classe de capacidade de uso sustentável da terra, para a microbacia hidrográfica da Água F, Vera Cruz, 1996.

\begin{tabular}{cl}
\hline Classes & \multicolumn{1}{c}{ Atividades recomendadas } \\
\hline III & Culturas anuais, culturas permanentes, pastagens e florestas \\
IV & Culturas permanentes, pastagens e florestas \\
V & Mata ciliar e reserva florestal \\
VI & Pastagens e florestas \\
VII & Mata ciliar e reserva florestal \\
VIII & Reserva florestal \\
\hline
\end{tabular}

Fonte: Donzeli (1996)

\subsection{A programação por metas lexicográficas}

As atividades que otimizam os múltiplos objetivos do $\mathrm{PEMBH}$, sujeitas às restrições do planejamento do uso sustentável do solo e às restrições de disponibilidade de recursos de máquinas, capital, mão-de-obra e tração animal, em cada propriedade agrícola, foram obtidas usando a programação por metas lexicográficas. A escolha deste método se deve à quantidade de objetivos considerados, neste caso são 6 objetivos. Pois, considerando uma análise paramétrica com apenas 5 intervalos para cada um dos 6 objetivos seriam obtidas 3125 soluções a serem apresentadas ao tomador de decisão. Isto 
inviabiliza o uso dos métodos de programação multi-objetivo com restrições ou com ponderações, ver Apêndice 1. Outros aspectos que influíram na escolha do método foram: o tamanho do modelo (em função da quantidade de variáveis de decisão e quantidade de restrições), disponibilidade de "software" (planilhas eletrônicas e "software" de programação linear são suficientes para a solução da programação por metas lexicográficas), da baixa capacidade dos tomadores de decisão em interagirem com o analista e da pouca disponibilidade dos produtores em confidenciarem sobre seus propósitos com respeito aos objetivos (a Programação por Metas Lexicográficas exige apenas que o tomador de decisão ordene os objetivos conforme suas prioridades, isto não toma muito tempo do produtor). Além disto, os diferentes métodos de programação multicritério, quando aplicados no mesmo conjunto de objetivos e de restrições, selecionam um conjunto similar de variáveis de decisão.

O propósito geral da programação por metas (PM) é de minimizar os desvios entre o nível de ganho de cada meta e seu correspondente nivel de aspiração. As metas são incluídas na formulação do modelo, convertendo as inequações em equações, mediante a adição de variáveis de desvio positivo e negativo, as quais representam o excesso e a falta de ganho para cada meta. Uma das principais técnicas algorítmicas usadas no processo de minimização dos desvios é a Programação por Metas Lexicográficas (PML). A Programação por Metas Lexicográficas foi introduzida na literatura por Charnes \& Cooper (1961) de forma muito embrionária, sendo consideravelmente desenvolvida pelos trabalhos de Ijiri (1965), Lee (1972) e Ignizio (1976). Dentro desta variante da programação por metas, supõe-se que o tomador de decisão seja capaz de subdividir o conjunto de suas metas em diferentes prioridades, atribuindo pesos excludentes ("preemptive weights"), com valores absolutos, às metas situadas em diferentes prioridades. Em outras palavras, o ganho das metas situadas numa certa prioridade, $h_{i}$, é incomensuravelmente preferido ao ganho de qualquer outro subconjunto de metas de menor prioridade, $h_{j}$, isto é, $h_{i} \gg>h_{j}$. Nesse algoritmo, as metas de maior prioridade são satisfeitas primeiro, para depois serem consideradas as metas de menor prioridade. Esse tipo de ordenação recebe o nome lexicográfica por analogia com a ordenação de palavras no léxico ou dicionário. 
A estrutura do modelo matemático de minimização lexicográfica (Ignizio, 1976) é:

$$
\begin{gathered}
\operatorname{LEXMIN} Z_{h}=\left[h_{l}(n, p), h_{2}(n, p), \ldots, h_{k}(n, p)\right] \\
\text { Sujeito } a \\
f_{i}(X)+n_{i}-p_{i}=b_{i} \\
X \in x
\end{gathered}
$$

onde,

LEX MIN $Z_{\mathrm{h}}=$ significa processo de minimização lexicográfico;

$h_{k}=k$-ésima prioridade envolvendo uma dada combinação de elementos para os vetores n e p;

$\mathrm{n}_{\mathrm{i}}=$ variável de desvio negativo associada ao i-ésimo objetivo;

$\mathrm{p}_{\mathrm{i}}=$ variável de desvio positivo associada ao i-ésimo objetivo;

$\mathrm{f}_{\mathrm{i}}(\mathbf{X})$ = função matemática das variáveis de decisão para o i-ésimo objetivo;

$\mathbf{b}_{\mathrm{i}}=$ conjunto de metas do i-ésimo objetivo;

$\mathbf{X}=$ vetor de variáveis de decisão;

$\mathbf{x}=$ conjunto de restrições básicas.

As equações das funções objetivos, das metas e das restrições para os modelos de programação por metas lexicográficas para uma propriedade agrícola (P1) da microbacia hidrográfica da Água F, Vera Cruz, são mostradas no Apêndice 2.

Para a resolução dos problemas de programação linear seqüencial foi usado o "software" "XA System" ("Extended Application System") com as equações formuladas, no "Style II" (variáveis de decisão nas linhas e restrições nas colunas) na planilha eletrônica Excell 5.0, com arquivos wk1, conforme Sunset Software Technology (1993) 


\subsection{Hierarquia dos múltiplos objetivos}

A hierarquização dos múltiplos objetivos, por parte do tomador de decisão, é fundamental para a execução do algoritmo da programação por metas lexicográficas. Para facilitar a hierarquização dos objetivos foram usados cartões com motivos referentes à cada objetivo (ver Apêndice 2). Estes cartões permitiram ao analista apresentar e explicar cada objetivo de forma padronizada, casualizada (embaralhando os cartões na frente do tomador de decisão) e sem interferir na decisão do produtor rural. Em seguida, o analista solicitou ao tomador de decisão que ordenasse os cartões em ordem decrescente de preferência da realização dos objetivos. O tomador de decisão tem que estar cônscio da importância da escolha dos primeiros objetivos, pois estes têm muita influência na seleção de alternativas ótimas para o uso sustentável da terra, quando se usa a programação por metas lexicográficas (após a otimização do objetivo de primeira prioridade, a meta do objetivo de segunda prioridade será melhorada apenas quando existirem mais de uma solução ótima para o primeiro objetivo, o mesmo ocorre para os demais objetivos.).

\subsection{Sistema de Informações Geográficas aplicado no planejamento da microbacia hidrográfica da Água F}

O Sistema de Informações Geográficas - SIG - é um importante instrumento computacional usado no processamento de informações edáficas, hídricas, topológicas, uso atual do solo e capacidade de uso sustentável e no planejamento da microbacia hidrográfica. Cada conjunto de variáveis afins constitui um plano de informações referenciado espacialmente, que pode ser plotado em um mapa com auxílio de computador (DONZELI et al., 1992). Neste trabalho, foi usado o "software" denominado SGI/INPE, desenvolvido pelo Instituto Nacional de Pesquisas Espaciais. Assim, a microbacia possui plano hídrico, plano de solos, plano topográfico, plano de uso do solo e plano de risco de erosão, os quais geram o plano de capacidade de uso sustentável da terra. 
Para fins deste trabalho, foi necessário criar o plano de informações das propriedades agrícolas que possibilitou a obtenção da capacidade de uso sustentável da terra para cada propriedade. Todos os limites das propriedades foram demarcados no mapa da microbacia com auxílio de fotografia aérea e uso de equipamento de Sistema de Posicionamento Global de Superficie (GPS). Criou-se, desta forma, um plano de informação dos limites jurídicos das propriedades que passou a fazer parte do SIG. Também foram demarcados os limites das glebas de terra com diferentes usos, formando o plano de informações do uso atual da terra em cada propriedade. O cruzamento de informações dos planos de limite das propriedades e CUST da microbacia possibilitou a obtenção da CUST por propriedade.

A Figura 4 mostra a carta da microbacia hidrográfica da Água F com destaque para os limites das propriedades, o plano hídrico e a capacidade de uso sustentável da terra para 6 propriedades agrícolas.

A descrição das classes de capacidade de uso sustentável da terra que ocorrem nas 6 propriedades agrícolas, conforme Lombardi Neto e Camargo (1992) compreende:

\section{Classe III}

São terras com declividade de $12 \%$, produtivas, com limitações moderadas das características do solo ou erosão. São próprias para culturas anuais com práticas intensivas para conservação do solo contra a erosão e aumento da fertilidade, tais como: terraceamento, cordões de contorno, subsolagem, drenagem artificial, calagem profunda para eliminação da toxicidade do alumínio e fertilizações segundo recomendações técnicas.

Subclasse IIIe. Declives de 6-12\% ou com médio potencial natural de erodibilidade. Recomendam-se práticas que promovam a proteção contra a erosão ou risco de degradação.

Subclasse IIIf. Solos arenosos e álicos. Recomendam-se calagem, adubação verde e outras práticas que promovam a melhoria da fertilidade natural.

Subclasse IIIef. Associação das principais características limitantes das subclasses IIIe e IIIf. 


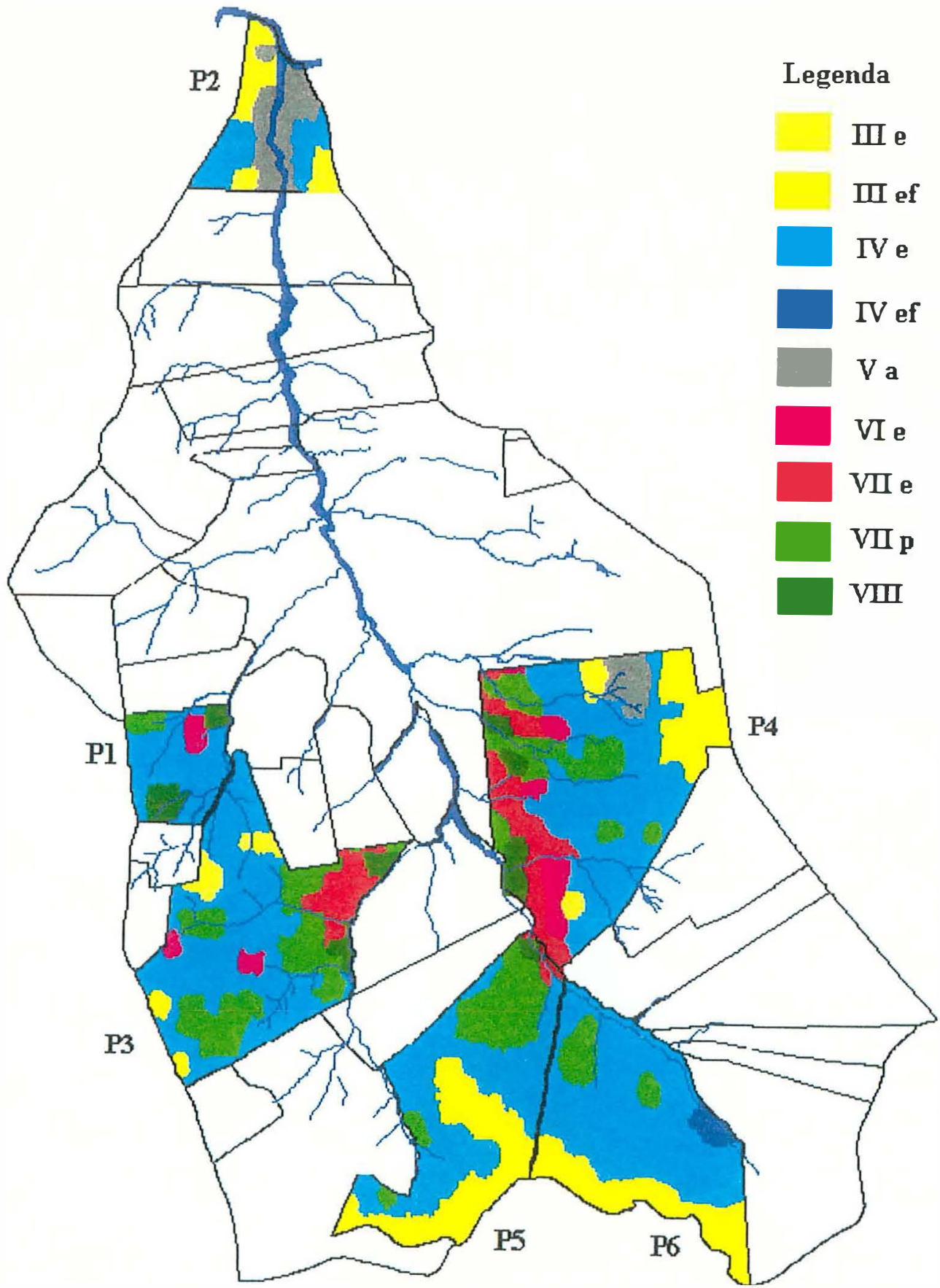

Fonte: Donzeli (1996).

As letras junto das classes de uso indicam: e, limitação por erosão; f, limitação por fertilidade; a, limitação por drenagem; e p, limitação por profundidade do solo.

Figura 4 - Carta da capacidade de uso sustentável da terra, limites das propriedades e plano hídrico da microbacia hidrográfica da Água F, Vera Cruz, 1996. 


\section{Classe IV}

São terras declivosas, até o limite de mecanização agrícola ou com médioalto potencial de erosão. Podem ser planas, mas com sérios problemas de produtividade, devido à natureza dos solos. O uso com culturas anuais só deve ser recomendado sob manejo desenvolvido em rotação com pastagens e, de preferência, devem ser aradas uma vez em cada quatro ou cinco anos, nesta rotação. São adequadas às culturas perenes, também sob manejo complexo de práticas conservacionistas ou para a melhoria da produtividade.

Subclasse IVe. Terras com declives de até $20 \%$ ou com médio-alto potencial de erodibilidade, onde as práticas conservacionistas são complexas: terraceamento em desnivel, faixas de retenção etc. São apropriadas às culturas perenes e pastagens.

Subclasse IVf. Solos com alto potencial de erodibilidade, em declives mais suaves, com problemas de fertilidade. São apropriadas às culturas perenes e pastagens.

\section{Classe V}

Terras planas e mal drenadas com excesso de água.

Subclasse Va. Recomendam-se drenagem artificial e calagem. Podem ser utilizadas para pastagens com práticas mais simplificadas de drenagem e espécies adaptadas. No caso da Microbacia da Água F são áreas próprias para instalação de mata ciliar.

\section{Classe VI}

São terras de boa fertilidade natural e produtividade, apresentando problemas de declives muito acentuados, além do limite da mecanização ou com faixas de declive de 12 a $20 \%$ mas com alto potencial de erodibilidade. Podem ser pedregosas, erodidas ou com solos de pequena profundidade efetiva. São impróprias para culturas anuais, mas podem ser adaptadas para pastagens com restrições moderadas de uso e práticas conservacionistas simples. Com exceção dos solos muito rasos, podem ser utilizadas para reflorestamento sem problemas. 
Subclasse VIe. Terras com declives de 20 a $40 \%$ ou de 12 a $20 \%$ com alto potencial de erodibilidade. Recomendam-se práticas conservacionistas. Pastagens adaptadas que promovam a proteção do solo contra a erosão em declives mais acentuados. Práticas de calagem e adubação fosfatada no plantio, consorciação, manejo de pastoreio, divisão de pastos em nível com bebedouros artificiais etc.

\section{Classe VII}

Terras acidentadas ou com declives acima de $40 \%$. O uso com pastagens apresenta restrições mais severas que a classe VI, sendo as práticas conservacionistas mais complexas com implantação racional dificultada. Em solos rasos, recomenda-se o uso de forrageiras adaptadas e estoloniferas que proporcionem melhor proteção ao solo. No geral, são mais adaptadas ao reflorestamento, observando-se o manejo do corte seletivo.

Subclasse VIIe. Declives acima de $40 \%$ ou com muito alto potencial de erodibilidade (limitações severas).

Subclasse VIIp. Solos litólicos ou textura média (muito rasos).

\section{Classe VIII}

Solos litólicos, extremamente rasos, extremamente declivosos ou escarpados. Uso exclusivo para reserva florestal e abrigo da flora e fauna.

\subsection{Método de Planejamento do Uso Sustentável da Terra}

O fluxograma do Planejamento do Uso Sustentável da Terra em Microbacias Hidrográficas, proposto neste trabalho, é apresentado na Figura 5. A Capacidade de Uso Sustentável da Terra (CUST) gera informações sobre a adequação do solo para fins de exploração agropecuária e tem como área de abrangência a microbacia hidrográfica. Utilizando o plano de informações de uso atual da terra e o plano de informações dos limites das propriedades agrícolas contidas na microbacia, foi obtida a distribuição atual das glebas de terra por propriedade. O cruzamento das informações da CUST e das glebas atuais de terra gerou uma nova disposição ("layout") de glebas. Por exemplo, a atividade de pasto na propriedade 2 (P2) que era praticada em área contínua, 
Planejamento do Uso Sustentável da Terra em Microbacias Hidrográficas

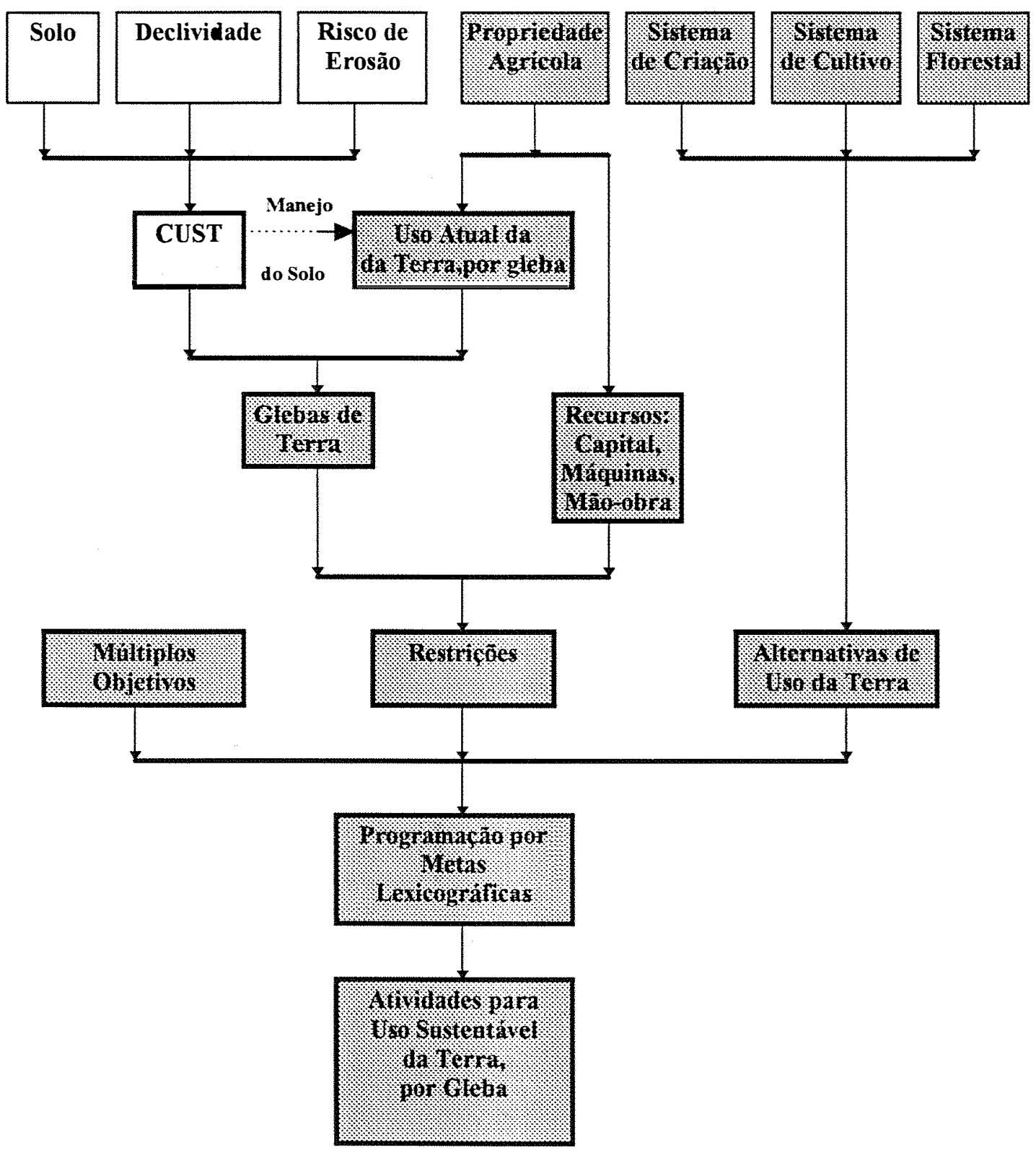

Figura 5 - Fluxograma do Planejamento do Uso Sustentável da Terra em Microbacias Hidrográficas. 
numa única gleba, englobando duas classes de CUST, IIIe e IVf, gerou duas novas glebas de terra, para as quais foram testados novos usos. As alternativas de uso da terra foram obtidas, utilizando os sistemas de cultivo, criação e florestal recomendados para a região de Marilia. Foram acrescentados a estes sistemas as recomendações de adubação conforme análise de solo em cada gleba e as recomendações de conservação e manejo do solo. A seleção destas alternativas, para cada propriedade, foi feita com a otimização lexicográfica dos múltiplos objetivos, conforme hierarquização do tomador de decisão, estando sujeitas às restrições de disponibilidade de trator, mão-de-obra familiar e residente, tração animal, fluxo de caixa e da disponibilidade de área em cada uma das novas glebas de terra. Assim, obedecendo-se estas etapas no planejamento de microbacias é possivel obter atividades de uso de cada gleba de terra, seguindo a CUST, as disponibilidades de recursos em cada propriedade da microbacia e, principalmente, atendendo à hierarquização dos objetivos do tomador de decisão. Na Figura 5, destacase, em sombreado, as etapas do Planejamento do Uso Sustentável da Terra que representam as contribuições ao planejamento de microbacias hidrográficas, propostas por este trabalho.

\subsection{Microbacia hidrográfica da Água F, Vera Cruz}

A microbacia hidrográfica estudada é a Microbacia da Água F localizada no município de Vera Cruz, DIRA de Marilia, Estado de São Paulo. A Microbacia da Água F, conforme levantamento de 1991 (Otani et. al., 1994), representado na Tabela 2, possuia área total de 1947,50 ha, sendo totalmente explorada por 27 proprietários e não apresentando parceiros nem arrendatários. A área média das 27 propriedades era de 72,12 ha, sendo o limite inferior de 10,89 ha e o superior de 462,95 ha. As propriedades com área menor de 50 ha representavam $59,26 \%$ das propriedades e ocupavam $21,31 \%$ da área total da microbacia, enquanto que as propriedades com área acima de 100 ha representavam $18,52 \%$ das propriedades e ocupavam $58,69 \%$ da área total. As áreas de pastagem ocorriam em 22 propriedades, principalmente nas propriedades com mais de 100 ha. Estas áreas eram formadas por pasto natural $(64,36 \%)$, braquiária $(33,10 \%)$, 
Jaraguá $(1,82 \%)$ e Napier $(0,73 \%)$ e comportavam um rebanho bovino de 1243 cabeças. As áreas com culturas perenes eram formadas por café $(98,51 \%)$ em plena produção em 16 propriedades e maracujá $(1,49 \%)$ que vem crescendo de importância nos últimos anos. As culturas anuais presentes na microbacia da Água F eram: amendoim, arroz, feijão, milho e hortaliças e ocupavam uma área de 13,32 ha sendo 54,50\% em consorciação com o café. As práticas agrícolas mais comuns na microbacia eram o plantio em nível, a análise de solo, a adubação química, a calagem e o uso de defensivos químicos, principalmente nas áreas de café e maracujá. Da produção de café de 11519 sacas, em 1991, 3750 sacas foram comercializadas com a cooperativa, 2919 com intermediários e 4850 sacas foram armazenadas. Da produção de 6280 caixas de maracujá, 3480 caixas foram destinadas à indústria de sucos e 2800 comercializadas com intermediários.

Tabela 2 - Uso da terra, microbacia hidrográfica da Água F, Vera Cruz, 1991.

\begin{tabular}{lrc}
\hline $\begin{array}{c}\text { Uso } \\
\text { da } \\
\text { terra }\end{array}$ & \multicolumn{2}{c}{ Área } \\
\cline { 2 - 3 } & $($ ha $)$ & $\%$ \\
\hline Pastagens & 1331,98 & 68,39 \\
Cultura perene & 431,80 & 22,17 \\
Cultura anual & 6,06 & 0,31 \\
Mata natural & 72,07 & 3,70 \\
Reflorestamento & 13,07 & 0,67 \\
Inaproveitável & 92,52 & 4,75 \\
\hline Total & 1947,50 & 100,00 \\
\hline
\end{tabular}

Fonte: Otani et al. (1994) 


\subsection{Propriedades estudadas}

A demarcação dos limites fisicos das propriedades na microbacia da Água F permitiu identificar, em 1994, 32 propriedades agrícolas e uma área da prefeitura usada como lixão. Esta quantidade de propriedades é superior às 27 propriedades cadastradas em 1991 por Otani et al. (1994), cujo trabalho se baseou no levantamento de dados das propriedades via questionários. As 32 propriedades já existiam em 1991. Então, obtevese uma maior exatidão no levantamento de propriedades quando seus limites foram demarcados.

Neste trabalho, foram identificados três grupos de propriedades agrícolas na microbacia da Água $F$, em função do tamanho da área e do uso atual da terra. $O$ primeiro grupo (G1) foi formado por 12 pequenas propriedades, com área menor que 60 ha, possuindo as atividades de culturas anuais, maracujá e café e/ou pecuária. O segundo grupo (G2) foi formado por 11 propriedades, com área maior que 100 ha, sendo a pecuária a atividade principal em termos de ocupação da terra. O terceiro grupo (G3) foi formado por 9 propriedades, com área entre 60 e 100 ha, localizadas na parte mais elevada da microbacia, com melhores solos e que possuíam o café como atividade principal. Para fins de obtenção das atividades que otimizam os sistemas de produção, foram sorteadas 2 propriedades de cada grupo totalizando 6 propriedades estudadas ( $\mathrm{P} 1$, P2, P3, P4, P5, e P6)

As quantidades de recursos de capital, trator e mão-de-obra familiar e residente disponíveis nestas propriedades são mostradas na Tabela 3. O capital próprio disponível no primeiro dia do ano agrícola (início em agosto) foi usado para suprir o fluxo de caixa, já que nenhuma das 6 propriedades usava o crédito agrícola. No modelo de programação por metas lexicográficas, este valor retorna ao caixa no final do ano agrícola. O capital disponível, no início do ano agrícola, foi arbitrariamente estimado em função do valor total da produção em cada propriedade. 
Tabela 3 - Disponibilidade de recursos de capital próprio, trator, mão-de-obra familiar e residente em 6 propriedades da microbacia da Água F, Vera Cruz, 1994.

\begin{tabular}{|c|c|c|c|c|c|c|c|}
\hline \multirow[b]{3}{*}{ Recursos } & \multirow[b]{3}{*}{ (unid.) } & \multicolumn{6}{|c|}{ Propriedades } \\
\hline & & \multicolumn{2}{|c|}{ Grupo 1} & \multicolumn{2}{|c|}{ Grupo 2} & \multicolumn{2}{|c|}{ Grupo 3} \\
\hline & & $\mathrm{P} 1$ & $\mathrm{P} 2$ & P3 & P4 & P5 & P6 \\
\hline Capital próprio & (US\$) & 5000 & 5000 & 5000 & 50000 & 50000 & 50000 \\
\hline Trator & (unid.) & 1 & 1 & - & 1 & 1 & 1 \\
\hline Mão-de-obra & (h/mês) & 384 & - & 192 & 384 & - & - \\
\hline familiar & & & & & & & \\
\hline $\begin{array}{l}\text { Mão-de-obra } \\
\text { residente }\end{array}$ & (h/mês) & - & 384 & - & 1344 & 1728 & 4800 \\
\hline
\end{tabular}

As propriedades P1, P3 e P4 usavam mão-de-obra familiar e as propriedades P2, P4, P5 e P6 usavam mão-de-obra permanente contratada (residente na propriedade). A maior quantidade de mão-de-obra encontrada nas propriedades P4, P5 e P6 deve-se às necessidades da cultura do café, no período de colheita. Nas propriedades onde predominava a pecuária a quantidade de mão-de-obra era menor.

Os tratores das propriedades da microbacia tinham de 10 a 20 anos e eram usados nas operações de preparo do solo, plantio, cultivo, pulverizações e transporte de insumos e produtos. Apenas a propriedade P3 não possuía trator e usava mão-de-obra familiar e eventual para limpeza manual do pasto. Eventualmente, os tratores eram alugados para prestarem serviços em propriedades de terceiros. Do mesmo modo, os serviços de terceiros eram contratados para suprir a necessidade de trator, em determinados períodos. A estimativa da disponibilidade de horas de trabalho de trator, que varia ao longo do ano em função da umidade do solo, é mostrada na Tabela 4 . Observa-se que no período chuvoso há diminuição das horas trabalháveis com trator. Estes valores foram usados no segundo membro das equações de restrição de disponibilidade mensal de horas de trator. 
Tabela 4 - Total mensal de horas trabalháveis com trator na microbacia hidrográfica da Água F, Vera Cruz.

\begin{tabular}{lllllllllllll} 
Mês & Ago & Set & Out & Nov & Dez & Jan & Fev & Mar & Abr & Mai & Jun & Jul \\
\hline Horas & 232 & 216 & 200 & 192 & 173 & 176 & 160 & 192 & 208 & 224 & 224 & 232 \\
\hline
\end{tabular}

Fonte: Seção de Climatologia do IAC

O uso atual do solo nas propriedades é apresentado na Tabela 5. Observase que as áreas com pasto de braquiária ocorriam em todas as propriedades. Não havia nestas propriedades a renovação de pastagem. Apenas as propriedades P1 e P3 adubavam o pasto anualmente.

Os pastos naturais, com predominância de gramão, estavam localizados nos solos menos férteis e com ocorrência de erosão. As propriedades P1, P2 e P6 usavam a capineira de Napier para suprir a alimentação do gado no período de seca, entre maio e setembro. As propriedades P1 e P2 possuíam 0,97 e 0,75 unidades animais (ua) por hectare de pasto. Esta capacidade de suporte é considerada baixa. Nas demais propriedades o suporte dos pastos variava de 1,20 a 1,70 ua/ha. Estes valores são razoáveis para o atual sistema de manejo dos pastos das propriedades. O café era a principal fonte de renda nas propriedades P4, P5 e P6, ocupando $22 \%, 57 \%$ e $61 \%$ da área destas propriedades.

O maracujá era cultivado nas propriedades $\mathrm{P} 1$ e P2. O milho era cultivado na $\mathrm{P} 2$ e sua produção era destinada à alimentação do gado de leite. O eucalipto estava presente na $\mathrm{P} 5$, sendo seu principal uso a produção de mourões destinados ao uso na propriedade e à venda para terceiros. As matas ciliares e matas de reserva florestal estavam presentes em quatro propriedades (P2, P3, P4 e P5). A diversidade na ocupação do solo encontrada nestas 6 propriedades da microbacia hidrográfica da Água F é adequada como estudos de casos para testar o método de programação por metas lexicográficas e determinar o impacto do planejamento do uso sustentável da terra nos sistemas de produção, nestas propriedades. 
Tabela 5 - Uso atual do solo, atividades em ha, em 6 propriedades da microbacia hidrográfica da Água F, Vera Cruz, 1994.

Grupos de Propriedades

\begin{tabular}{|c|c|c|c|c|c|c|}
\hline \multirow[b]{2}{*}{ Uso atual do solo } & \multicolumn{2}{|c|}{ G1 } & \multicolumn{2}{|c|}{ G2 } & \multicolumn{2}{|c|}{ G3 } \\
\hline & P1 & P2 & P3 & P4 & P5 & P6 \\
\hline Pastagem braquiária & 10,07 & 18,95 & 66,66 & 82,95 & 19,00 & 33,56 \\
\hline Pastagem natural & 5,67 & 29,05 & 28,44 & - & 9,00 & - \\
\hline Capineira & 1,20 & 1,00 & - & - & - & 2,16 \\
\hline Café & - & - & - & 30,00 & 58,05 & 52,43 \\
\hline Maracujá & 4,84 & 0,50 & - & - & - & . \\
\hline Milho & - & 2,50 & - & - & - & - \\
\hline Eucalipto & - & & - & - & 4,81 & - \\
\hline Mata (reserva) & - & 0,50 & 6,75 & 18,72 & 1,08 & \\
\hline Área total (ha) & 21,78 & 52,50 & 101,85 & 131,67 & 91,94 & 88,15 \\
\hline Pecuária de leite (ua) $)^{1}$ & 16,2 & 22,2 & - & - & 11,2 & 53,5 \\
\hline Pecuária de corte (ua) & - & 51,2 & 71,3 & 115,5 & 23,5 & \\
\hline
\end{tabular}

As classes de capacidade de uso sustentável da terra e as respectivas áreas em cada propriedade são apresentadas na Tabela 6. As classes de capacidade de uso sustentável da terra que ocorriam com maior freqüência foram a classe IV, para a qual não são recomendadas as culturas anuais e a classe VII que deve ser ocupada com reserva florestal. Os solos da classe III ocorriam em 5 propriedades (P2, P3, P4, P5, e P6) mas apenas na P2 era ocupada com cultura anual, em pequena área.

A capacidade de uso sustentável da terra implica na recomendação de ocupação das glebas, que possuem solos das classes Va, VIIp, VIIe e VIII, com mata ciliar ou mata de reserva de flora e fauna. Qualquer outro uso implica em sobreuso da CUST e, consequentemente, provoca a degradação do solo. Todas glebas com solos dessas classes, nas propriedades P1 e P6, estavam com sobreuso. As propriedades P2, P3, P4 e P5 apresentavam, respectivamente, os seguintes percentuais de áreas de solos destas classes com sobreuso: $53 \%, 81 \%, 61 \%$ e $97 \%$. A proporção de áreas que 
deveriam receber mata ciliar ou de reserva florestal, em relação à área total de cada propriedade, é: $26 \%$ na P1, 27\% na P2, 34\% na P3, 37\% na P4, 16\% na P5 e 6\% na P6. Estas áreas se tornariam improdutivas, se o CUST fosse adotado. Além disso, seriam gastos recursos para a implantação e a manutenção de aceiros e cercas.

Tabela 6 - Áreas, em hectares, das classes de capacidade de uso sustentável da terra, em 6 propriedades da microbacia da Água F, Vera Cruz, 1996.

Classes de

Capacidade de Áreas das propriedades, em ha

Uso Sustentável da Terra ${ }^{1}$

P1

Pl

P2

P3

P4

P5 P6

\begin{tabular}{lrrrrrr}
\hline IIIe & - & 12,31 & 3,49 & 2,70 & - & - \\
IIIef & - & - & 1,52 & 13,41 & 18,00 & 18,00 \\
IVe & 13,59 & 25,83 & 59,76 & 59,22 & 59,05 & 62,59 \\
IVef & - & - & - & - & - & 2,16 \\
Va & - & 14,36 & - & 5,22 & - & - \\
VIe & 2,52 & - & 1,89 & 7,74 & - & - \\
VIIe & 1,89 & - & 26,19 & 19,26 & 13,00 & 5,40 \\
VIIp & 3,78 & - & 2,25 & 5,40 & 0,81 & - \\
VIII & - & - & 6,75 & 18,72 & 1,08 & - \\
\hline Área total & 21,78 & 52,50 & 101,85 & 131,67 & 91,94 & 88,15 \\
\hline
\end{tabular}

Fonte: Seção de Fotointerpretação do IAC

${ }^{1}$ Fatores limitantes dos solos: erosão (e); fertilidade (f); profundidade (p) e drenagem. (a).

Observa-se na Tabela 6 que o planejamento do uso sustentável da terra propõe mudanças significativas na distribuição e tamanho das glebas de terra produtivas de cada propriedade. Para a efetiva implementação do PEMBH, torna-se necessário recomendar atividades que otimizam os múltiplos objetivos, considerando-se as restrições de uso do solo e as restrições de disponibilidade de outros recursos nas propriedades agrícolas. 


\subsection{Construção de cenários para otimização dos múltiplos objetivos}

As técnicas de modelagem amplamente usadas na programação linear também são úteis na programação multicritério para a construção de diversos cenários de forma a aproximar o modelo matemático ao mundo real do produtor rural. neste trabalho foram construídos dois cenários: cenário 1 e cenário 2 .

No cenário 1 qualquer alternativa de uso da terra, que pertença ao conjunto das soluções possíveis, delimitado pelas restrições de cada propriedade, poderá ser selecionada, mesmo que os valores ótimos obtidos para cada objetivo sejam piores (maior ou menor dependendo do objetivo ser de maximização ou minimização) que os respectivos valores considerando o uso atual da terra na propriedade.

No cenário 2 foram acrescentadas restrições que limitam os valores ótimos a serem alcançados pelos objetivos em níveis melhores (maior ou menor dependendo do objetivo ser de maximização ou minimização) ou iguais ao alcançado, considerando o uso atual da terra na propriedade. Assim, supõe-se que os produtores rurais não pretendem piorar o valor de nenhum objetivo, em detrimento da melhora dos valores de outros objetivos. Por exemplo, considerando que o produtor obtém um lucro de $\mathrm{R} \$$ $10.000,00 /$ ano com o uso atual da terra, consumindo R \$ 1.000,00/ano com defensivos químicos. Então, o objetivo de maximizar o lucro (em níveis acima de $\mathrm{R} \$ 10.000,00 / a n o$ ) só poderá ser alcançado com alternativas de uso da terra que usem menos ou a mesma quantidade de defensivos químicos, ou seja $\mathrm{R} \$ 1.000,00 / \mathrm{ano}$.

Os cenários 1 e 2 foram suficientes para se testar o método de planejamento proposto. Outros cenários podem ser criados, em função da interação do analista com o tomador de decisão, sem acrescentar dificuldades ao método. 


\section{RESULTADOS E DISCUSSÃO}

\subsection{Hierarquização dos múltiplos objetivos}

Na hierarquização dos múltiplos objetivos todos os objetivo foram aceitos, pelos tomadores de decisão, como objetivos importantes na escolha de atividades para uso da terra. O uso de cartões foi adequado à hierarquização dos objetivos. Dos cartões usados apenas o que representava o objetivo de minimizar o uso de defensivos químicos foi erroneamente interpretado por um tomador de decisão analfabeto, exigindo novas explicações sobre este objetivo. Este fato ocorreu porque o cartão mostra uma informação visual de uso intenso de defensivo químico enquanto que o objetivo de minimizar o uso só é percebido quando se lê o título do cartão. A hierarquia dos objetivos de cada tomador de decisão é apresentada na Tabela 7.

Tabela 7 - Hierarquia dos múltiplos objetivos dos tomadores de decisão em 6 propriedades da microbacia hidrográfica da Água F, Vera Cruz, 1996.

\begin{tabular}{|c|c|c|c|c|c|c|}
\hline \multirow[b]{3}{*}{ Objetivos } & \multicolumn{6}{|c|}{ Propriedades } \\
\hline & \multicolumn{2}{|c|}{ Grupo 1} & \multicolumn{2}{|c|}{ Grupo 2} & \multicolumn{2}{|c|}{ Grupo 3} \\
\hline & $\mathrm{P} 1$ & $\mathrm{P} 2$ & P3 & P4 & P5 & P6 \\
\hline Min. uso de defensivos agrícolas & $5^{-}$ & $3^{0}$ & $1^{\circ}$ & $1^{\mathbf{o}}$ & $1^{\mathrm{o}}$ & $6^{0}$ \\
\hline Max. lucro & $2^{\underline{o}}$ & $2^{\underline{0}}$ & $6^{\mathrm{o}}$ & $3^{\mathrm{o}}$ & $3^{\mathfrak{o}}$ & $1^{\underline{0}}$ \\
\hline Min. estacionalidade. do fluxo de caixa & $1^{\underline{o}}$ & $6^{0}$ & $5^{\circ}$ & $2^{0}$ & $6^{0}$ & $2^{o}$ \\
\hline Max. uso da mão-de-obra permanente & $3^{\circ}$ & $4^{\circ}$ & $3^{0}$ & $6^{0}$ & $2^{\underline{o}}$ & $3^{0}$ \\
\hline Max. produção de alimentos básicos & $4^{0}$ & $5^{0}$ & $2^{\underline{0}}$ & $4^{\mathrm{o}}$ & $4^{0}$ & $4^{\underline{0}}$ \\
\hline Min. estacionalidade da mão-de-obra & $6^{\underline{0}}$ & $1^{\underline{o}}$ & $4^{\underline{0}}$ & $5^{0}$ & $5^{0}$ & $5^{\underline{0}}$ \\
\hline
\end{tabular}


O objetivo de minimizar o uso de defensivos agrícolas foi escolhido por três tomadores de decisão como sendo de primeira prioridade para a seleção de alternativas para o uso do solo em suas propriedades. Os objetivos que seguiram em ordem decrescente de prioridade, para o conjunto dos tomadores de decisão, foram: maximizar o lucro, minimizar a estacionalidade do fluxo de caixa, maximizar o uso da mão-de-obra permanente, maximizar a produção de alimentos básicos e minimizar a estacionalidade da mão-de-obra. Todos os objetivos foram considerados importantes pelos tomadores de decisão da microbacia da Água F e nenhum objetivo foi rejeitado para obtenção de alternativas ótimas do uso do solo. Também, nenhum objetivo obteve o mesmo nível hierárquico que outro objetivo.

Para fins de verificação da coerência do tomador de decisão na escolha do objetivo de primeira prioridade, calculou-se o valor alcançado por este objetivo considerando o uso atual do solo em sua propriedade, como mostra a Tabela 8.

Tabela 8 - Valores calculados para o uso de defensivos químicos, lucro, estacionalidade do fluxo de caixa, uso da mão-de-obra permanente, produção de alimentos básicos, estacionalidade do uso da mão-de-obra, considerando o uso atual da terra, em 6 propriedades da microbacia hidrográfica da Água F, Vera Cruz, 1996.

\begin{tabular}{rrrrrrr}
\hline \multicolumn{2}{c}{$\begin{array}{c}\text { Uso de } \\
\text { Propriedadensivos } \\
\text { químicos } \\
\text { (US\$) }\end{array}$} & $\begin{array}{l}\text { Lucro } \\
\text { (US\$) }\end{array}$ & $\begin{array}{l}\text { Estacionalidade } \\
\text { do fluxo de } \\
\text { caixa } \\
\text { (US\$) }\end{array}$ & $\begin{array}{l}\text { Uso da } \\
\text { mão-de-obra } \\
\text { permanente } \\
\text { (h) }\end{array}$ & $\begin{array}{l}\text { Produção de } \\
\text { alimentos } \\
\text { básicos } \\
\text { (US\$) }\end{array}$ & $\begin{array}{l}\text { Estacionalidade } \\
\text { do uso da } \\
\text { mão-de-obra } \\
\text { (h) }\end{array}$ \\
\hline P1 & 435 & 1987 & 9828 & 4134 & 2515 & 6913 \\
P2 & 302 & 370 & 20357 & 3428 & 10485 & 1656 \\
P3 & 532 & 2862 & 25034 & 1723 & 9550 & 365 \\
P4 & 5897 & 121725 & 206092 & 13302 & 7500 & 23538 \\
P5 & 10176 & 116409 & 283535 & 13214 & 4553 & 41694 \\
P6 & 9053 & 247920 & 382158 & 29555 & 2245 & 1690 \\
\hline
\end{tabular}

A Tabela 8 mostra que os valores alcançados pelos objetivos, considerando o uso atual da terra, apresentam certa homogeneidade dentro dos grupos 
G1 e G3 de propriedades, mas são bastantes diferentes entre as duas propriedades do grupo G2. A propriedade P6 que priorizou o objetivo de maximizar o lucro foi a que apresentou melhor resultado neste objetivo. A P1 priorizou o objetivo de minimizar a estacionalidade do fluxo de caixa e apresentou a menor estacionalidade neste objetivo. A propriedade P2 priorizou o objetivo de minimizar a estacionalidade do uso da mão-deobra e apresentou baixo valor neste objetivo. A P3 priorizou o objetivo de minimizar o uso de defensivos químicos e apresentou baixo valor no gasto com estes insumos. $\mathrm{O}$ mesmo não aconteceu com as propriedades P4 e P5. Estes resultados mostram coerência dos tomadores de decisão em relação à busca de otimização dos objetivos declarados como de primeira prioridade. Portanto, o uso de cartões com motivos referentes aos objetivos foi adequado para captar a hierarquização dos objetivos por parte do tomador de decisão.

\subsection{Otimização dos objetivos}

A otimização de cada objetivo individualmente, usando a programação linear, sujeitos às restrições de disponibilidade de área, trator, capital, mão-de-obra etc, é necessária para se obter a meta máxima (meta otimista) que um objetivo pode alcançar em cada propriedade. Os valores dessas metas foram usadas na programação por metas lexicográficas para a otimização dos múltiplos objetivos. Foram utilizados dois cenários para selecionar as alternativas ótimas de uso sustentável da terra. No cenário 1 quaisquer alternativas podem ser selecionadas, independentemente dos valores alcançados pelos objetivos. Isto implica há a possibilidade de determinados objetivos alcançarem valores menores que os calculados para o uso atual da terra. No cenário 2 os valores dos objetivos considerando o uso atual da terra formam um conjunto de restrições que devem ser atendidas na otimização dos objetivos. Isto implica que o tomador de decisão não está disposto a piorar os niveis atuais dos objetivos, em detrimento da melhora de outros objetivos. A construção de cenários via modelagem de programação matemática permite maior interação do analista e o tomador de decisão, aproximando os modelos matemáticos do mundo real do produtor rural. 


\subsubsection{Otimização individual dos objetivos no cenário 1}

Os resultados das otimizações individuais dos objetivos, no cenário 1, são apresentados na Tabela 9 para a propriedade P1, Tabela 10 para a propriedade P2, Tabela 11 para a propriedade P3, Tabela 12 para a propriedade P4, Tabela 13 para a propriedade P5 e Tabela 14 para a propriedade P6.

Observa-se nas Tabelas 9 a 14 que na otimização do objetivo de maximização do lucro (margem bruta) a cultura de goiaba foi selecionada para ocupar as glebas com aptidão para a fruticultura (classes III e IV de capacidade de uso sustentável da terra) e a atividade eucalipto foi selecionada para as glebas de classe VI.

Para otimizar o objetivo de minimizar o uso de defensivos químicos, as culturas de milho e arroz foram selecionadas para as glebas de classe III e a pastagem de braquiária e capineira de Napier para as de classes IV e VI, associadas à pecuária de leite e corte, sem mudança na tecnologia atualmente em uso nas propriedades.

$\mathrm{Na}$ otimização do objetivo de maximização da produção de alimentos básicos, a cultura de feijão das águas e seca, com tecnologia manual e mecânica, foi selecionada para as glebas de classe III, e a pastagem de braquiária e capineira de Napier foram selecionadas para as glebas de classe IV e VI, associadas com a pecuária de leite.

$\mathrm{Na}$ otimização do objetivo de minimizar a estacionalidade da mão-de-obra, as culturas de milho, feijão e amendoim foram selecionadas para as glebas de classe III. Para as glebas de classe IV foram selecionadas as culturas de acerola, manga, café, tangerina e goiaba, e para as glebas de classe VI foram selecionadas o eucalipto, pastagem de braquiária e capineira de Napier associadas com a pecuária de leite e corte, com tecnologia atualmente praticada nas propriedades.

$\mathrm{Na}$ otimização do objetivo de maximizar o uso da mão-de-obra permanente, as culturas de feijão e amendoim foram selecionadas para as glebas de classe III. Para as glebas de classe IV foram selecionadas as atividades de mamão, abacate, café, manga, tangerina, maracujá, acerola e seringueira e para as glebas de classe VI foram selecionadas as atividades de eucalipto, pastagem de braquiária e capineira associadas com a pecuária de leite e corte. 


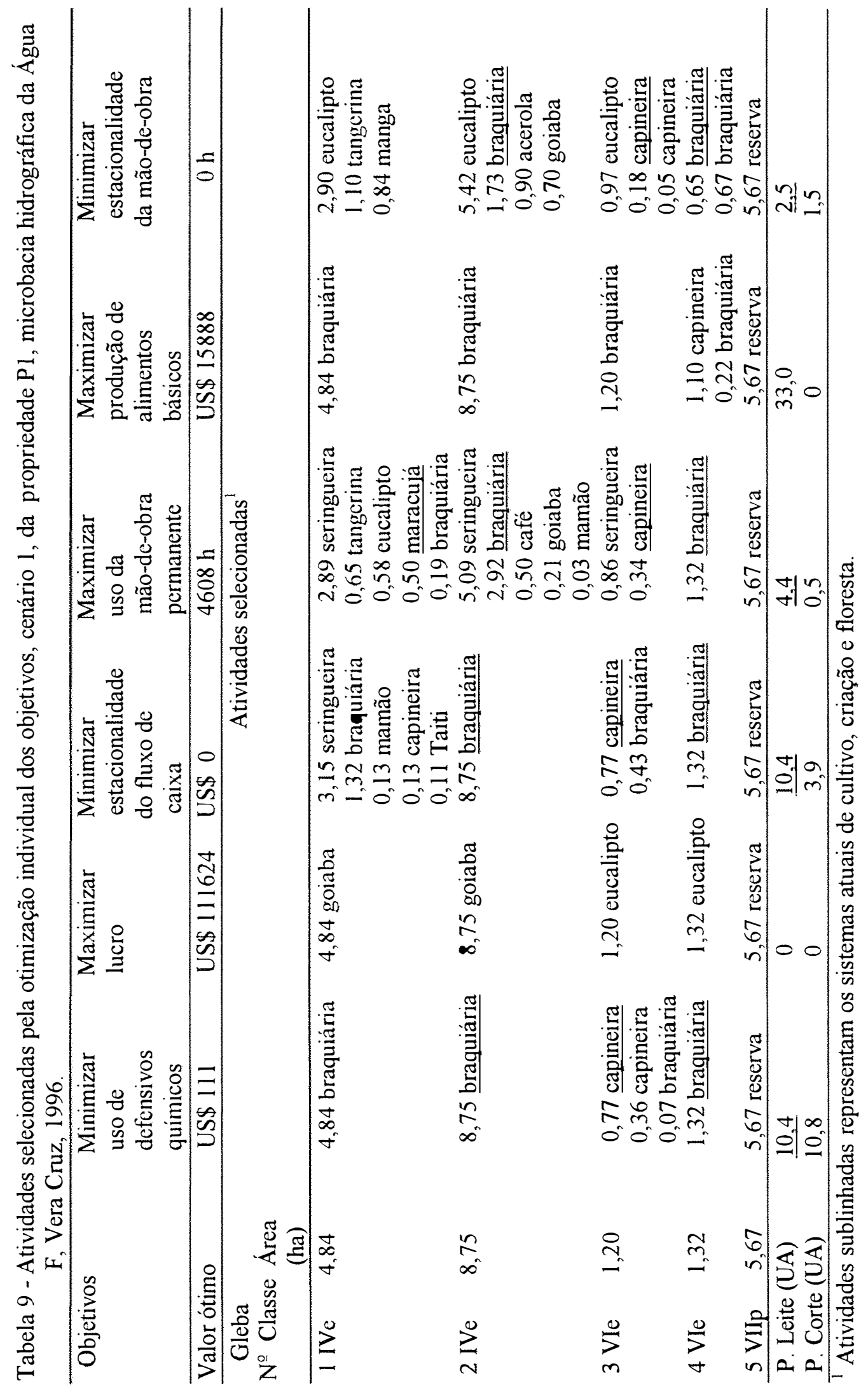




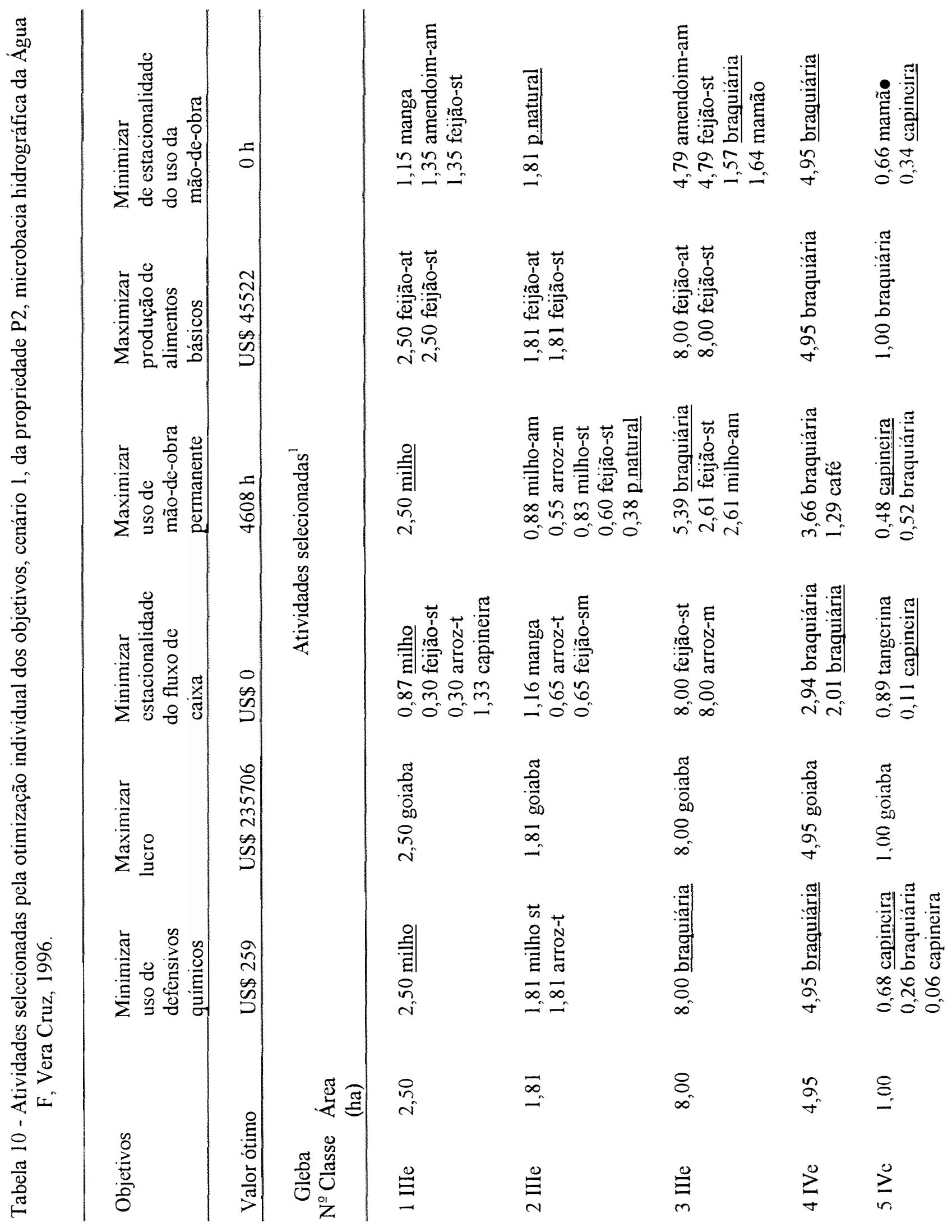




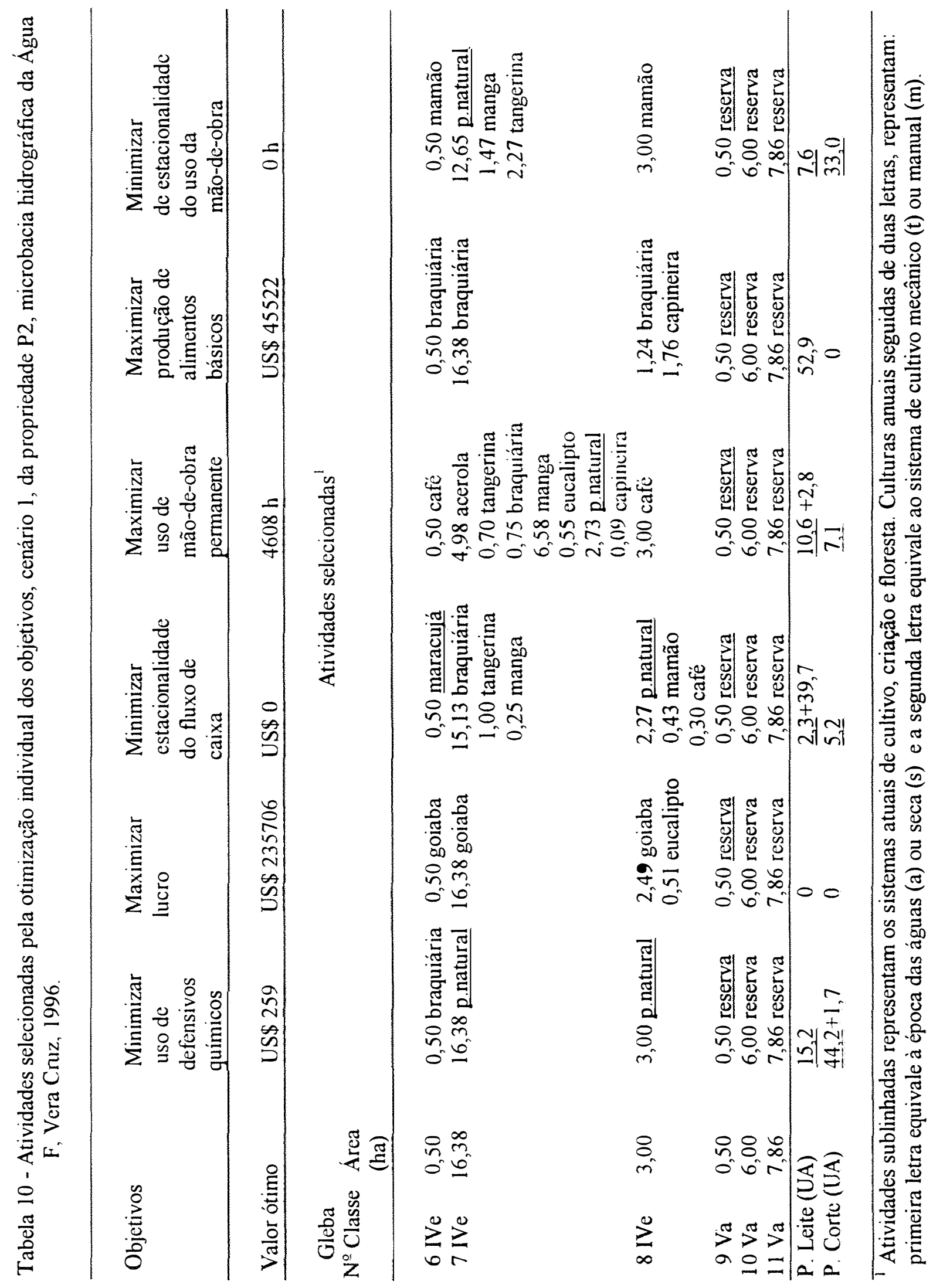




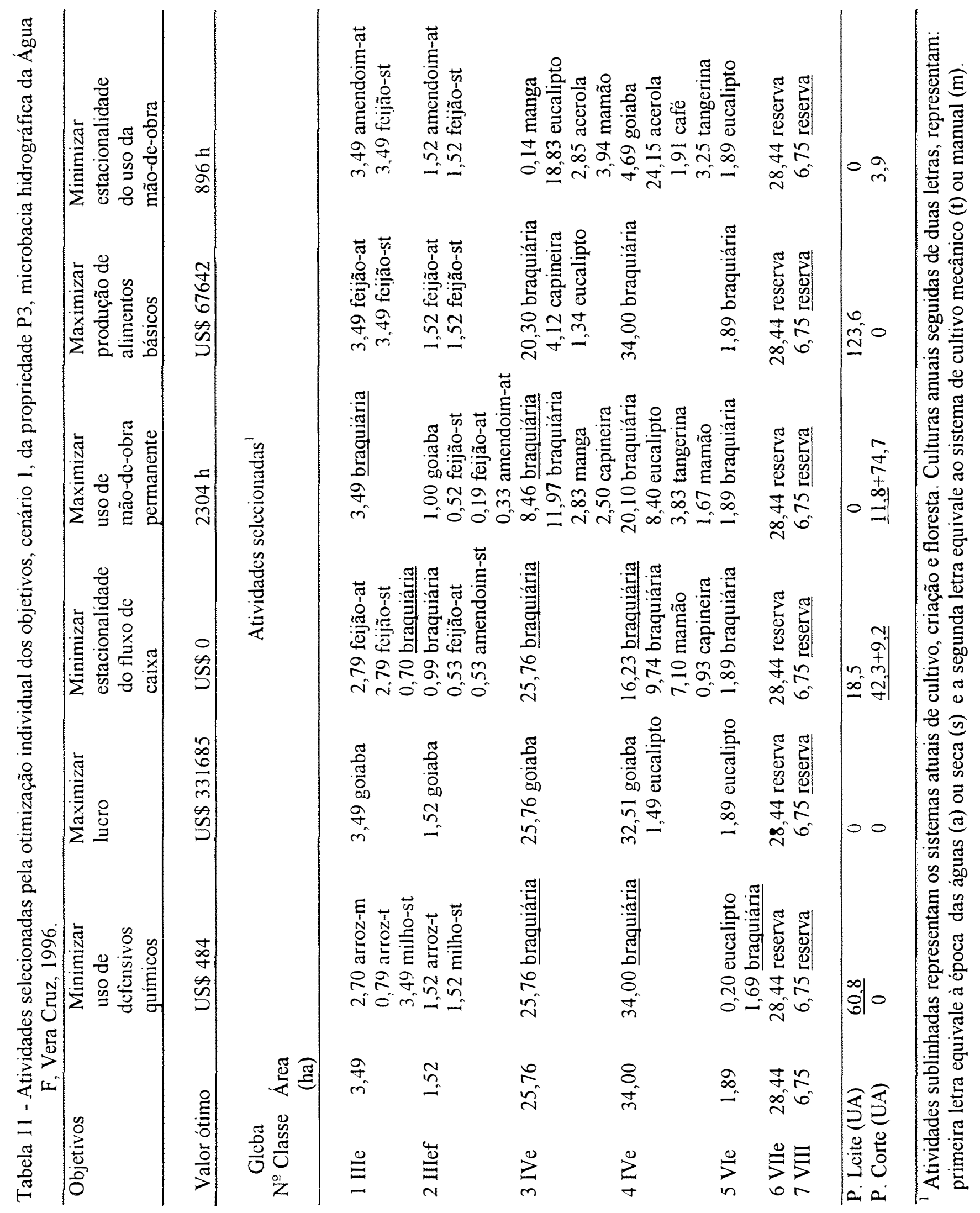




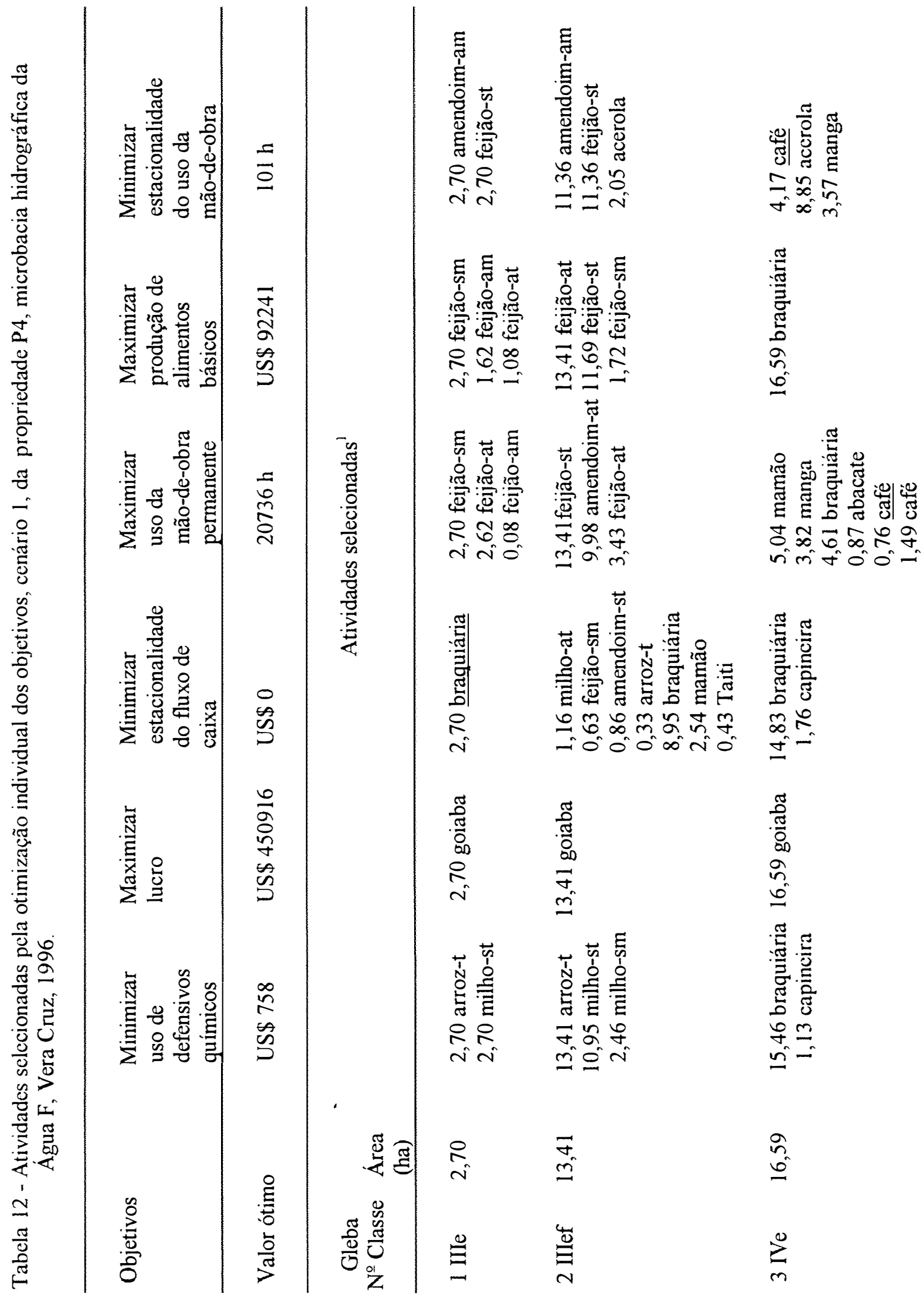




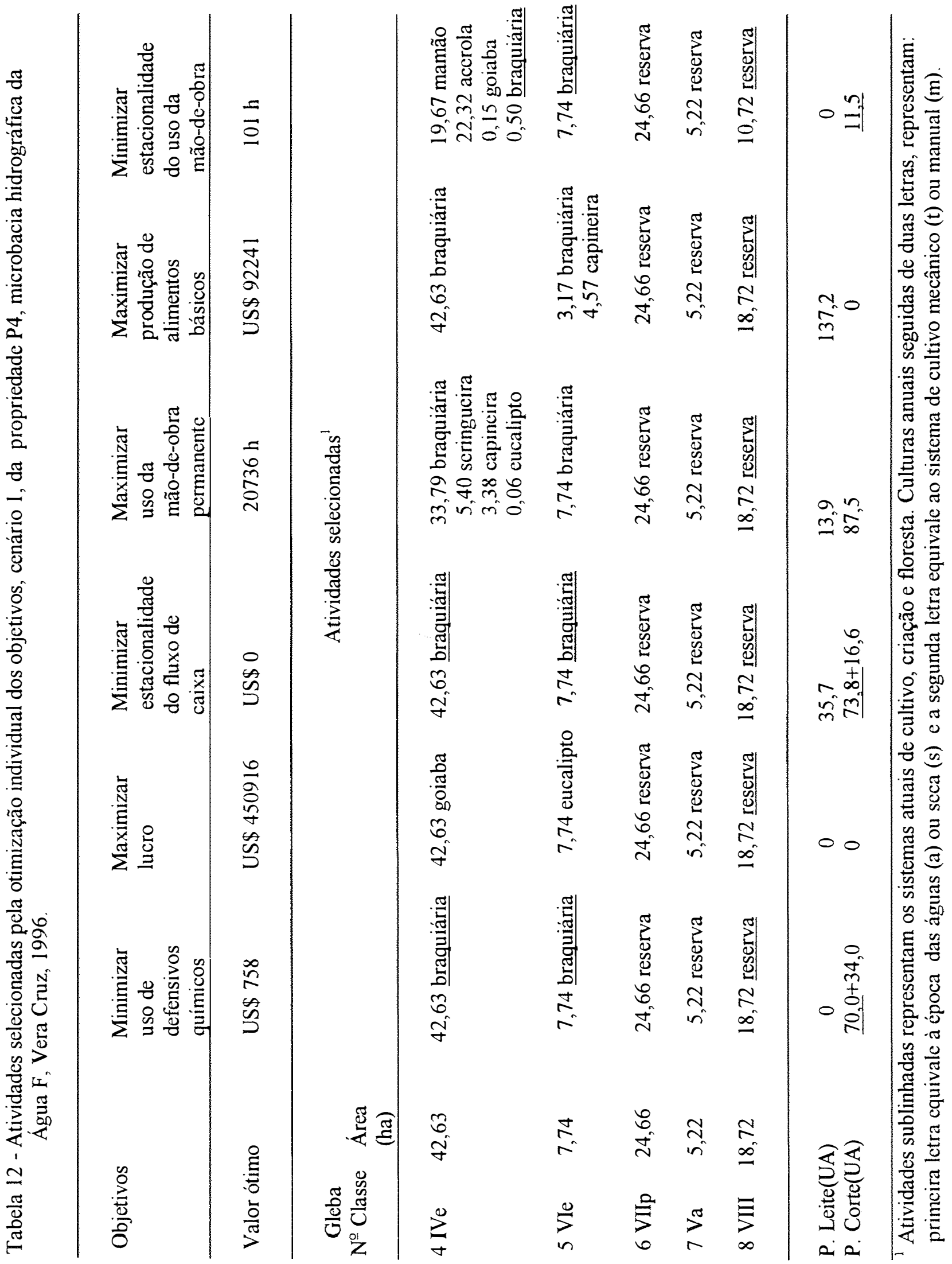




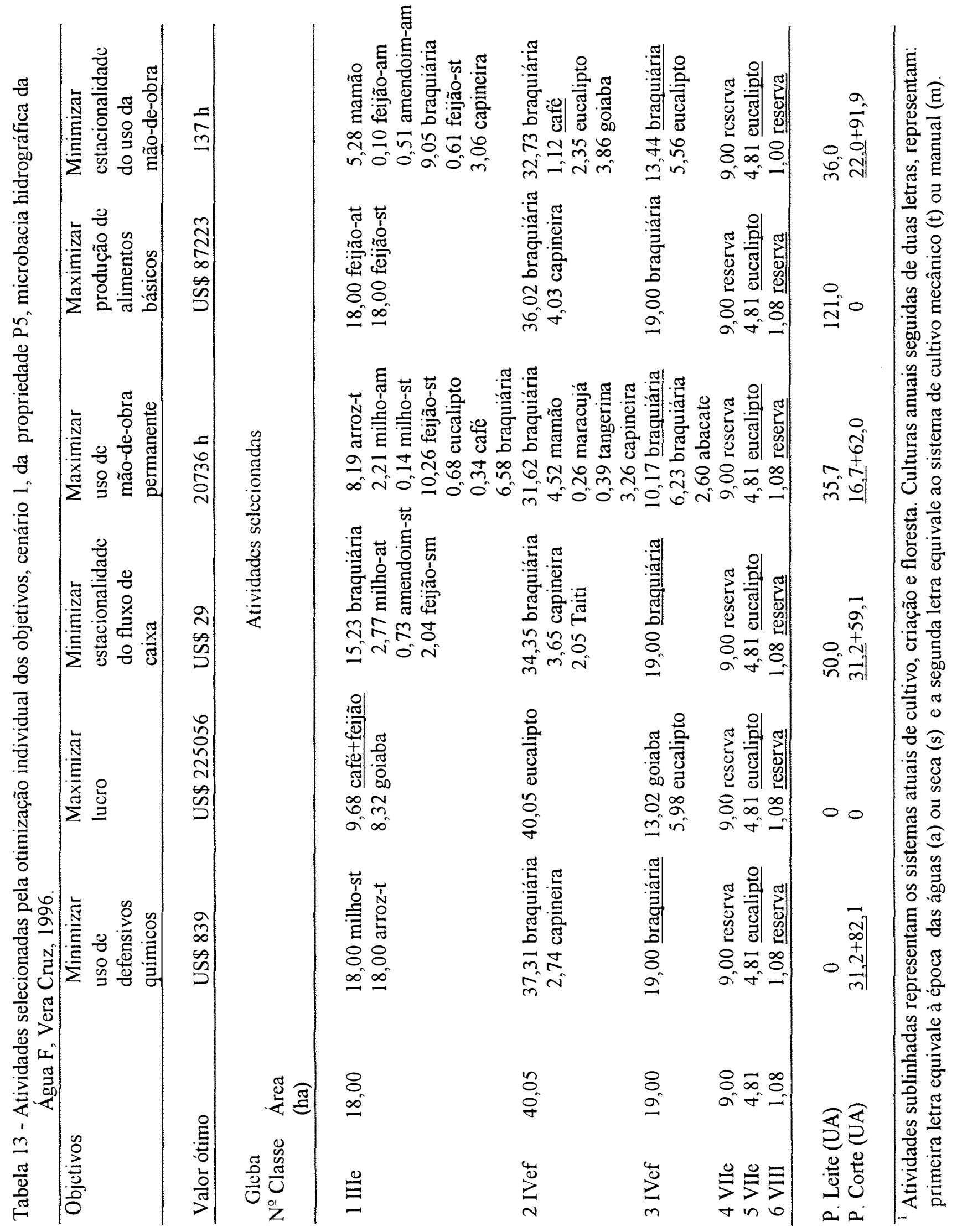




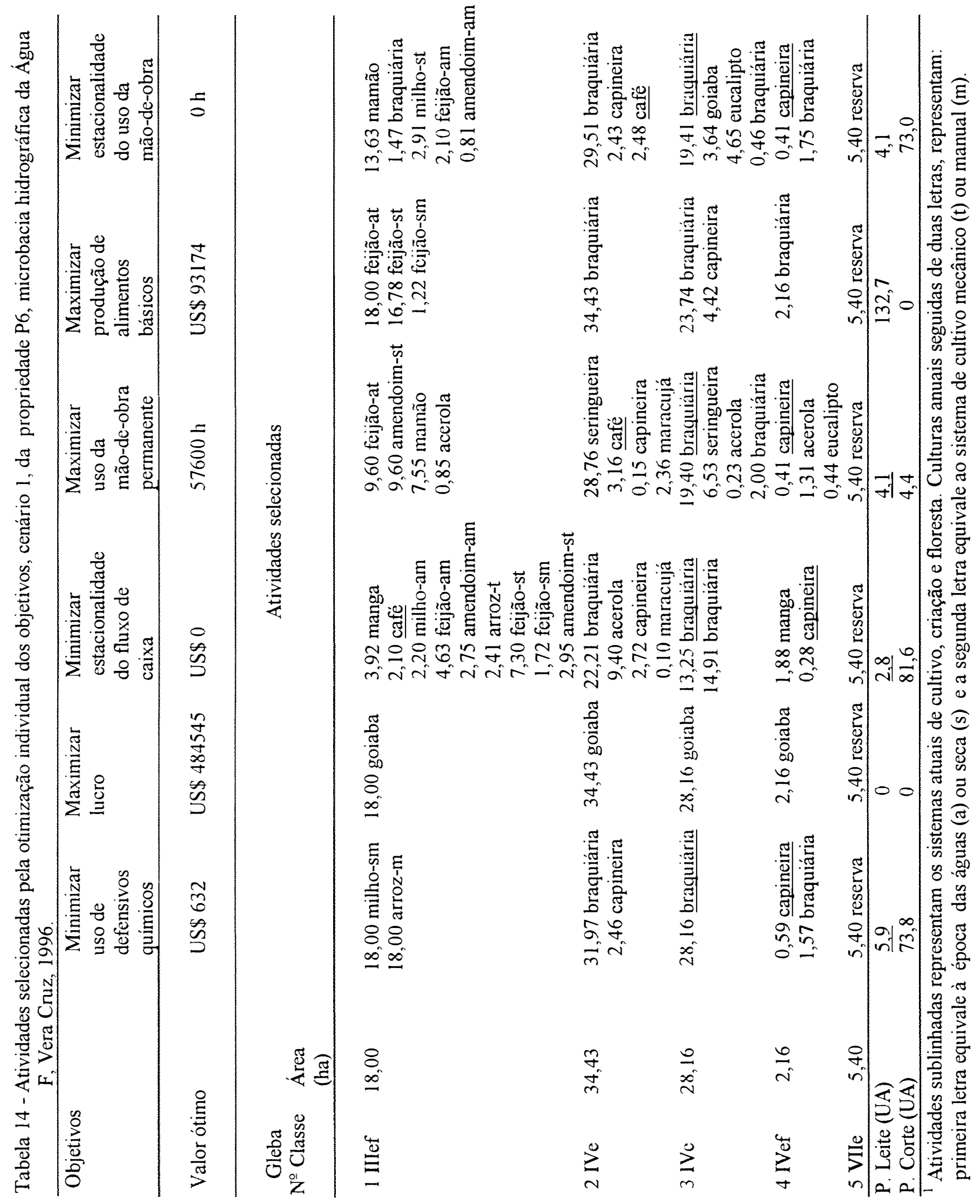


$\mathrm{Na}$ otimização do objetivo de minimizar a estacionalidade do fluxo de caixa, as culturas de milho, feijão, arroz e amendoim foram selecionadas para ocuparem as glebas de classe III. Eventualmente, pequenas áreas de cultura permanente (manga, limão Taiti, tangerina, mamão, maracujá e café) foram selecionadas para ocuparem estas glebas. Para as glebas de classe IV e VI foram selecionadas a pastagem de braquiária e a capineira de Napier, associadas com a pecuária de leite e corte.

\subsubsection{Otimização individual dos objetivos no cenário 2}

Os resultados das otimizações individuais dos objetivos, no cenário 2 , são apresentados na Tabela 15 para a propriedade P1, Tabela 16 para a propriedade P2, Tabela 17 para a propriedade P3, Tabela 18 para a propriedade P4, Tabela 19 para a propriedade $\mathrm{P} 5$ e Tabela 20 para a propriedade P6.

Observa-se nas Tabelas 15 a 20 que na otimização do objetivo de maximização do lucro (margem bruta) há uma predominância de culturas anuais (milho, feijão, arroz, e amendoim) para ocupar as glebas de classe III; as culturas de goiaba, acerola, tangerina, café e pastagem com braquiária foram selecionadas para as glebas de classe III de capacidade de uso sustentável da terra, e as atividades de eucalipto, pastagens com braquiária e capineira foram selecionadas para as glebas de classe VI.

Para otimizar o objetivo de minimizar o uso de defensivos químicos, as culturas de milho, feijão, arroz e braquiária foram selecionadas para as glebas de classe III e a pastagem de braquiária e capineira de Napier para as de classes IV e VI, associadas à pecuária de leite e corte, sem mudança na tecnologia atualmente em uso nas propriedades

$\mathrm{Na}$ otimização do objetivo de maximização da produção de alimentos básicos, a cultura de feijão, milho, arroz e amendoim, foram selecionadas para as glebas de classe III, e a pastagem de braquiária e capineira de Napier foram selecionadas para as glebas de classe IV e VI, associadas com a pecuária de leite.

$\mathrm{Na}$ otimização do objetivo de minimizar a estacionalidade da mão-de-obra, as culturas de milho, arroz, feijão e amendoim foram selecionadas para as glebas de classe 


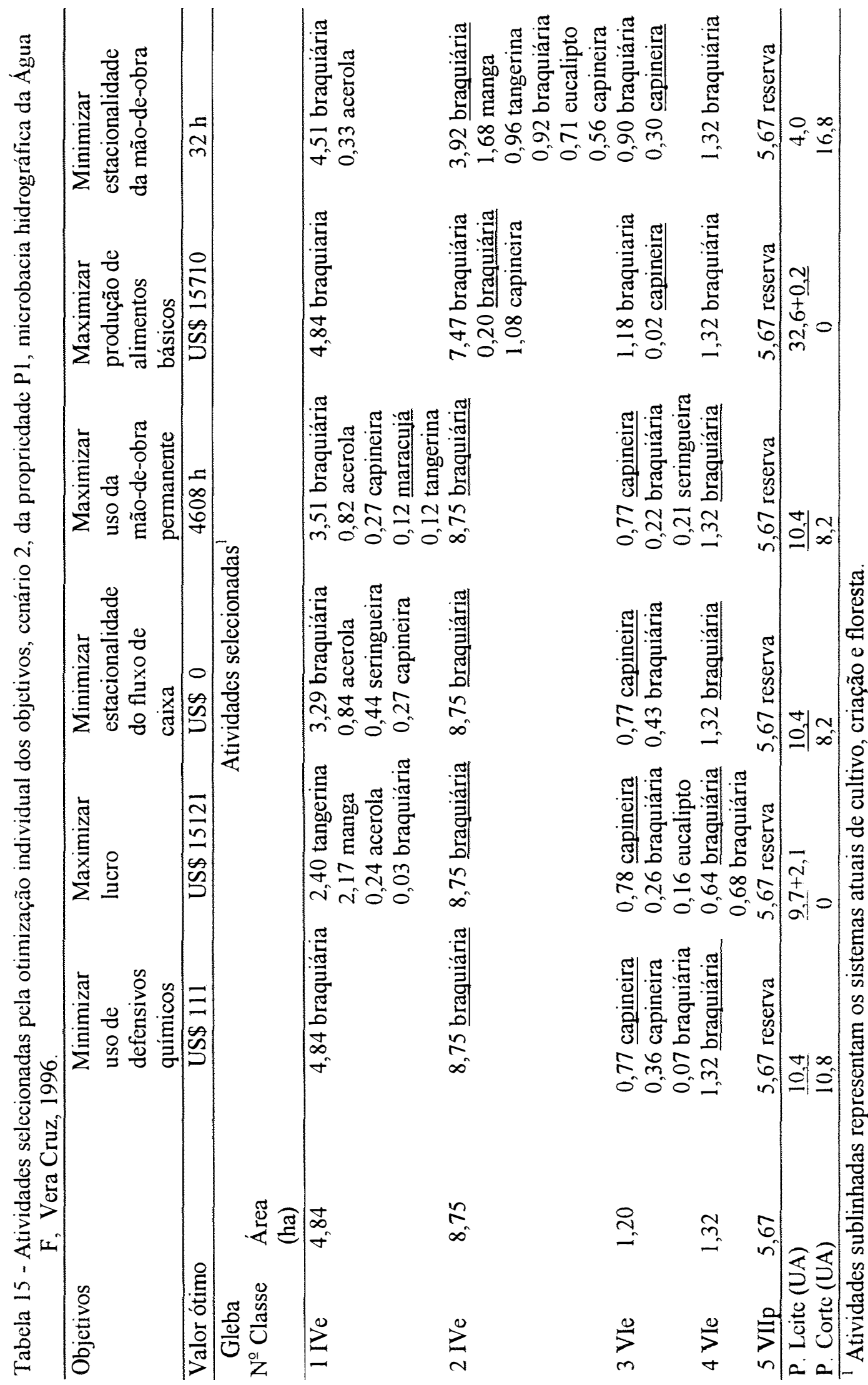




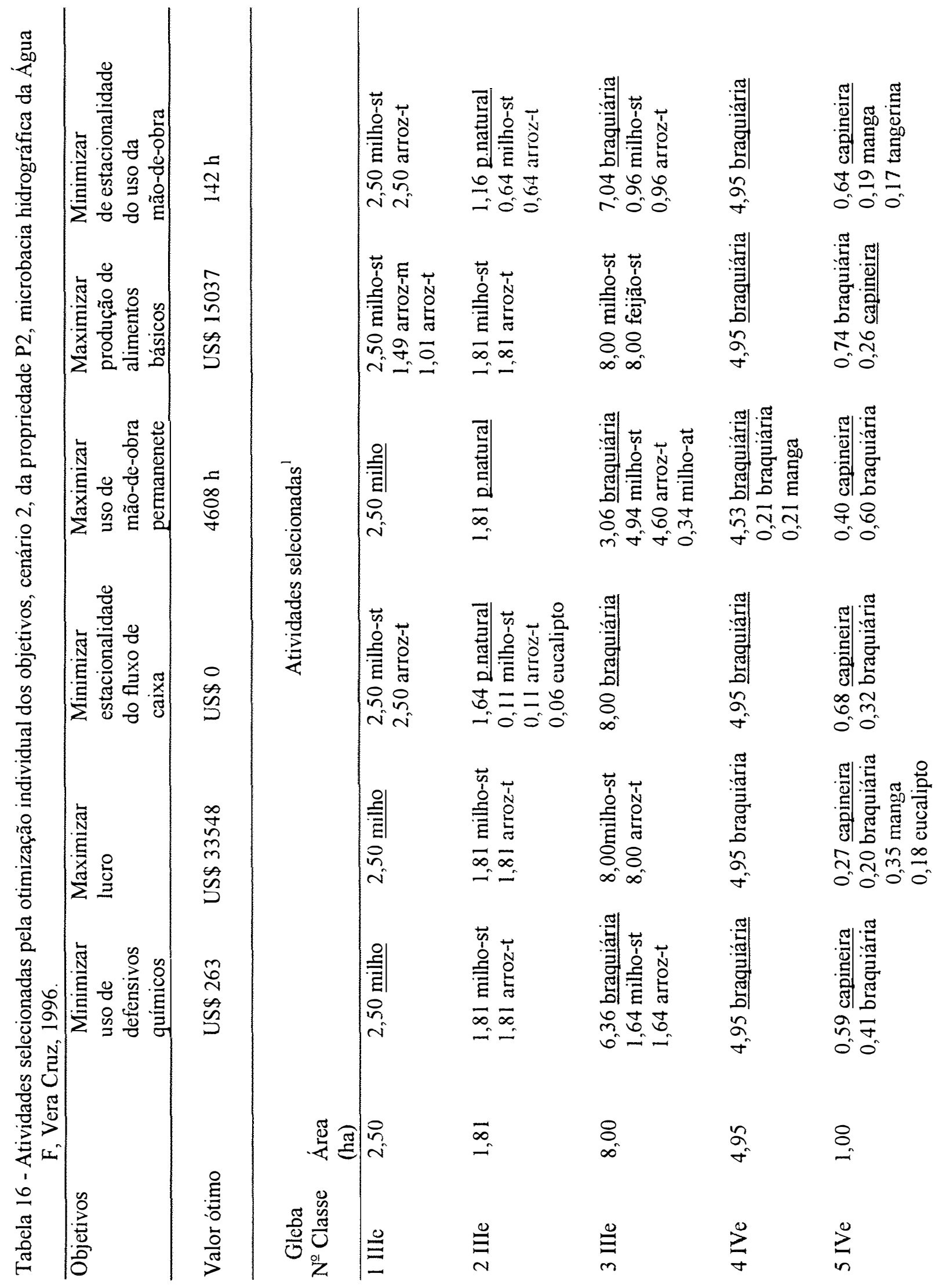




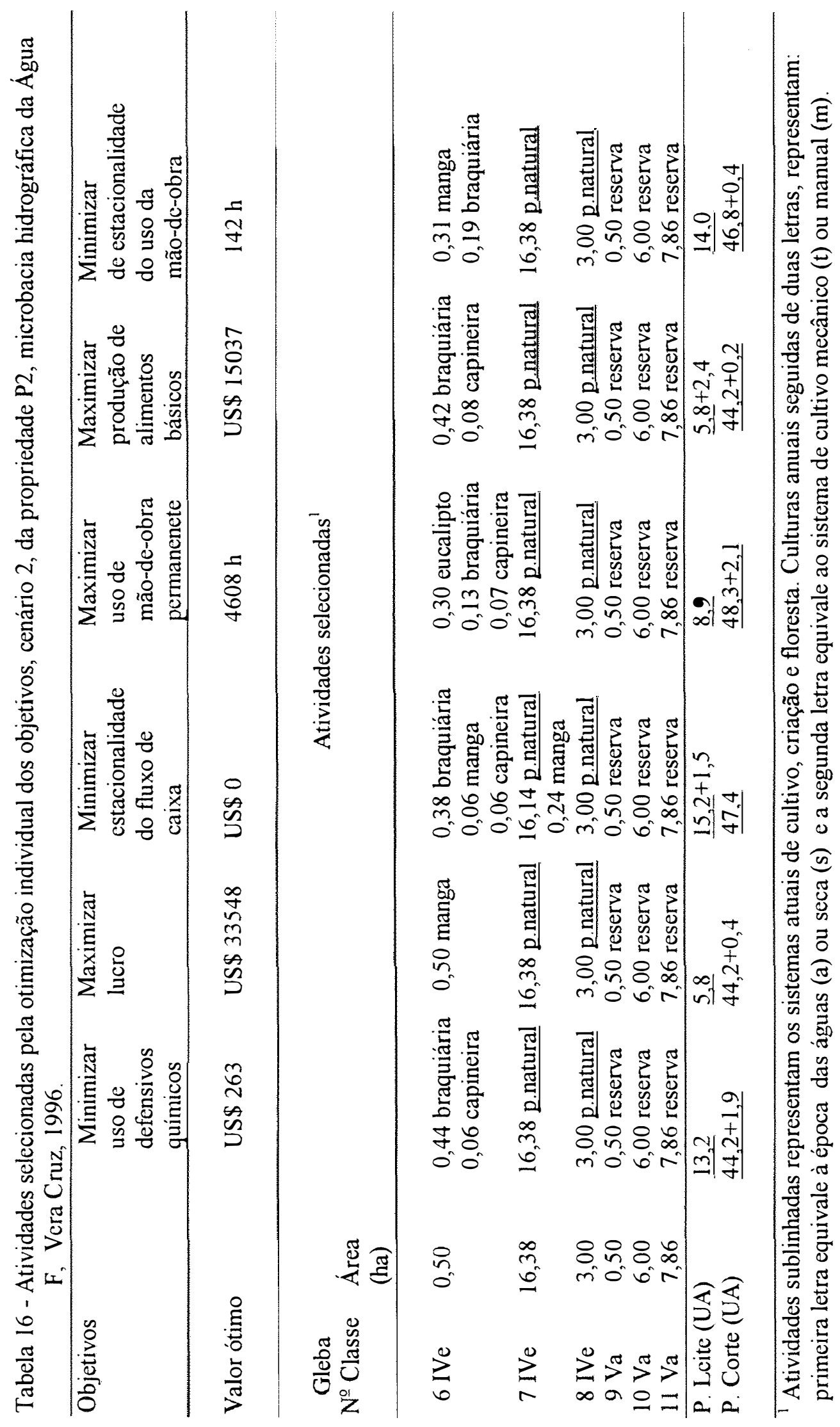




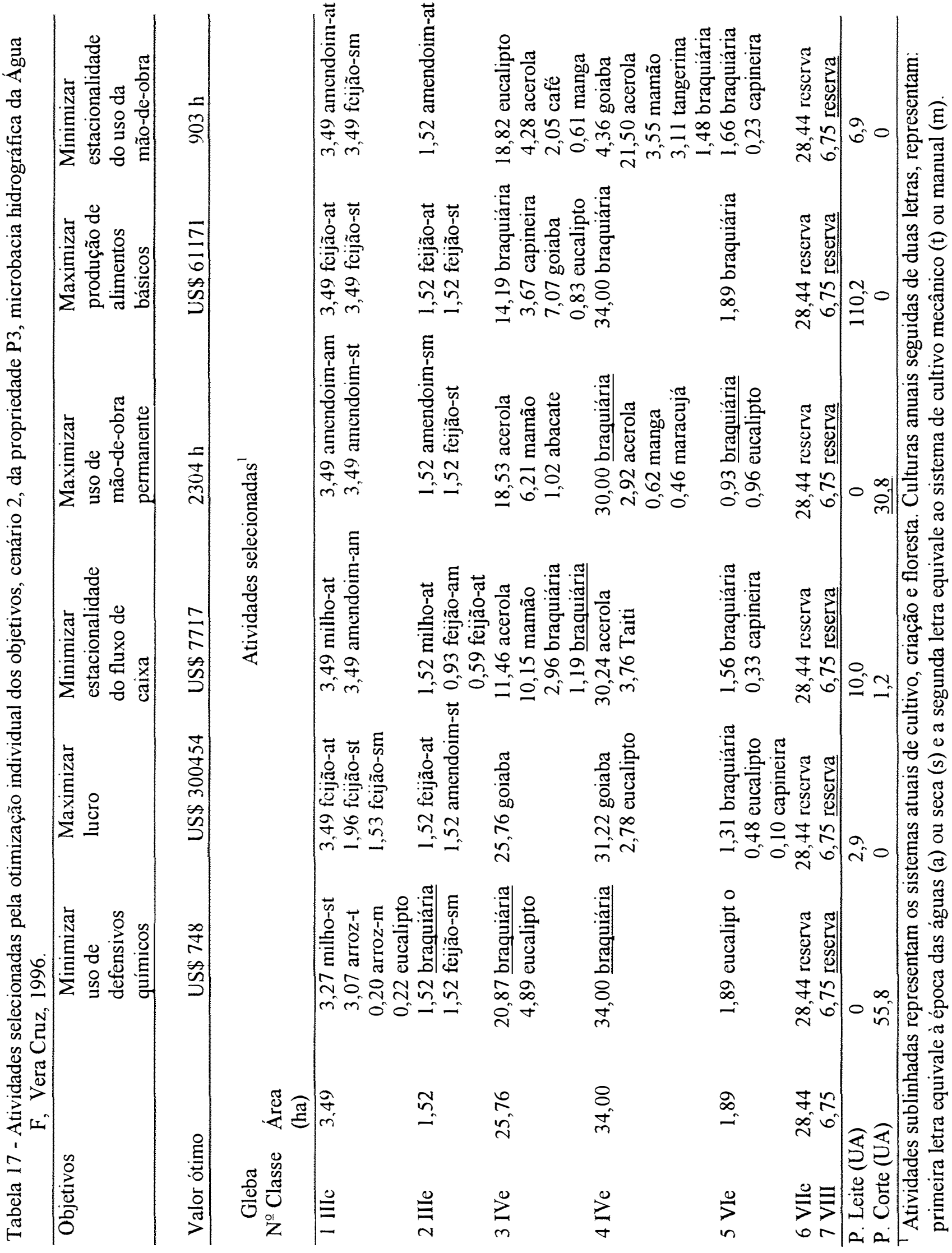




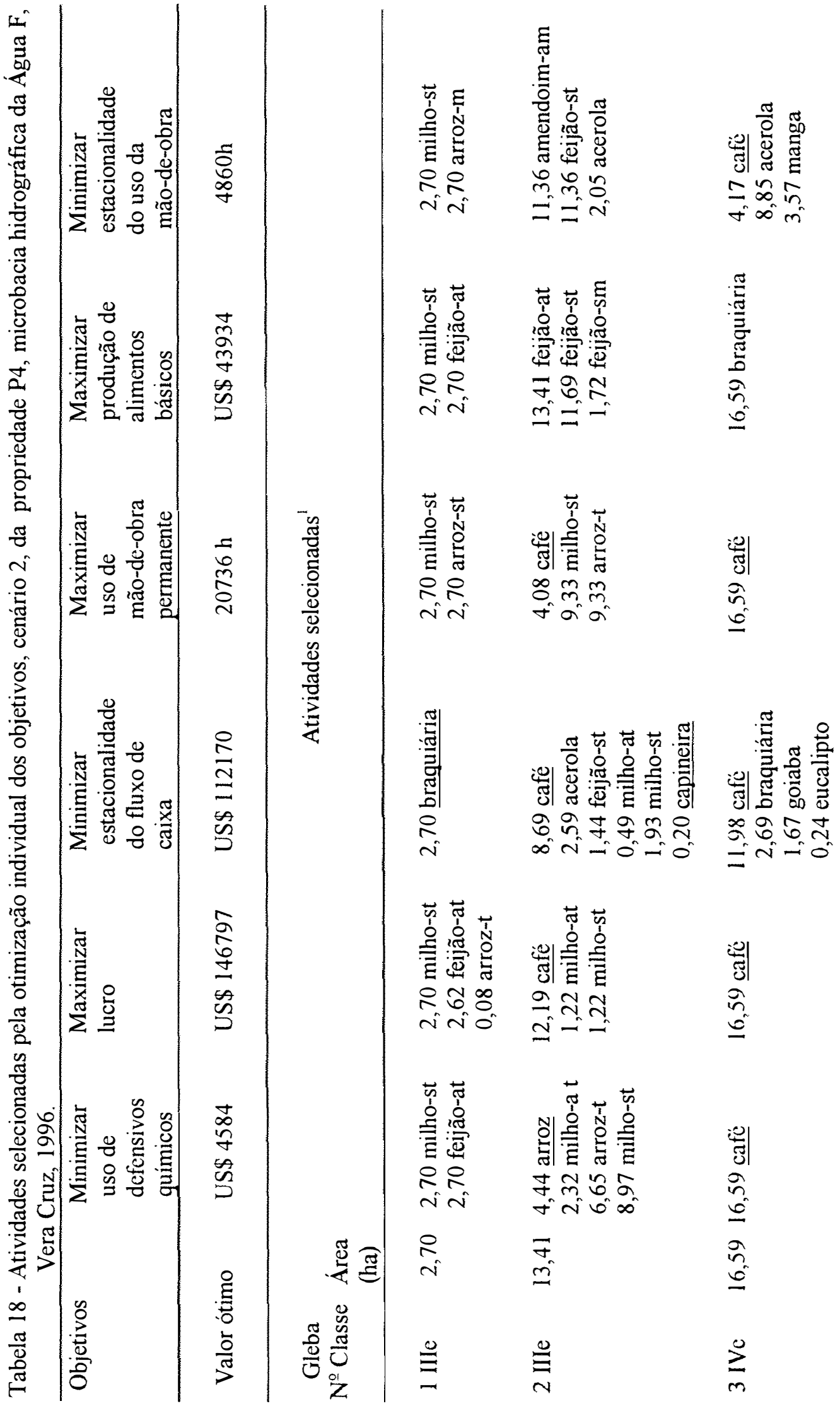




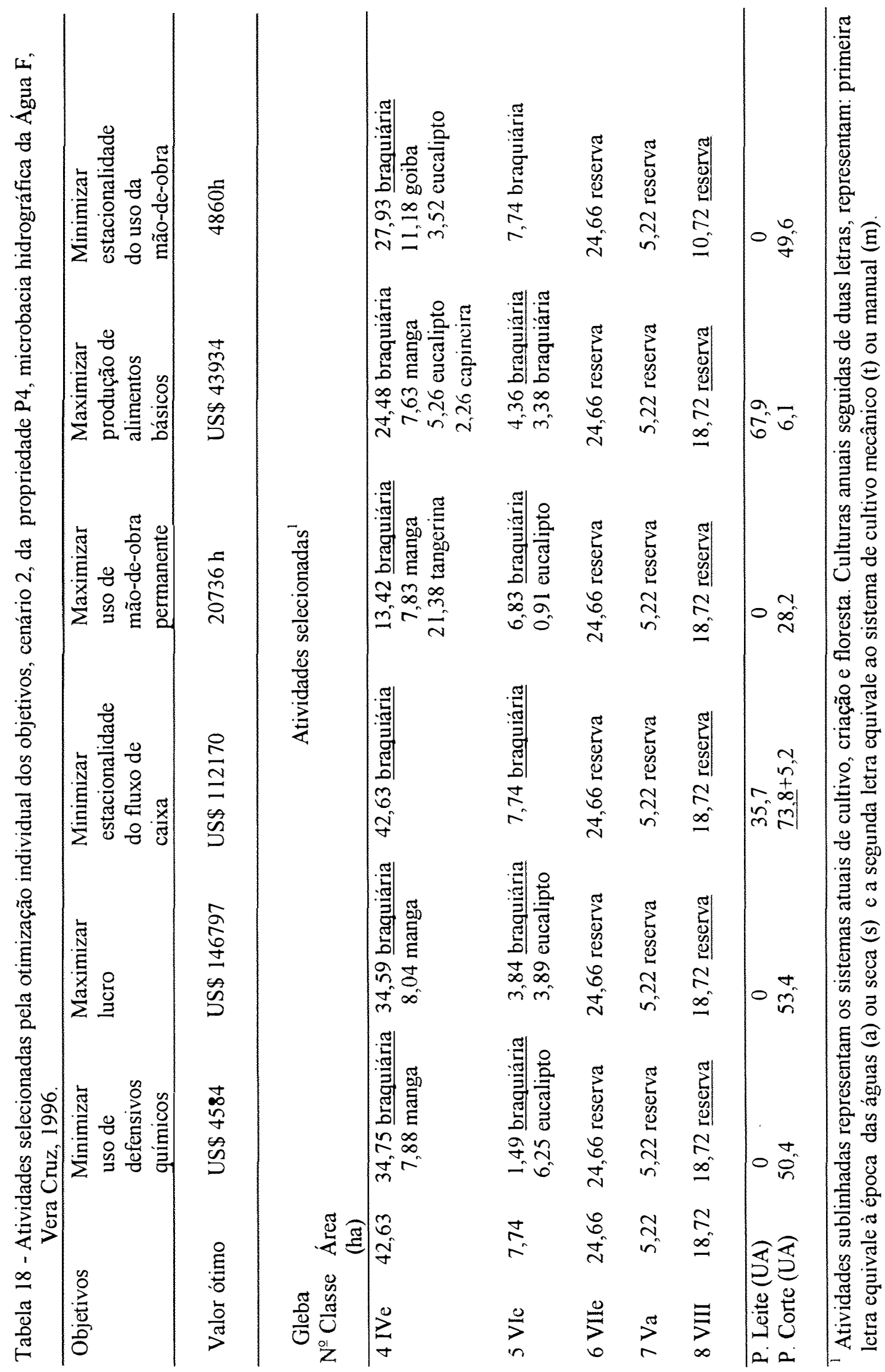




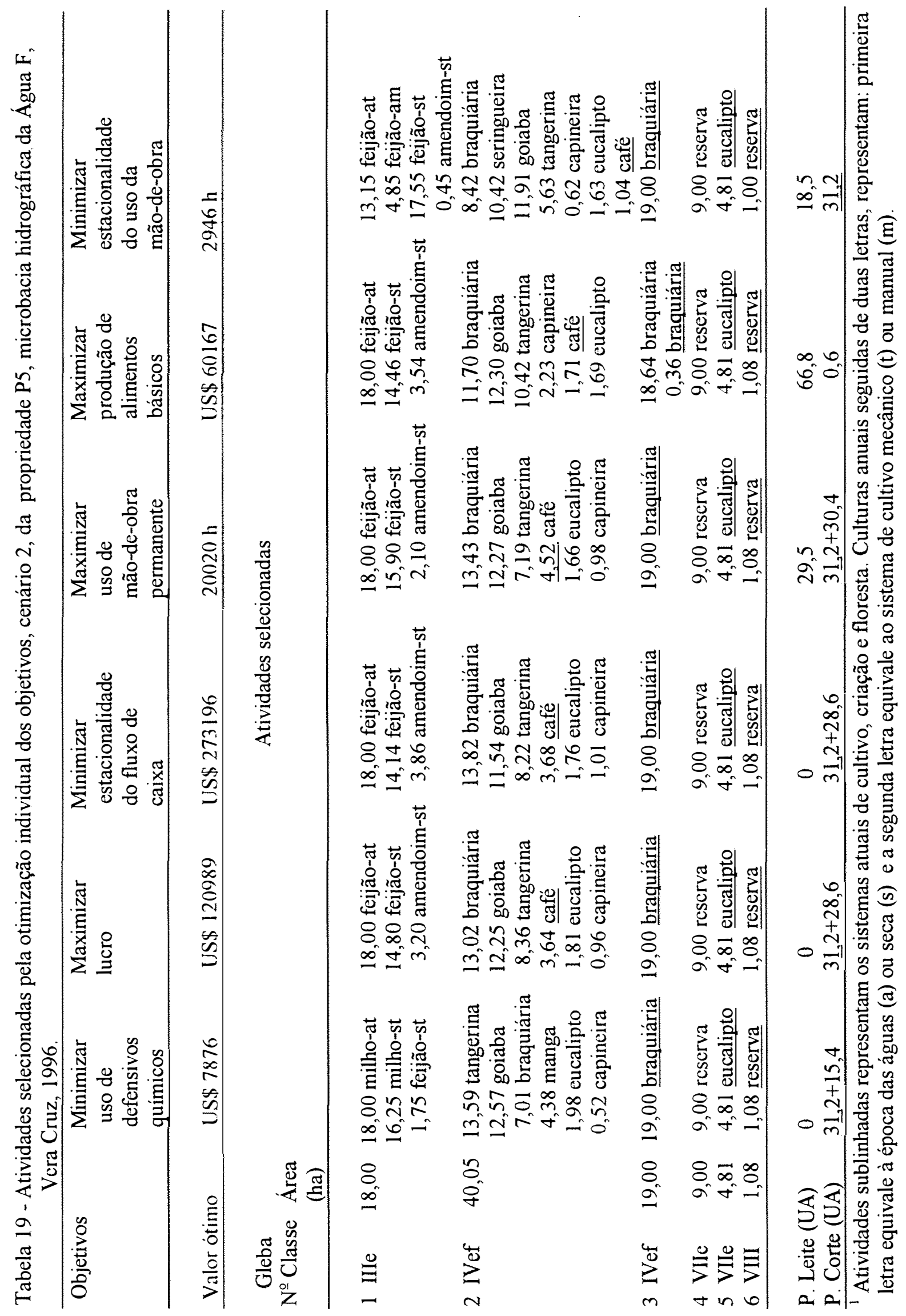




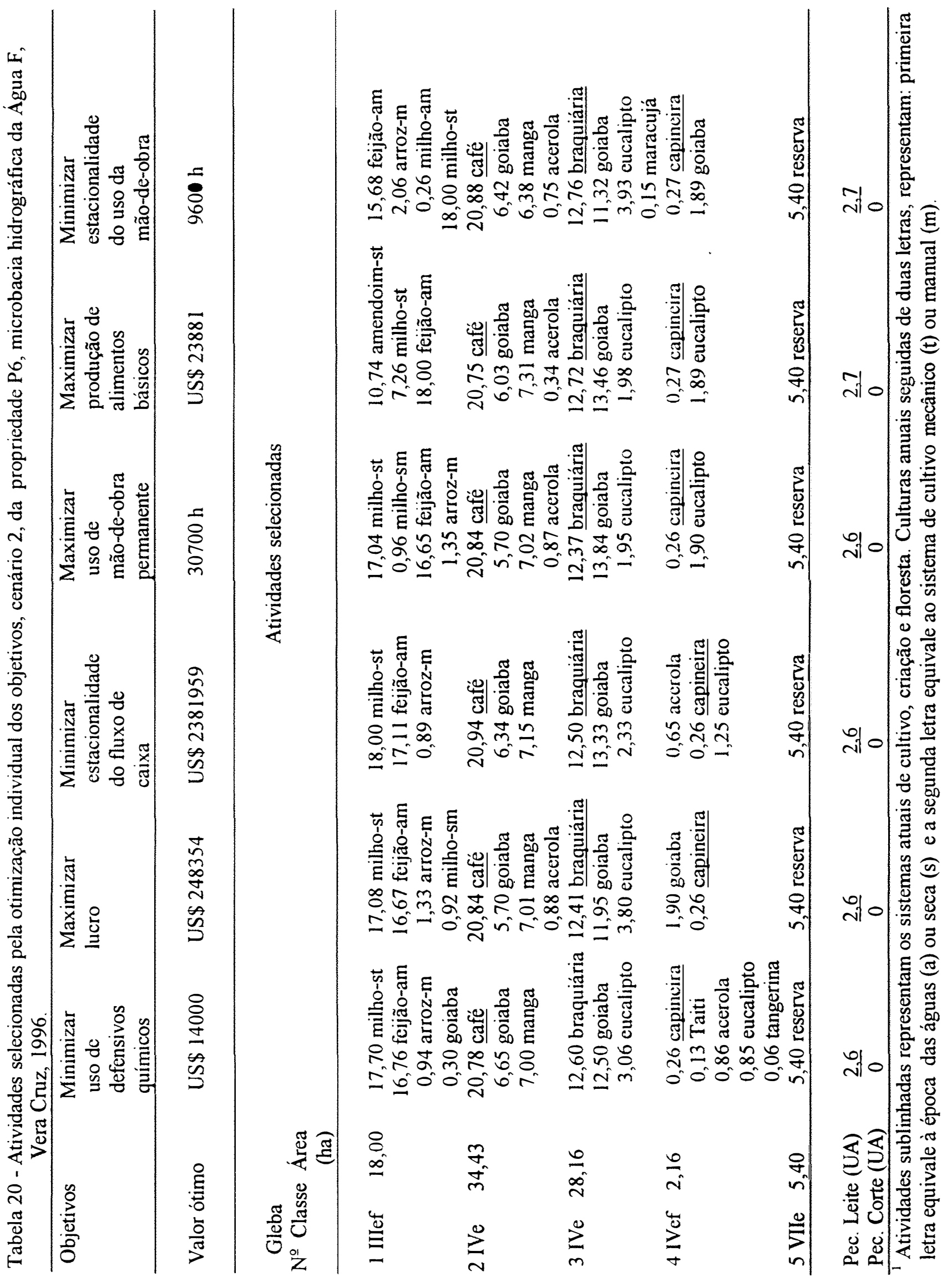


III. Para as glebas de classe IV foram selecionadas as culturas de acerola, manga, café, tangerina e goiaba, tangerina e pastagens de braquiária, e para as glebas de classe VI foram selecionadas a pastagem de braquiária e a capineira de Napier associadas com a pecuária de leite e corte, com tecnologia atualmente praticada nas propriedades e tecnologia recomendada pela CATI.

$\mathrm{Na}$ otimização do objetivo de maximizar o uso da mão-de-obra permanente, as culturas de milho, arroz, feijão e amendoim foram selecionadas para as glebas de classe III. Para as glebas de classe IV foram selecionadas as atividades de café, manga, tangerina, goiaba, acerola, seringueira e pastagem de braquiária e para as glebas de classe VI foram selecionadas as atividades de eucalipto, pastagem de braquiária e capineira associadas com a pecuária de leite e corte.

$\mathrm{Na}$ otimização do objetivo de minimizar a estacionalidade do fluxo de caixa, as culturas de milho, feijão, arroz e amendoim foram selecionadas para ocuparem as glebas de classe III. Para as glebas de classe IV foram selecionadas a pastagem de braquiária, a capineira de Napier, goiaba, acerola, café, tangerina e manga. Para as glebas de classe VI foram selecionadas a pastagens de braquiária e a capineira de Napier associadas com a pecuária de leite e corte.

\subsubsection{Comparação das atividades selecionadas na otimização individual dos objetivos nos cenários 1 e 2}

Os resultados da otimização individual dos objetivos mostram que os diferentes objetivos, sujeitos às mesmas restrições, no cenário 1 , foram otimizados com atividades diferentes, variando da seleção de duas atividades, no caso da maximização do lucro, até uma dezena de variáveis, no caso da minimização da estacionalidade do fluxo de caixa. Portanto, as atividades selecionadas para o uso sustentável da terra dependeram dos objetivos otimizados, além das restrições das propriedades. No cenário 2 , houve menor variação na seleção de atividades para otimizar os diferentes objetivos individualmente. Neste cenário houve maior quantidade de glebas ocupadas com a tecnologia atualmente em uso nas propriedades, especialmente nas atividades pecuárias. 
Assim, considerando a otimização dos objetivos individualmente, o cenário 2 foi mais restritivo na seleção de novas atividades, isso influenciou a otimização lexicográfica dos múltiplos objetivos, como mostrado a seguir.

\subsection{Otimização lexicográfica dos múltiplos objetivos}

No algoritmo da programação por metas lexicográficas a equação do objetivo de primeira prioridade é incluída, com seu valor ótimo, no conjunto das restrições que delimitam o conjunto de soluções possiveis para a otimização do objetivo de segunda prioridade. Isto implica que não há mudança nas variáveis de decisão selecionadas para o primeiro objetivo, quando a solução ótima é única. As Tabelas $21 \mathrm{e}$ 22 mostram as variáveis de decisão selecionadas pela programação por metas lexicográficas que atendem ao planejamento do uso sustentável da terra e otimizam os múltiplos objetivos hierarquizados pelos tomadores de decisão, respectivamente, para os cenários 1 e 2 .

Observa-se na Tabela 21 que, para as propriedades P5 e P6, no cenário 1, prevaleceu a escolha das variáveis de decisão obtidas pela otimização do primeiro objetivo (minimizar o uso de defensivos químicos e maximizar o lucro, respectivamente). Por ser solução única, não foi possivel obter outra combinação de variáveis de decisão que melhorasse os valores alcançados pelos demais objetivos, mantendo o valor do objetivo de primeira prioridade.

Para a propriedade $\mathrm{P} 1$, cenário 1 , prevaleceu a escolha das variáveis de decisão obtidas pela otimização lexicográfica do segundo objetivo (maximização do lucro). Isto implica que o objetivo de minimizar a estacionalidade do fluxo de caixa não apresentou solução única. conseqüentemente, houve mudanças na solução obtida no primeiro objetivo, melhorando a meta alcançada pelo segundo objetivo, o qual, por sua vez, apresentou solução única e, portanto, não permitiu a melhora nas metas dos demais objetivos

Para as propriedades $\mathrm{P} 2, \mathrm{P} 3$, e P4, no cenário 1, prevaleceu a escolha das variáveis de decisão obtidas pela otimização lexicográfica do objetivo de sexta prioridade 


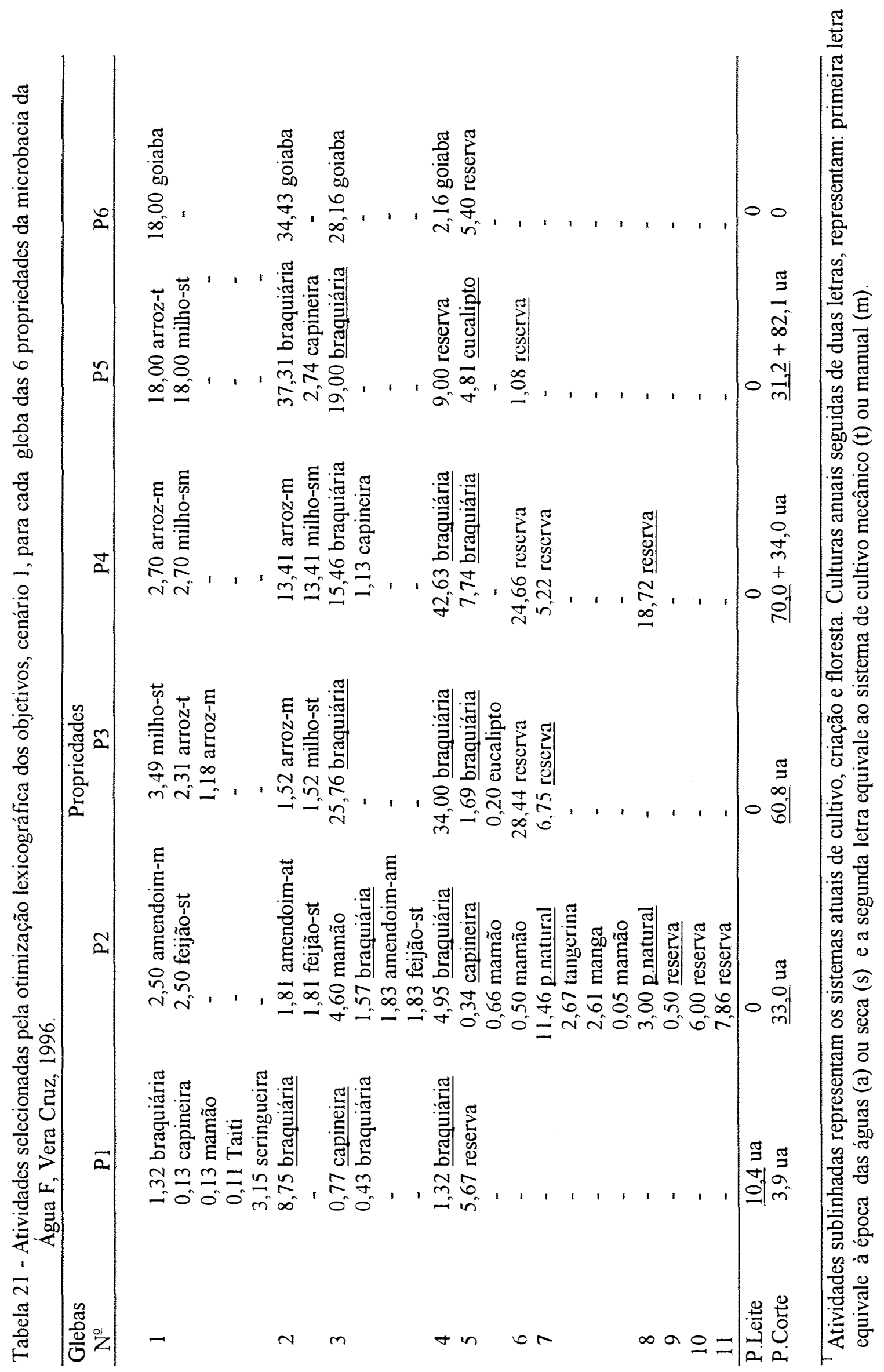




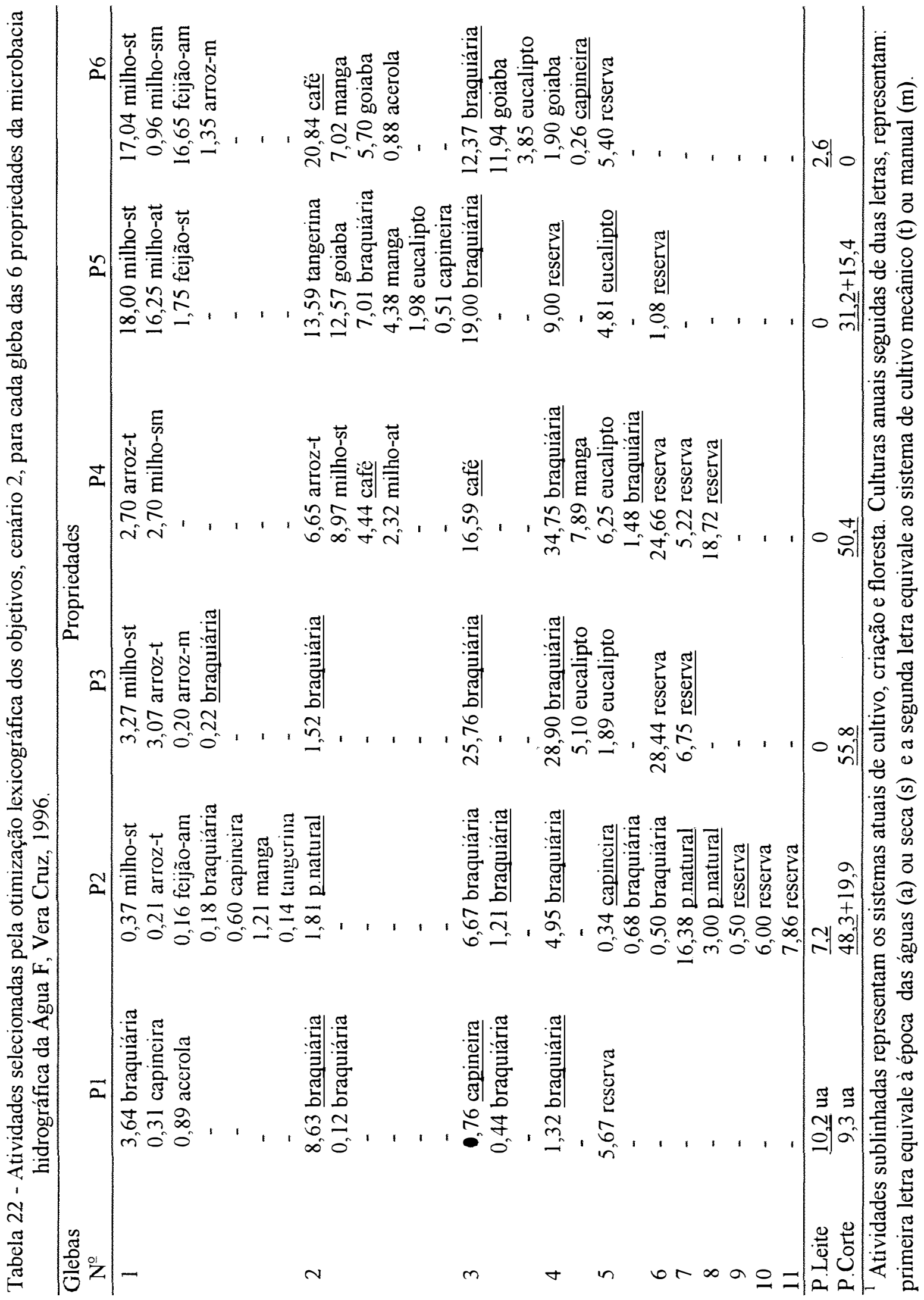


(minimizar a estacionalidade do fluxo de caixa, maximizar o lucro e maximizar o uso da mão-de-obra permanente, respectivamente).

Observa-se na Tabela 22 que as variáveis selecionadas pela otimização lexicográfica dos objetivos, no cenário 2 , foram obtidas na sexta rodada do computador, ou seja na otimização do objetivo de sexta prioridade. Portanto, as metas estabelecidas para os objetivos, no cenário 2 , possibilitaram o surgimento de mais de uma solução ótima, ou seja diferentes conjuntos de atividades selecionadas apresentaram o mesmo valor ótimo para os objetivos. E, a solução ótima lexicográfica não coincidiu com nenhuma solução obtida pela otimização individual dos objetivos.

Os valores alcançados pelos múltiplos objetivos com a otimização lexicográfica, nos cenários 1 e 2, são apresentados na Tabela 23. Obviamente, por ter sido usado como uma meta otimista, o valor do objetivo de primeira prioridade, tanto no cenário 1 como no cenário 2 , foi igual ao valor da otimização individual deste objetivo. A existência de conflito entre os objetivos é indicada pela diferença entre o valor de um objetivo, otimizado após a otimização de outros objetivos, e o seu respectivo valor ótimo (otimização individual). Assim, o objetivo de maximizar o lucro se mostrou conflitante com os demais objetivos, principalmente no cenário 1. Foi selecionada atividade (goiaba) que usa intensivamente os defensivos químicos, usa mais mão-de-obra eventual do que permanente, não é alimento básico e concentra o uso de mão-de-obra e o fluxo de caixa no período de colheita, conforme mostra a Tabela 23. Assim, para a P6, no cenário 1, o lucro aumentou em 95\% (em relação ao uso atual da terra), o uso de defensivos químicos aumentou em $319 \%$, a estacionalidade do fluxo de caixa aumentou em $217 \%$, a produção de alimentos básicos diminuiu em 100\% e a estacionalidade do uso da mão-deobra aumentou em $1073 \%$.

As propriedades P1, P3 e P4 apresentaram valores negativos para o objetivo de maximizar o lucro, no cenário 1 , porque as atividades foram selecionadas considerando prioritariamente outros objetivos. Além disto, a atividade de pecuária associada com a pastagem de braquiária, capineira de Napier e uso de milho para ração é deficitária (dá prejuizo) em glebas cujos solos apresentam fertilidade baixa, exigindo altas doses de adubo para atender ao planejamento do uso sustentável da terra. 


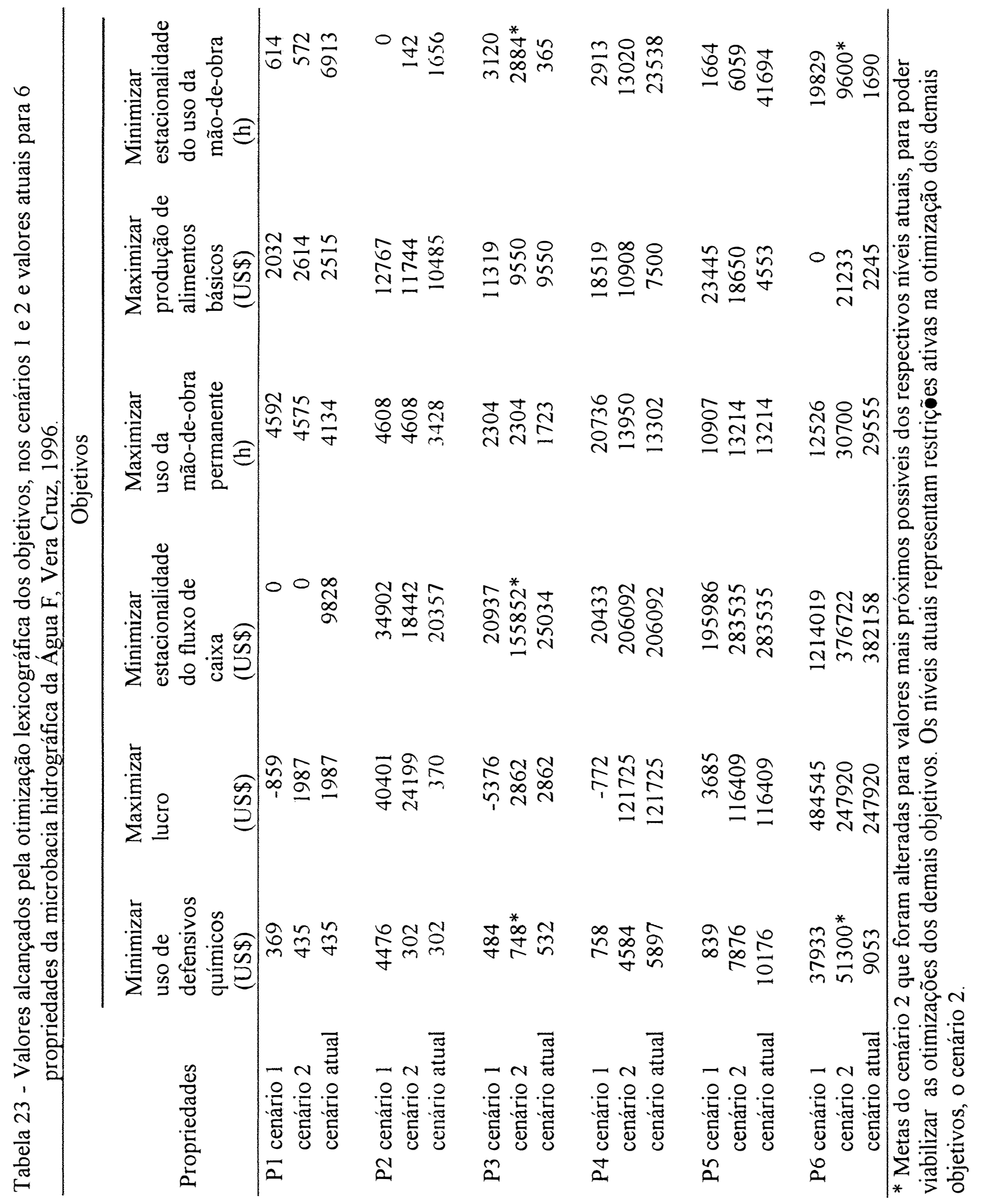


O cenário 2 corrige as distorções surgidas no cenário 1, permitindo apenas valores para a maximização do lucro maiores ou iguais ao alcançado pelo uso atual da terra. Isto explica a seleção de atividades de pastagens com a tecnologia atual, que usa menor quantidade de defensivos químicos.

As atividades que dão prejuizos podem ser retiradas do modelo, mas isto não é interessante porque estas atividades são necessárias para atender às restrições da capacidade de uso sustentável da terra. Também, ocorrem prejuizos em glebas que devem ser incorporadas como reserva florestal pois esta atividade geram gastos com implantação e manutenção, sem retorno financeiro.

No cenário 2, Tabela 23, foi possível obter alternativas de uso sustentável da terra que otimizam lexicograficamente os múltiplos objetivos para as propriedades $\mathrm{P} 1$, P2, P4 e P5. Assim, nestas propriedades, os valores alcançados pelos objetivos foram sempre melhores (maior ou menor dependendo do objetivo) ou iguais aos valores correspondentes ao uso atual da terra. Para a propriedade P3, no cenário 2, houve a necessidade de relaxamento das metas (niveis inferiores ao do uso atual) para os objetivos de minimizar o uso de defensivos químicos, minimizar a estacionalidade do fluxo de caixa e minimizar a estacionalidade do uso da mão-de-obra. Sem isto não seria possivel otimizar lexicograficamente os demais objetivos. Para a propriedade P6 houve a necessidade de relaxamento das metas para os objetivos de minimizar o uso de defensivos químicos e minimizar a estacionalidade do uso da mão-de-obra. O cenário 2 propiciou melhores resultados que podem ser apresentados ao tomador de decisão para sua avaliação. Caso alguma alternativa selecionada ou algum objetivo tiver seu valor refutado, então novos cenários poderão ser montados e testados para atender as exigências do tomador de decisão. Com este procedimento, ocorre maior interação entre o analista e o tomador de decisão, podendo perdurar até a obtenção de alternativas adotáveis pelo produtor rural.

A Tabela 24 apresenta as quantidades de recursos de mão-de-obra (familiar, residente e eventual) e de trator (uso próprio, aluguel e contratação) necessárias para a otimização lexicográfica dos objetivos, nos cenários 1 e 2 . 
Observa-se, na Tabela 24, que nas propriedades P1, P2 e P3 foram usadas $100 \%$ da mão-de-obra permanente (familiar e residente) disponível, em ambos cenários. $\mathrm{Na}$ propriedade 4 , no cenário 1, foram usadas $100 \%$ da mão-de-obra permanente disponível e no cenário 2 foram usadas 58\%. Nas propriedades P5 e P6 foram usadas, no cenário $1,53 \%$ e $22 \%$, respectivamente, da mão-de-obra disponível, enquanto que no cenário 2 foram usadas $65 \%$ e $53 \%$, respectivamente. Portanto, o cenário 2 propiciou uma melhora no uso da mão-de-obra permanente disponível.

Tabela 24 - Uso dos recursos de mão-de-obra (familiar, residente e eventual) e de trator (uso próprio, aluguel e contratação) resultantes da otimização lexicográfica dos objetivos, em 6 propriedades da microbacia hidrográfica da Água F, Vera Cruz, 1996.

\begin{tabular}{|c|c|c|c|c|c|c|c|c|c|c|c|c|}
\hline \multirow[b]{4}{*}{ Recursos (unid.) } & \multicolumn{12}{|c|}{ Propriedades } \\
\hline & \multicolumn{2}{|c|}{$\mathrm{P} 1$} & \multicolumn{2}{|c|}{$\mathrm{P} 2$} & \multicolumn{2}{|c|}{ P3 } & \multicolumn{2}{|c|}{ P4 } & \multicolumn{2}{|c|}{ P5 } & \multicolumn{2}{|c|}{ P6 } \\
\hline & \multicolumn{12}{|c|}{ Cenários } \\
\hline & 1 & 2 & 1 & 2 & 1 & 2 & 1 & 2 & 1 & 2 & 1 & 2 \\
\hline \multicolumn{13}{|l|}{ Mão-de-obra (h/ano) } \\
\hline familiar & 4608 & 4608 & - & - & 2304 & 2304 & +608 & 4608 & - & - & - & - \\
\hline residente & - & - & 4608 & 4608 & - & - & 16128 & 9342 & 10907 & 13416 & 12526 & 30700 \\
\hline eventual & 3626 & 4112 & 13352 & 59 & 1876 & 1698 & - & 6962 & - & - & 3232 & - \\
\hline \multicolumn{13}{|l|}{ Trator (h/ano) } \\
\hline uso & 2413 & 2398 & 1373 & 591 & - & - & $2+29$ & 1290 & 1764 & 1751 & 675 & 1433 \\
\hline aluguel & 16 & 131 & 1056 & 1838 & - & - & - & 1139 & 665 & 678 & 1754 & 996 \\
\hline contratação & - & - & 178 & 696 & 211 & 301 & - & - & - & - & 72 & 8 \\
\hline
\end{tabular}

O uso de mão-de-obra eventual ocorreu nas propriedades P1, P2, P3 e P6, no cenário 1, devido à seleção das atividades de frutíferas, que apresenta um curto período de colheita manual, e de culturas anuais, que requerem trabalho manual na colheita e na capina. No cenário 2, as propriedades P1, P2, P3, e P4 usam mão-de-obra eventual. A propriedade P2 teve grande redução de uso da mão-de-obra eventual, no cenário 2 em relação ao cenário 1 . 
A propriedade $\mathrm{P} 4$, no cenário 1 , usou $100 \%$ da disponibilidade de trator nas atividades produtivas da propriedade. As P1, P2, P5 e P6 usaram, no cenário 1, respectivamente, $99 \%, 56 \%, 72 \%$ e $22 \%$ da disponibilidade de trator nas atividades produtivas. As horas disponiveis não ocupadas na propriedade foram alugadas para terceiros. A P5, que não possui trator, dependeu da contratação de horas de trator de terceiros para atender suas necessidades, no cenário 1 . No cenário 2 as propriedades $\mathrm{P} 1$, P2, P4, P5 e P6 usaram nas atividades produtivas, respectivamente, 99\%, 24\%, 53\%, $72 \%$ e $59 \%$ da disponibilidade de horas de trator. Portanto, de modo geral, o cenário 2 usou menos horas máquinas para otimizar lexicograficamente os objetivos das propriedades.

O cenário 2, de modo geral, possibilitou a obtenção de alternativas de uso sustentável da terra que racionalizam o uso de recursos de mão-de-obra e máquinas. Isto favorece a adoção, por parte do tomador de decisão, dessas alternativas selecionas no contexto da microbacia hidrográfica.

\subsection{Discussão do impacto do planejamento do uso sustentável da terra nos sistemas de produção}

O planejamento do uso sustentável da terra introduz na microbacia hidrográfica um conjunto de tecnologias capaz de promover a conservação do solo e melhoria nos recursos naturais e das condições ambientais. Com a adoção deste planejamento é de se esperar uma reversão no processo de degradação do solo (com observância da capacidade de uso sustentável do solo), tendo como conseqüência o aumento da produtividade, da produção agrícola e da renda dos agricultores. Um dos principais instrumentos deste planejamento é a determinação da capacidade de uso sustentável da terra que estabelece um novo arranjo, indicando novas explorações, para as glebas das propriedades. Conforme a teoria geral dos sistemas, as atividades das glebas são interrelacionadas competindo entre si pelos recursos de máquina, mão-de-obra e capital. Portanto, mudanças no "layout" das glebas implica em mudanças em outros subsistemas. As restrições da capacidade de uso sustentável da terra, consideradas neste 
trabalho, permitiram a seleção de atividades que otimizaram individualmente os múltiplos objetivos, mesmo quando houve diminuição da área explorada em cada propriedade para se estabelecer a mata ciliar e/ou a reserva florestal, conforme resultados da Tabela 23.

Os resultados da otimização lexicográfica mostram que a hierarquização dos objetivos influenciou na seleção de alternativas, ocorrendo inclusive a seleção de alternativas economicamente inviáveis ou não sustentáveis, no cenário 1. Isto ocorreu devido à natureza conflitante dos objetivos estudados. Assim, por exemplo, o maior lucro proporcionado pela fruticultura foi conflitante com o menor uso de defensivos agrícolas. A natureza conflitante dos objetivos, em ambos cenários, é mostrada na Tabela 23.

Do ponto de vista econômico, o uso atual da terra nas propriedades $\mathrm{Pl}$, P2 e P3 resultam em baixa eficiência e baixa renda bruta. Entretanto, nestas propriedades o uso atual da terra permite a obtenção de valores próximos do ótimo para outros objetivos prioritários para o tomador de decisão, como por exemplo, o de minimizar o uso de defensivos agrícolas. Neste aspecto, a família rural, que é o subsistema tomador de decisões, também deve ser mudada, em especial, recebendo uma formação empresarial tal que a permita rever as prioridades atribuídas aos objetivos.

Da mesma forma, a otimização lexicográfica pode selecionar alternativas que atinjam as metas estabelecidas para o uso da mão-de-obra permanente, porém de forma não sustentável, gerando inclusive menor lucro que o proporcionado pelo uso atual do solo, tal como ocorreu em 4 propriedades, no cenário 1. Isto, transgride o princípio da racionalidade econômica dos produtores rurais. Portanto, as atividades selecionadas no cenário 1 não são adotáveis. As atividades selecionadas pela otimização lexicográfica não contribuem para a fixação do homem no campo, em 2 propriedades, no cenário 1. Pois, quando o uso da mão-de-obra permanente foi otimizado, não se obteve sustentabilidade econômica. Da mesma forma, quando o lucro foi maximizado, houve expressiva redução no uso da mão-de-obra permanente e grande aumento na estacionalidade do uso da mãode-obra (aumento da mão-de-obra eventual). Isto não ocorreu no cenário 2 o qual aumentou o uso da mão-de-obra permanente $\mathrm{O}$ conflito entre a otimização dos objetivos também inviabiliza a produção de alimentos básicos, como no caso da maximização do lucro, cujas alternativas selecionadas não produzem alimentos básicos, no cenário 1. Isto 
torna necessária a interação do analista com o tomador de decisão, em especial na construção de cenários que representem os reais interesses do produtor rural. $\mathrm{O}$ cenário 2 por não piorar os valores atuais dos objetivos e por melhorar o uso de recursos de máquinas e mão-de-obra, gerou alternativas de uso sustentável da terra que não contrariam os princípios da racionalidade econômica e portanto, são adotáveis pelo produtor rural.

Os efeitos do PUST podem serem avaliados, comparando-se os valores do uso de defensivos químicos, lucro, estacionalidade do fluxo de caixa, uso da mão-de-obra permanente, produção de alimentos básicos e estacionalidade do uso da mão-de-obra calculados para o atual uso da terra (Tabela 8) com o uso ótimo selecionado para as condições estabelecidas para cada cenário de análise, como mostrado na Tabela 23. Entretanto, em termos de impacto do PUST interessa analisar o melhor cenário, ou seja o que gera atividades adotáveis pelos produtores rurais. Nestes termos o cenário 2 foi melhor do que o cenário 1, para cada propriedade.

Para a propriedade $\mathrm{P} 1$, as alternativas selecionadas, no cenário 2, permitiram obter uma estacionalidade do fluxo de caixa ótima (primeira prioridade). Além de manterem o mesmo gasto com o uso de defensivos químicos do uso atual, também permitiram manter o lucro atual (margem bruta). Também melhoraram a estacionalidade do uso da mão-de-obra. O uso da mão-de-obra permanente e a produção de alimentos básicos alcançaram, na otimização lexicográfica, no cenário 2 , níveis de $10 \%$ e $4 \%$ maiores em relação ao uso atual.

Para a propriedade $\mathrm{P} 2$, as atividades selecionadas, no cenário 2, permitiram a obtenção de um valor igual a 142 para a estacionalidade do uso da mão-deobra (primeira prioridade) que representa $8 \%$ do valor atual. Também permitiram o aumento do lucro (margem bruta) em $6440 \%$, o aumento da produção de alimentos básicos em $12 \%$ e o aumento do uso da mão-de-obra permanente em $18 \%$ e a diminuição da estacionalidade do uso do fluxo de caixa em $9 \%$. Entretanto, manteve os gastos com uso de defensivos químicos.

Para a propriedade $\mathrm{P} 3$, no cenário 2, houve a necessidade de relaxar os níveis da metas dos objetivos de minimizar o uso de defensivos químico (primeira 
prioridade) em $40 \%$ maior, minimizar a estacionalidade do fluxo de caixa em 522\% maior e minimizar a estacionalidade do uso da mão-de-obra em 690\% maior, para selecionar atividades para o uso sustentável da terra que possibilitaram manter o nível do lucro e da produção de alimentos básicos e aumentar o uso da mão de obra permanente em $33 \%$.

Para a propriedade $\mathrm{P} 4$, as atividades selecionadas para o uso sustentável da terra permitiram a diminuição do uso de defensivos químicos (primeira prioridade) em $22 \%$ do uso atual. Também permitiram manter da estacionalidade do fluxo de caixa e o lucro (margem bruta). Permitiram o aumento em $5 \%$ do uso da mão-de-obra permanente, o aumento em $45 \%$ da produção de alimentos básicos e a diminuição em $45 \%$ da estacionalidade do uso da mão-de-obra.

Para a propriedade $\mathrm{P} 5$, no cenário 2, as atividades selecionadas pela otimização lexicográfica permitiram a redução do uso de defensivos químicos em $22 \%$ do uso atual. Também, permitiram o aumento da produção de alimentos básicos em $310 \% \mathrm{e}$ a diminuição da estacionalidade do uso da mão-de-obra em $85 \%$. Entretanto, apenas permitiram a manutenção dos níveis do uso da mão-de-obra permanente, do lucro e da estacionalidade do fluxo de caixa.

Para a propriedade P6, no cenário 2, houve a necessidade de relaxar os níveis da metas dos objetivos de minimizar o uso de defensivos químicos (aumentando em $466 \%$ os gastos com defensivos) e minimizar a estacionalidade do uso da mão-de-obra (aumentando em $468 \%$ a estacionalidade), para obter alternativas de uso sustentável da terra que permitiram manter o lucro atual (margem bruta). E, permitiram diminuir em $2 \%$ a estacionalidade do fluxo de caixa, aumentar o uso da mão-de-obra permanente em $4 \% \mathrm{e}$ aumentar a produção de alimentos básicos em $845 \%$.

Em sintese, a Tabela 23 também mostra que a quantidade de objetivos melhorados por propriedade foi: a P1 melhorou 4 objetivos e manteve os valores em 2 objetivos. A P2 melhorou 5 objetivos e manteve o valor em 1 objetivo. A P3 melhorou 1 objetivo, manteve os valores em 2 objetivos e piorou em 3 objetivos. A P4 melhorou em 4 objetivos e manteve os valores de 2 objetivos. A P5 melhorou em 3 objetivos e manteve os valores em 3 objetivos. A P6 melhorou em 3 objetivos, manteve o valor em 1 objetivo e piorou os valores em 2 objetivos. Por outro lado, 2 propriedades melhoraram, 2 
mantiveram e 2 pioraram o objetivo de minimizar o uso de defensivos químicos; 1 propriedade melhorou o objetivo de maximizar o lucro e 5 propriedades mantiveram os mesmos valores do uso atual; 4 propriedades melhoraram o objetivo de minimizar a estacionalidade do fluxo de caixa e 2 mantiveram os mesmos valores; 5 propriedades melhoraram os objetivos de maximizar o uso de mão-de-obra permanente e maximizar a produção de alimentos básicos e 1 manteve os mesmos valores; 4 propriedades melhoraram o objetivo de minimizar a estacionalidade do uso da mão-de-obra e 2 pioraram. 


\section{CONCLUSÕES}

Os múltiplos objetivos estabelecidos no PEMBH refletem os interesses atuais dos seis produtores rurais da microbacia hidrográfica da Água F de Vera Cruz. O planejamento do uso sustentável da terra estabeleceu restrições que reduziram a área produtiva das propriedades porém, permitiram a otimização individual dos objetivos.

A programação por metas lexicográficas se mostrou adequada para determinar o impacto do planejamento do uso sustentável da terra nos sistemas de produção da microbacia hidrográfica. A PML permitiu a obtenção de alternativas que otimizaram os múltiplos objetivos e a comparação dos seus efeitos com o uso atual da terra, em termos de lucro, fluxo de caixa, uso da mão-de-obra, máquinas e defensivos químicos e produção de alimentos básicos.

O impacto positivo do PUST nos sistemas de produção foi o de permitir a seleção de alternativas que diminuem o uso de defensivos químicos, diminuem a estacionalidade do fluxo de caixa, aumentam a produção de alimentos básicos e fixam o homem no campo com o aumento do uso da mão-de-obra permanente e diminuem a estacionalidade do uso da mão-de-obra, na maioria das propriedades.

O impacto negativo do PUST foi causado pelo grau de conflito entre a maximização do lucro e as otimizações dos objetivos de minimizar o uso de defensivos químicos, minimizar a estacionalidade do fluxo de caixa, maximizar o uso da mão-deobra, maximizar a produção de alimentos básicos e minimizar a estacionalidade do uso da mão-de-obra, que determinou a seleção de alternativas que apenas mantém os resultados 
econômicos das propriedades, quando não foi permitida a violação nos níveis atuais dos demais objetivos (cenário 2 ).

O método proposto para o PUST permitiu a construção de cenários alternativos que aproximaram o modelo de programação por metas lexicográficas às condições de cada propriedade e podem promover maior interação entre o analista e o tomador de decisão, tornado adotáveis as alternativas selecionadas.

Em termos práticos, a programação por metas lexicográficas é um instrumento útil para o planejamento do uso sustentável da terra no contexto de microbacias hidrográficas. Permite selecionar alternativas de uso da terra que otimizam os múltiplos objetivos do tomador de decisão, tendo a Capacidade do Uso Sustentável da Terra como prioridade absoluta e considerando as restrições de disponibilidade de recursos em cada propriedade agrícola. A PML pode ser adotada com facilidade pelo Programa Estadual de Microbacias Hidrográficas, desde que os técnicos responsáveis por sua implantação e os agricultores se conscientizem sobre a importância da priorização dos objetivos na seleção de alternativas tecnológicas para as propriedades agrícolas.

O método proposto para Planejamento do Uso Sustentável da Terra no contexto de microbacias hidrográficas aprofunda a análise sistêmica das tecnologias conservacionistas, incorporadas nos sistemas de cultivo, criação e florestal e mostra que estas tecnologias são adotáveis pelos produtores rurais. O PUST, por considerar os múltiplos objetivos hierarquizados pelos tomadores de decisão, aproxima-se do mundo real dos produtores rurais, resolvendo o problema metodológico para seleção de atividades de uso da terra.

Sugestões para novos estudos são para se testar outros métodos de programação multicritérios e tornar a geração dos resultados do uso sustentável da terra em microbacias hidrográficas compativeis com os "software" de Sistemas de Informação Geográficas. 


\section{REFERÊNCIAS BIBLIOGRÁFICAS}

ACKOFF, R.L.; GUPTA, S.K. Scientific methods: optimizing applied research decisions. New York: John Wiley \& Sons, 1962. 234p.

ALONSO, R.; IRURETAGOYENA, M.T. La obtención de alternativas de cultivos mediante programación por metas lexicograficas. Investigatión Agraria: Economia, v.1, n.1-2, p.11-24, 1986.

ALONSO, R.; IRURETAGOYENA, M.T. Los métodos multicriterio en la programación de actividades agrarias. Madri, Espanha. Instituto Nacional de Investigaciones Agrarias. Comunicaciones INIA, v.29. p.49, 1988.

AMBRÓSIO, L.A.; PERES, F.C.; SALGADO, J.M. Contribuição dos produtos dos quintais na alimentação da família rural: Microbacia da Água F, Vera Cruz, SP. Informações Econômicas, v.26, n.7, p.27-39, 1996.

ARIAS, P. El método de ponderaciones recursivas de programación multicriterio y sua aplicación a la planificación agraria. Madri. Investigación Agraria: Economia, v.4, n. 2, p.175-190, 1989.

BARNETT, D.; BLAKE, B.; McCARL, B.A. Goal programming via multidimensional scaling applied to senegalese subsistence farms. American Journal of Agricultural Economics, v.64, n.4, p.720-727, 1982. 
BARTLETT, E.T.; CLAWSON, W.J. Profit, meat production or efficient use of energy in ranching. Journal of Animal Science, v.46, n.3, p.812-818, 1978.

BERTAlAnfFy, L. VON. Teoria Geral dos Sistemas. 2.ed. Petrópolis: Editora Vozes/MEC, 1975. 351p.

BERTONI, J.; LOMBARDI NETO, F. Conservação do solo. 2.ed. São Paulo: Ícone Editora, 1990. 355p.

BOUZAHER, A.; MENDOZA, G.A. Goal Programming: Potential and limitations for agricultural economics. Canada Journal of Agricultural Economics, v.35, n.1, p.89$107,1987$.

BRINK, L.; McCARL, B. Tradeoff between expected return and risk among Corn Belt farmers. American Journal of Agricultural Economics, v.60, p259-63, 1978.

CALATRAVA REQUENA, J. La programación multicriterio: consideraciones teoricas y estudio de las ventajas e inconvenientes de su empleo como instrumento de analisis en planificación agraria. Madri, Espanha, Instituto Nacional de Investigaciones Agrarias. Anais del Instituto Nacional de Investigaciones Agrarias, v.5, p.131-145, 1980. (Series Economia y Sociologia Agraria).

CALKINS, P. Nutritional adaptations on linear programming for planning rural development. American Journal of Agricultural Economics, v.53, p.325-30, 1971.

CHARNES, A.; COOPER, W.W. Management models and industrial applications of linear programming. New York: John Wiley \& Sons, 1961. 2v.

CHARNES, A.; COOPER, W.W.; FERGUSON, O. Optimal estimation of executive compensation by linear programming. Management Science, v. 1, p. 138-51, 1955. 
COETZEE, K.; HECKROODT, J.; VAN RENSBURG, J.J.; VILJOEN, M.F. Multicriteria programming models: suitable planning strategies for entrepreneurs in changing agricultural environment. Agrekon, v.32, n.4, p.217-222, 1993

COHON, J.L. Multiobjective programming and planning. New York: Academic Press, 1978. 333p.

DONZELI, P.L. Planejamento da microbacia hidrográfica da Água F, Vera Cruz, SP. Campinas: Instituto Agronômico, Seção de Fotointerpretação. (Em elaboração)

DONZELI, P.L.; VALÉRIO FILHO, M.; PINTO, S.A.F.; NOGUEIRA,, F.P.; ROTTA, C.L.; LOMBARDI NETO, F. Técnicas de sensoriamento remoto aplicadas ao diagnóstico básico para planejamento e monitoramento de microbacias hidrográficas. In: LOMBARDI NETO \& CAMARGO coord. Microbacia do Córrego São Joaquim: município de Pirassununga, SP. Campinas: Instituto Agronômico, 1992. 138p.(Documentos IAC, 29)

EL-SHISHINY, H. A goal programming model for planning the development of newly reclaimed lands. Agricultural Systems, v.26, n.4, p.245-261, 1988.

FLINN, J.C.; JAYASURIYA, S.; KNIGTH, C.G. Incorporating multiple objectives in planning models of low resource farmers. Australian Journal of Agricultural Economics, v.24, n.1, p.34-55, 1980.

HARPER, M.W. ; EASTMAN, C. An evaluation of goal hierarchies for small farm operators. American Journal of Agricultural Economics, v.62, n.4, p742-747, 1980. 
HITCHENS, M.T.; THAMPAPILLAI, D.J.; SINDEN, J.A. The opportunity cost criterion for land allocation. Review of Marketing and Agriculture Economics, v.46, p.275-293, 1978 .

IGNIZIO, J.P. Goal programming and extensions. Massachusetts, Lexington: Lexington Book, 1976. 216p.

IJIRI, Y. Management goals and accounting for control. Amsterdam: North-Holland Publishing Company, 1965. $191 \mathrm{p}$.

KUHN, H.Z.; TUCKER, A. Nonlinear programming. In: Proc. Berkeley Symp. Math. Statist. Probability. Berkeley: Univ. of California Press, 1951. p.481-492.

LEE, S.M. Goal programming for decision analysis. Philadelphia: Auerbach Publishers, 1972. 387p.

LOMBARDI NETO, F. Trabalhos de manejo do solo e água em microbacias hidrográficas. Campinas: Instituto Agronômico. O Agronômico, v.45, n.1, p.24-25, 1993.

LOMBARDI NETO, F. Recomendações conservacionistas para diferentes classes de uso. Campinas: Instituto Agronômico, Seção de Fotointerpretação, 1996. 12p.

LOMBARDI NETO, F.; CAMARGO, O.T. coord. Microbacia do Córrego São Joaquim (município de Pirassununga, SP). Campinas, Instituto Agronômico. 1992. 138p. (Documentos IAC, 29). 
LOMBARDI NETO, F.; BELLINAZZI JÚNIOR, R.; LEPSH, I.F.; OLIVEIRA, J.B.; GALETI, P.A.; DRUGOWICH, M.I. Terraceamento agrícola. Campinas: Coordenadoria de Assitência Técnica Integral, 1994. 39p. (Boletim Técnico, 206)

MAINO, M.; ALONSO, R.; IRURETAGOYENA T. Planificación de fincas ganaderas bovinas mediante modelos de programación multiobjetivo. Investigación Agraria: Economia, v.2,n. 1, p.9-25, 1987.

MARSS, E.R.; HATCH, J.K.; MICKELWART, D.R.; SWEET, C.F. Strategies for small farmer development, westview special studies in social and economic development. Boulder, Colorado: Praeger Publisher, 1976. 2v.

MILLAN, J.S.; BERBEL, J. A multicriteria model for irrigated agricultural planning under economic and technical risk. Agricultural Systems, v.44, n.2, p. 105-117, 1994.

NADALL, R.; WILDNER, L.P.; SILVESTRO, M.L.; ZANATTTA, J.C. O enfoque sistêmico em projetos de pesquisa e desenvolvimento na agricultura: o caso do Leste Catarinense. In: ANAIS DA SEMANA DE ATUALIZAÇÃO EM ADMINISTRAÇÃo RURAL. Lages: SAA/EPAGRI/CTA do Planalto Serrano Catarinense, 1992. p.133-160.

OTANI, M.N.; ANGELO, J.A.; SERRA, R. Desenvolvimento de um modelo de diagnóstico sócio-econômico de microbacias hidrográficas. Informações Econômicas, v.24, n.2, p.45-64, 1994.

PANAGIDES, S.; FERREIRA, L.R.F. Absorção de mão-de-obra na agricultura da Zona da Mata de Minas Gerais. In: Estudos sobre uma Região Agrícola: Zona da Mata de Minas Gerais. v. 1, Rio de Janeiro: IPEA/INPES, 1972. (Série Monográfica n.9). 
PEDRO JÚNIOR, M.J. coord. Instruções agrícolas para o Estado de São Paulo. 4.ed. Campinas: Instituto Agronômico de Campinas, 1987. 231p. (Boletim 200)

PERES, A.R.P. Baixa produtividade do milho como conseqüência da tomada de decisão sob condições de risco na agricultura. Piracicaba, 1981. 118p. Dissertação (M.S.) - Escola Superior de Agricultura "Luiz de Queiroz", Universidade de São Paulo.

PIECH, B.; REHMAN, T. Application of multiple criteria decision making methods to farm planning: a case study. Agricultural Systems, v.41, n.3, p.305-319, 1993.

RAIJ, B. van; QUAGGIO, J.A.; CANTARELlA, H.; FURLANI, A.M.C. Recomendações de adubação e calagem para o Estado de São Paulo. 2.ed. Campinas: Instituto Agronômico, 1996. 285p. (Boletim técnico IAC, 100)

ROMERO, C.; AMADOR, F.; BARCO, A. Multiple objectives in agricultural planning: a compromise programming applications. American Journal of Agricultural Economics v.69, n.1, p.78-86, 1987.

ROMERO, C.; REHMAN, T. Goal programming via multidimensional scaling applied to senegalese subsistence farms: Comment. American Journal of Agricultural Economics, v.65, n.4, p.829-831, 1983.

ROMERO, C.; REHMAN, T. Goal programming and multiple criteria decision making in farm planning: an expository analysis. Journal of Agricultural Economics, v.35, n.2, p.177-190, 1984a.

ROMERO, C.; REHMAN, T. Multiple criteria decision making techniques and their role in livestock ration formulation. Agricultural Systems, v. 15, p. 13-49, $1984 \mathrm{~b}$. 
ROMERO, C.; REHMAN, T. Goal programming and multiple criteria decision making in farm planning: some extensions. Journal of Agricultural Economics, v.36, n.2, p.171-185, 1985.

SHAKYA, K.M.; LEUSCHNER, W.A. A multiple objective land use planning model for nepalese hill farms. Agricultural Systems, v.34, p. 133-149, 1990.

SIMON, H.A. A behavioural model of rational choice. Quarterly Journal of Economics, v.69, p.99-118, 1955.

SOARES, N. coord. Plano de fruticultura da Alta Paulista. São Paulo: Secretaria de Agricultura e Abastecimento de São Paulo, CATI/IEA/IAC, 1994. 40p. (relatório não publicado)

SUNSET SOFTWARE TECHNOLOGY. XA User reference manual. San Marino, California, 1993. 73p.

TOSCANO, L.F. Recomposição ciliar da microbacia hidrográfica do córrego do Marinheirinho Votuporanga. Campinas: Coordenadoria de Assistência Técnica Integral, 1994. 46p. (Boletim Técnico, 223)

WHEELER, B.M.; RUSSELL, J.R.M. Goal programming and agricultural planning. Operational Research Quarterly, v.28, n.1, p.21-32, 1977.

WILLIS, C.E.; PERLACK, R.D. A comparison of generating techniques and goal programming for public investment: multiple objective decision making. American Journal of Agricultural Economics, v.62, p.66-74, 1980. 
WISCHMEIER, W.H.; SMITH, D.D. Predicting rainfall erosion losses: a guide planning. Washington, D.C. USDA, 1978. 58p. (Handbook, 537).

ZELENY, M. Compromise programming. In: COCHRANE, J.L.; ZELENY, M. ed. Multiple criteria decision making. Columbia: University of South Carolina Press, 1973. 816p.

ZELENY, M. Multiple criteria decision making. New York: McGraw HILL, 1982. cap.9. 


\section{APÊNDICE 1}

PROGRAMAÇÃO MULTICRITÉRIO:

UM INSTRUMENTO PARA PLANEJAMENTO AGRÍCOLA 


\section{PROGRAMAÇÃO MULTICRITÉRIO: \\ UM INSTRUMENTO PARA PLANEJAMENTO AGRÍCOLA ${ }^{1}$}

\section{A1 - 1 INTRODUÇÃO}

O Planejamento Agrícola, tanto no âmbito de uma empresa quanto no de uma região, pode ser entendido como um processo no qual o analista identifica e define um problema, coleta dados, formula um modelo matemático, gera e avalia alternativas para solucionar o problema. Esse processo termina quando o tomador de decisão escolhe uma alternativa para implementar. Basicamente, o planejamento é entendido como um processo de tomada de decisão.

A Programação Matemática é aplicada em uma fase do planejamento, ou seja, na formulação e resolução de problemas de otimização que possuem como estrutura: Maximizar (ou minimizar) uma função objetivo sujeita ao conjunto de restrições, as quais definem o conjunto de soluções possíveis (Cohon, 1978). Dentre os métodos de programação matemática encontram-se: Programação Linear, Programação Inteira, Programação Dinâmica, Programação Quadrática e Programação Não-Linear; cujas funções objetivos envolvem um único objetivo a ser otimizado. Além desses, há a Programação Multicritério que trata da otimização simultânea de mais de um objetivo.

\footnotetext{
${ }^{1}$ Trabalho parcialmente publicado como:
}

AMBRÓSIO, L.A. Introdução à Programação Multicritério: Um Instrumento para Planejamento Agrícola. Piracicaba. Escola Superior de Agricultura 'Luiz de Queiroz", Departamento de Economia e Sociologia Rural, 1995. 29p. ( Série Didática n. 100). 
O método de Programação Multicritério é referido, na literatura, como 'Multiple Criteria Decision Making" - MCDM - subdividido em duas classes de métodos: Programação por Metas ('Goal Programming') e Programação Multi-objetivos ('Multiobjectives Programming').

A Programação Multicritério representa uma generalização da Programação Linear e tem sido desenvolvida como método aplicado ao planejamento que envolve múltiplas metas e objetivos conflitantes. A consideração de múltiplas metas e objetivos acrescenta três grandes melhorias no processo de planejamento:

(1) considerando o analista e o tomador de decisão como atores principais no processo de planejamento, a Programação Multicritério promove papéis mais apropriados a estes participantes do planejamento;

(2) uma ampla variedade de alternativas é identificada quando se empregam métodos multicritérios; $\mathrm{e}$

(3) a percepção do analista e a adequação dos modelos são mais realistas, quando múltiplos objetivos são considerados no planejamento.

\section{A1 - 2 VOCABULÁRIO}

Alguns sinônimos adquirem significados específicos dentro de determinados contextos, isto ocorre, por exemplo, com os vocábulos: alvo ('target'), meta ('goal') e objetivo ('Objective'). Os conceitos veiculados através desses vocábulos usados na Programação Multicritério são:

ATRIBUTOS são valores que o tomador de decisão (TD) associa à realidade objetiva. Um atributo é representado por uma função matemática das variáveis de decisão, $\mathrm{f}(\mathbf{X})$.

OBJETIVOS ('objectives') representam a direção para a melhoria de um ou mais atributos. Quando a direção da melhoria implica em "mais é melhor" então o objetivo é maximizado. E, se implicar que "menos é melhor" então o objetivo é minimizado.

NÍVEIS DE ASPIRAÇÃO ('targets'), ou alvos, são níveis aceitáveis, pelo tomador de decisão, a serem alcançados na busca dos vários atributos considerados. 
META ('goal') uma meta se estabelece quando há a combinação de um atributo com um nível de aspiração.

VARIÁVEIS DE DESVIO NEGATIVO $\left(\mathrm{n}_{\mathrm{i}}\right)$ medem a extensão de quanto uma meta deixa de alcançar o nível de aspiração.

VARIÁVEIS DE DESVIO POSITIVO $\left(\mathrm{p}_{\mathrm{i}}\right)$ medem a extensão de quanto uma meta excede o nível de aspiração.

CRITÉRIO é a noção geral da combinação de atributos, objetivos e metas.

RESTRIÇÕES representam as disponibilidades dos recursos necessários para otimizar determinados objetivos e limitam o conjunto das soluções possíveis.

A diferenciação conceitual entre objetivos ('Đbjectives') e metas ('goals') é necessária na escolha das técnicas algorítmicas da Programação Multicritério. Romero \& Rehman (1983) esclarecem que os objetivos podem ser expressos como funções matemáticas das variáveis de decisão. Assim, por exemplo, maximizar o lucro, minimizar o risco e maximizar o uso da mão-de-obra permanente, constituem exemplos típicos de objetivos, no setor agrícola. Em geral, os objetivos são expressos na forma: $\operatorname{Max} f(\mathbf{x})$ ou $\operatorname{Min} f(\mathbf{x})$, onde $\mathbf{x}$ é um vetor de variáveis de decisão.

Para estabelecer o conceito de meta, os autores definem, previamente, o que se entende por nivel de aspiração. Este conceito representa um nível aceitável de ganho para um dos possíveis objetivos do TD. Por exemplo, se o tomador de decisão deseja um lucro de $\mathrm{R} \$ 100.000,00$ no ano, neste caso, tem-se uma meta. De modo geral, as metas são expressas na forma de $\mathrm{f}(\mathbf{x})>\mathbf{a}, \mathrm{f}(\mathbf{x})<\mathbf{a}$ ou $\mathrm{f}(\mathbf{x})=\mathbf{a}$, onde a representa o valor do nível de aspiração.

Os conceitos de metas e de restrições, embora tenham a mesma expressão matemática, diferenciam no significado atribuído ao segundo membro de ambas inequações. Assim, nas inequações das metas, o segundo membro representa um nível de aspiração que o TD quer alcançar, podendo não atingir este propósito. Nas inequações das restrições, o segundo membro deve ser satisfeito para poder obter uma solução possível. Em outras palavras, as metas permitem certas violações das inequações, o que não é possível no domínio das restrições. 


\section{A1 - 3 MARCO TEÓRICO DA PROGRAMAÇÃO MULTICRITÉRIO}

Um dos pressupostos da Teoria Econômica da Produção é de que os empresários, tomadores de decisão, são agentes econômicos que se movem única e exclusivamente em busca da maximização do lucro. Uma primeira crítica a este ponto de vista neoclássico, realizada por Simon (1955), sustenta que os tomadores de decisão (TD) mais do que otimizar um objetivo, o lucro, tratam de alcançar um conjunto de múltiplos objetivos conflitantes, isto é, que não se podem otimizar simultaneamente. Simon (1957) apresenta uma conceituação de comportamento racional que é compatível com o acesso à informação e a capacidade computacional como um substituição à racionalidade global do homem econômico. Com respeito aos agricultores familiares, Heady (1970) enfatiza o fato da propriedade agrícola ser uma unidade econômica completa na qual a interdependência entre renda e consumo gera dúvidas sobre a suposição do lucro ser o atributo supremo que o produtor familiar procura maximizar. Constatada a importância dos múltiplos critérios, a Programação Multicritério passou a ser desenvolvida como método aplicado ao planejamento agrícola que envolve múltiplas metas e objetivos conflitantes.

Os primeiros desenvolvimentos dos métodos de Programação Multicritério foram efetuados por Kuhn \& Tucker (1951), Charnes et. al. (1955) e Charnes \& Cooper (1961). Os trabalhos que se seguem contribuíram para melhorar o marco teórico: Ijiri (1965), Lee (1972), Ignizio (1976), Cohon (1978) e Zeleny (1973 e 1982).

Aplicações da Programação Multicritério no setor agrícola são encontradas em edição especial da Agricultural Systems, 41 (3), 1993. 


\section{A1 - 4 MÉTODOS DE PROGRAMAÇÃO MULTICRITÉRIO}

Os métodos de Programação Multicritério têm sido objeto de muitas classificações, (Arias, 1989), tais como: (1) a programação por metas e a programação multiobjetivo (Romero \& Rehman, 1983); (2) a que agrupa os métodos segundo a natureza dos dados em estocástico ou determinístico; (3) a natureza do mecanismo de geração de alternativas (Zionts, 1978) e (4) a classificação segundo a fase do processo em que se necessita de informação do tomador de decisão (Hwang \& Masud, 1979).

Por um motivo meramente didático, neste trabalho, apresenta-se a Programação Multicritério subdividida em duas classes de métodos: Programação por Metas (PM) e Programação Multi-objetivo (PMO).

\section{A1 - 4.1 Programação por Metas ("goal programming”)}

O propósito geral da Programação por Metas consiste em minimizar os desvios entre o nível de ganho de cada meta e seu correspondente nível de aspiração. As metas são incluídas na formulação do modelo, convertendo as inequações em equações, mediante a adição de variáveis de desvio positivo e negativo as quais representam o excesso e a falta de ganho para cada meta. As principais técnicas algorítmicas usadas no processo de minimização dos desvios são: Programação por Metas Lexicográficas (PML) e Programação por Metas Ponderadas (PMP).

\section{A1 - 4.1.1 Programação por Metas Lexicográficas}

A Programação por Metas Lexicográficas foi introduzida na literatura por Charnes \& Cooper (1961) de forma muito embrionária. Esse enfoque foi consideravelmente desenvolvido pelos trabalhos de Ijiri (1965), Lee (1972) e Ignizio (1976). Dentro desta variante da PM, supõe-se que o tomador de decisão seja capaz de subdividir o conjunto de suas metas em diferentes prioridades, atribuindo pesos excludentes ("preemptive weights"), 
com valores absolutos, às metas situadas em diferentes prioridades. Em outras palavras, o ganho das metas situadas numa certa prioridade, $h_{i}$, é incomensuravelmente preferida ao ganho de qualquer outro subconjunto de metas de menor prioridade, $h_{j}$, isto é, $h_{i}>>>h_{j}$. Nesse algoritmo, as metas de maior prioridade são satisfeitas primeiro, só então se considera a relação das metas de menor prioridade. Esse tipo de ordenação recebe o nome lexicográfica por analogia com a ordenação de palavras num léxico ou dicionário.

A estrutura do modelo matemático de minimização lexicográfica (Ignizio, 1976) é:

$\operatorname{LEXMIN~} Z_{\mathrm{h}}=\left[h_{1}(\mathbf{n}, \mathbf{p}), h_{2}(\mathbf{n}, \mathbf{p}), \ldots, h_{k}(\mathbf{n}, \mathbf{p})\right]$

Sujeito a

$f_{i}(\mathbf{X})+n_{i}-p_{i}=b_{i}$

$\mathbf{X} \in \mathbf{x}$

$\mathrm{i}=1, \ldots, \mathrm{j}$

Onde,

LEX MIN = significa processo de minimização lexicográfica;

$h_{k}=k$-ésima prioridade envolvendo uma dada combinação de elementos para os vetores de desvios n e p;

$\mathrm{n}_{\mathrm{i}}=$ variável de desvio negativo associada ao i-ésimo objetivo;

$\mathrm{p}_{\mathrm{i}}=$ variável de desvio positivo associada ao i-ésimo objetivo;

$\mathrm{f}_{\mathrm{i}}(\mathbf{X})$ = função matemática das variáveis de decisão para o i-ésimo objetivo;

$\mathbf{b}_{\mathrm{i}}=$ conjunto de metas do i-ésimo objetivo;

$\mathbf{X}=$ vetor de variáveis de decisão;

$\mathbf{x}=$ conjunto de restrições básicas 


\section{A1 - 4.1.2 Programação por Metas Ponderadas}

A Programação por Metas Ponderadas, PMP, foi introduzida na literatura por Charnes \& Cooper (1961). Nesse enfoque, todas as metas são consideradas simultaneamente em uma função objetivo composta. A PMP minimiza uma função objetivo composta a qual consiste da soma de todos os desvios em relação as metas e seus níveis de aspirações (Rehman e Romero, 1993). Os desvios são ponderados (pesos não excludentes) de acordo com a importância relativa que cada meta tem para o tomador de decisão.

O modelo matemático da Programação por Metas Ponderadas é expresso por:

$$
\operatorname{MIN} \sum_{i=1}^{n}\left(\alpha_{i} n_{i}-\beta_{i} p_{i}\right)
$$

Sujeito a

$$
\begin{aligned}
& f_{i}(X)+n_{i}-p_{i}=b_{i} \\
& \mathbf{X} \in \mathbf{X} \\
& i=1, \ldots, j
\end{aligned}
$$

Onde,

$\mathrm{n}_{\mathrm{i}}=$ variável de desvio negativo ligada ao i-ésimo objetivo;

$\mathrm{p}_{\mathrm{i}}=$ variável de desvio positivo ligada ao i-ésimo objetivo;

$\mathrm{a}_{\mathrm{i}}=$ peso relativo ligado ao $\mathrm{n}_{\mathrm{i}}$;

$\mathrm{b}_{\mathrm{i}}=$ peso relativo ligado ao $\mathrm{p}_{\mathrm{i}}$;

$\mathrm{f}_{\mathrm{i}}(\mathbf{X})$ = função matemática das variáveis de decisão para o i-ésimo objetivo;

$\mathrm{b}_{\mathrm{i}}=$ conjunto de metas para o i-ésimo atributo;

$\mathbf{X}=$ é o vetor de variáveis de decisão; $\mathrm{e}$

$\mathbf{x}=$ conjunto de restrições básicas. 


\section{A1 - 4.1.3 Exemplos de aplicação da Programação por Metas}

Exemplo 1. (Romero \& Rehman, 1989). Um agricultor (tomador de decisão) quer investir na produção de pêras e pêssegos em sua propriedade. Os dados usados no planejamento são apresentados na Tabela 1 .

Tabela 1 - Dados das variáveis de decisão e das restrições usados no planejamento, por hectare.

\begin{tabular}{|c|c|c|c|}
\hline \multirow{4}{*}{ Restrições } & \multicolumn{2}{|c|}{ Variáveis de Decisão } & \multirow{4}{*}{$\begin{array}{l}\text { Disponível } \\
\text { (max / ano) }\end{array}$} \\
\hline & Pêra & Pêssego & \\
\hline & \multirow[b]{2}{*}{ (ha) } & \multirow[b]{2}{*}{ (ha) } & \\
\hline & & & \\
\hline Valor Presente Líquido do Investimento $(\mathrm{R} \$ \mathrm{ha})$ & 6250 & 5000 & \\
\hline Capital Gasto (R $\$ / h a)$ - Ano 1 & 550 & 400 & 15000 \\
\hline Ano 2 & 200 & 175 & 7000 \\
\hline Ano 3 & 300 & 250 & 7000 \\
\hline Ano 4 & 325 & 200 & 7000 \\
\hline Mão-de-obra (H.Homem/ha)- podas & 120 & 180 & 4000 \\
\hline - colheita & 400 & - & 2000 \\
\hline - colheita & - & 450 & 2000 \\
\hline Máquinas (H.Máquina/ha) - cultivo & 35 & 35 & 1000 \\
\hline
\end{tabular}

A título de ilustração e para a comparação com a Programação Multicritério, resolve-se o problema de Programação Linear de maximizar o VPL, onde é considerada a possibilidade de transferência de excesso de caixa entre um ano e o seguinte:

$\operatorname{Max} \mathrm{VPL}=6250 \mathrm{X}_{1}+5000 \mathrm{X}_{2}$

Sujeito a:

ano 1:

ano 2 :
$550 X_{1}+400 X_{2} \leq 15000$

$750 X_{1}+575 X_{2} \leq 22000$ 


$$
\begin{aligned}
& \text { ano 3: } \quad 1050 X_{1}+825 X_{2} \leq 29000 \\
& \text { ano 4: } \quad 1375 X_{1}+1025 X_{2} \leq 36000 \\
& \text { m-obra poda } \quad 120 X_{1}+180 X_{2} \leq 4000 \\
& \text { m-obra colh. pêra } \quad 400 X_{1} \leq 2000 \\
& \text { m-obra colh. pêssego } \quad 450 X_{2} \leq 2000 \\
& \text { máquina } \quad 35 \mathrm{X}_{1}+35 \mathrm{X}_{2} \leq 1000 \\
& X_{1}, X_{2} \geq 0
\end{aligned}
$$

OBSERVAÇÃO: O excesso de caixa do ano 1 , transferido para o ano 2 , é dado pela expressão (15000 - $550 X_{1}-400 X_{2}$ ), que é a somada ao capital disponivel no ano 2 $(+7000)$. O total deve ser $\geq 200 X_{1}+175 X_{2}$. Passando $X_{1}$ e $X_{2}$ para o primeiro membro da inequação, obtem-se a restrição de capital do ano 2 :

$$
550 X_{1}-400 X_{2}+200 X_{1}+175 X_{2} \leq 7000+15000
$$

Este problema de Programação Linear tem como solução: $X_{1}=5,0$ ha, $X_{2}=$ 4,44 ha e VPL $=\mathrm{R} \$ 53472,22$. A mão-de-obra disponível para colheita é usada completamente.

Para exemplificar o uso de Programação por Metas, considera-se que os objetivos do agricultor são:

(a) maximizar o valor presente líquido do investimento;

(b) minimizar o empréstimo de capital nos quatro anos;

(c) minimizar a contratação de mão-de-obra eventual nas operações de podas e colheitas;

(d) minimizar o aluguel de máquinas para cultivo.

Na Programação por Metas é necessária a criação das Variáveis de Desvio das Metas, $n_{i}$ e $p_{i}$.

Para obter um modelo de Programação por Metas, neste exemplo, as Restrições da Programação Linear são transformadas em Metas, assim, as inequações são transformadas em equações e acrescenta-se duas variáveis de desvio $\left(n_{i}\right.$ e $\left.p_{i}\right)$ em cada equação. 
Outro artificio, usado neste exemplo, para transformar o VPL em meta, é atribuir valor tão alto para VPL (R\$200000) que seria impossivel de ser obtido, usando os recursos disponiveis e considerando que o tomador de decisão quer maximizar o VPL.

As variáveis de desvio representam o desvio para se alcançar o nivel de aspiração de uma meta. Por exemplo, o nivel de aspiração para VPL (meta $1=m_{1}$ ) é R\$ 200000 , então, se $n_{1}=R \$ 50000$, isto significa que $m_{1}$ deixou de ser alcançada em $R \$ 50000$. Em outras palavras, o atendimento real de $m_{1}$ é $\mathrm{R} \$ 150000$. Assim, o déficit numa meta é representado por uma variável de desvio negativa. A variável de desvio positiva indica o quanto uma meta foi superada em seu nivel de aspiração. Uma meta não pode ser ao mesmo tempo superada e não superada, então tem-se: $n_{i}=0$ e $p_{i}=1$ ou $n_{i}=1$ e $p_{i}=0$. Quando uma meta atinge exatamente o seu nível de aspiração, então $n_{i}=p_{i}=0$.

Para saber quais variáveis de desvio que compõem a função objetivo a ser minimizada, na Programação por Metas, deve-se considerar:

(a) se o alcance de uma meta deve ser maior ou igual ao seu nível de aspiração, então, a variável de desvio negativo deve ter valor tão pequeno quanto possivel, neste caso, $\mathrm{n}_{\mathrm{i}}$ deve ser minimizado;

(b) se o alcance de uma meta deve ser menor que ou igual ao nível de aspiração, então, a variável de desvio positivo deve ser tão pequena quanto possivel, neste caso, $p_{i}$ deve ser minimizado;

(c) se uma meta deve ser exatamente igual ao seu nivel de aspiração, então, ambas variáveis de desvio positivo e negativo devem ser tão pequenas quanto possível, neste caso, $p_{i}+n_{i}$ deve ser minimizada.

\section{Exemplo da estrutura da Programacão por Metas Lexicográficas}

Admite-se que o tomador de decisão tem como primeira prioridade, $h_{1}$, obter um equilibrio entre o fluxo de caixa e os recursos financeiros disponiveis e que é permitido transferir caixa de um período com superávit para o outro seguinte com déficit. Assim, a prioridade $h_{1}$ é atingir as metas $m_{2}, m_{3}, m_{4}$ e $m_{5}$. Portanto, o primeiro componente a ser 
minimizado em um processo lexicográfico é dado pela soma: $\mathrm{p}_{2}+\mathrm{p}_{3}+\mathrm{p}_{4}+\mathrm{p}_{5}$. A próxima prioridade em ordem de importância, $h_{2}$, é minimizar o aluguel de máquinas para cultivo, $\mathrm{m}_{9}$. Assim, o segundo componente é dado pela variável de desvio positivo, $\mathrm{p}_{9}$. A terceira

prioridade, $h_{3}$, é maximizar o VPL. Portanto, o terceiro componente é $n_{1}$. Finalmente, a última prioridade, $h_{4}$, é minimizar a contratação de mão-de-obra eventual, referente as metas $m_{6}, m_{7}$ e $m_{8}$. Então, o último componente a ser minimizado é dado pela soma: $p_{6}+p_{7}+p_{8}$.

\section{Modelo de Programacão por Metas Lexicográficas:}

$\operatorname{LEXMIN~} Z_{i}=\left[\left(p_{2}+p_{3}+p_{4}+p_{5}\right),\left(p_{9}\right),\left(n_{1}\right),\left(p_{6}+p_{7}+p_{8}\right)\right]$

Sujeito a:

$\mathrm{h}_{3}$

$$
6250 X_{1}+5000 X_{2}+n_{1}-p_{1}=200000 m_{1}
$$

$$
550 X_{1}+400 X_{2}+n_{2}-p_{2}=15000 m_{2}
$$

$h_{1}$

$$
750 X_{1}+575 X_{2}+n_{3}-p_{3}=22000 m_{3}
$$

$$
1050 X_{1}+825 X_{2}+n_{4}-p_{4}=29000 m_{4}
$$$$
1375 X_{1}+1025 X_{2}+n_{5}-p_{5}=36000 m_{5}
$$

$\mathrm{h}_{4}$

$$
\begin{aligned}
120 \mathrm{X}_{1}+180 \mathrm{X}_{2}+\mathrm{n}_{6}-\mathrm{p}_{6} & =4000 \mathrm{~m}_{6} \\
400 \mathrm{X}_{1} & +\mathrm{n}_{7}-\mathrm{p}_{7}=2000 \mathrm{~m}_{7}
\end{aligned}
$$

$\mathrm{h}_{4}$

$$
400 X_{1}
$$

$$
450 \mathrm{X}_{2}+\mathrm{n}_{8}-\mathrm{p}_{8}=2000 \mathrm{~m}_{8}
$$

$\mathrm{h}_{2}$

$$
\begin{aligned}
& 35 X_{1}+35 X_{2}+n_{9}-p_{9}=1000 \quad m_{9} \\
& x_{i}, n_{j} e p_{j} \geq 0 \quad i=1,2 \quad j=1, \ldots, 9
\end{aligned}
$$

Onde,

LEX MIN $Z_{i}=$ vetor de realizações com quatro componentes.

$$
\begin{aligned}
\mathrm{h}_{\mathrm{t}} & =\text { Prioridades } \\
\mathrm{m}_{\mathrm{j}} & =\text { metas }
\end{aligned}
$$




\section{Método Linear Seqüencial para Programacão por Metas Lexicográficas}

OLSON (1984) discute as vantagens relativas de quatro algoritmos usados para resolver problemas de Programação por Metas Lexicográficas. Aqui, o Método Linear Seqüencial (MLS) será usado por requer apenas o convencional método Simplex para obter uma solução eficiente. O método MLS resolve uma seqüência de problemas de Programação Linear. O primeiro problema de PL, da seqüência, minimiza o primeiro componente do vetor de realizações, sujeito as restrições formadas pelas metas correspondentes a prioridade $h_{1}$. $O$ segundo problema de PL minimiza o segundo componente do vetor de realizações, sujeito as restrições formadas pelas metas das prioridades $h_{1}$ e $h_{2}$, mas, os valores das variáveis de desvio de $h_{1}$ devem ser modificados colocando-se os valores obtidos na solução do problema anterior. O procedimento seqüencial continua até o último problema de PL ser solucionado ou até que um dos problemas da sequeência não tenha uma solução ótima, como mostrado a seguir:

Problema de PL 1. O primeiro nível de prioridade $\left(h_{1}\right)$

$$
\begin{array}{llc} 
& \text { Min } Z_{1}=p_{2}+p_{3}+p_{4}+p_{5} & \\
& \text { Sujeito a: } & \\
& 550 X_{1}+400 X_{2}+n_{2}-p_{2}=15000 & m_{2} \\
& 750 X_{1}+575 X_{2}+n_{3}-p_{3}=22000 & m_{3} \\
& 1050 X_{1}+825 X_{2}+n_{4}-p_{4}=29000 & m_{4} \\
& 1375 X_{1}+1025 X_{2}+n_{5}-p_{5}=36000 & m_{5}
\end{array}
$$

Solução ótima, para o problema de PL 1: $\mathrm{p}_{2}=\mathrm{p}_{3}=\mathrm{p}_{4}=\mathrm{p}_{5}=0 ; Z_{1}=0 ; X_{1}=0$ e $X_{2}=35,122 \quad$ (usando o Simplex) 
Problema de PL 2. O segundo nível de prioridade $\left(\mathrm{h}_{2}\right)$

$\operatorname{Min} Z_{2}=p_{9}$

Sujeito a:

$$
\begin{array}{ccc} 
& 550 X_{1}+400 X_{2}+n_{2}-0 p_{2}=15000 & m_{2} \\
h_{1} & 750 X_{1}+575 X_{2}+n_{3}-0 p_{3}=22000 & m_{3} \\
& 1050 X_{1}+825 X_{2}+n_{4}-0 p_{4}=29000 & m_{4} \\
& 1375 X_{1}+1025 X_{2}+n_{5}-0 p_{5}=36000 & m_{5} \\
& & \\
h_{2} & 35 X_{1}+35 X_{2}+n_{9}-p_{9}=1000 m_{9}
\end{array}
$$

Solução ótima para o problema de PL 2: $p_{9}=0 ; Z_{2}=0 ; X_{1}=19,18367$ e $X_{2}=9,38776$ (usando o Simplex)

Problema de PL 3. O terceiro nível de prioridade $\left(h_{3}\right)$

$$
\operatorname{Min} Z_{3}=n_{1}
$$

Sujeito a:

$$
\begin{array}{crc} 
& 550 \mathrm{X}_{1}+400 \mathrm{X}_{2}+\mathrm{n}_{2}-0 \mathrm{p}_{2}=15000 & \mathrm{~m}_{2} \\
750 \mathrm{X}_{1}+575 \mathrm{X}_{2}+\mathrm{n}_{3}-0 \mathrm{p}_{3}=22000 & \mathrm{~m}_{3} \\
1050 \mathrm{X}_{1}+825 \mathrm{X}_{2}+\mathrm{n}_{4}-0 \mathrm{p}_{4}=29000 & \mathrm{~m}_{4} \\
& 1375 \mathrm{X}_{1}+1025 \mathrm{X}_{2}+\mathrm{n}_{5}-0 \mathrm{p}_{5}=36000 & \mathrm{~m}_{5} \\
& 35 \mathrm{X}_{1}+35 \mathrm{X}_{2}+\mathrm{n}_{9}-0 \mathrm{p}_{9}=1000 & \mathrm{~m}_{9} \\
& & \\
\mathrm{~h}_{2} & & \\
& 6250 \mathrm{X}_{1}+5000 \mathrm{X}_{2}+\mathrm{n}_{1}-\mathrm{p}_{1}=200000 & \mathrm{~m}_{1}
\end{array}
$$

Solução ótima: $X_{1}=19,18367$ ha, $X_{2}=9,38776$ ha e $n_{1}=R \$ 33163,26$ 
Usando esse resultado, pode-se continuar o algoritmo MLS com a próxima prioridade. Mas, como um ótimo múltiplo não existe para o problema de PL $3, \mathrm{n}_{1}$ diferente de 0 (zero), a presente solução é considerada ótima com respeito a todas as prioridades. Então, substituindo os valores ótimos das variáveis de decisão $X_{1}$ e $X_{2}$ nas equações das metas $m_{6}$, $\mathrm{m}_{7}$ e $\mathrm{m}_{8}$, obtêm-se os valores das variáveis de desvio dessas metas: $\mathrm{n}_{6}=8,16$ horas homem, $\mathrm{p}_{7}=5673,468$ horas homem e $\mathrm{p}_{8}=2224,492$ horas homem.

\section{Exemplo 2. Programação por Metas Ponderadas (PMP)}

Usando os mesmos dados do Exemplo 1, considerar as metas $m_{2}, m_{3}, m_{4}$ e $m_{5}$ como restrições rígidas, ou seja, o Tomador de Decisão não quer assumir quaisquer violações nessas metas. Assim, o modelo de PMP é constituído de 5 metas $\left(\mathrm{m}_{1}, \mathrm{~m}_{6}, \mathrm{~m}_{7}, \mathrm{~m}_{8}\right.$ e $\left.\mathrm{m}_{9}\right)$ e 4 restrições.

Primeiramente, neste exemplo, atribui-se o valor de 175600 para VPL porque este é o máximo que se pode obter com as restrições fixas de caixa.

As variáveis da função objetivo devem representar desvios percentuais das metas ao invés de desvios absolutos, porque são usadas diferentes unidades de medida para as metas $m_{1}(R \$) ; m_{6}, m_{7}$ e $m_{8}$ (horas homem) e $m_{9}$ (horas máquina).

O modelo de Programação por Metas Ponderadas é:

$\operatorname{Min} Z: W_{1}\left[\left(\mathrm{n}_{1} / 175600\right) 100\right]+\mathrm{W}_{2}\left[\left(\mathrm{p}_{6} / 4000\right) 100\right]+\mathrm{W}_{3}\left[\left(\mathrm{p}_{7} / 2000\right) 100\right]$

$$
+\mathrm{W}_{4}\left[\left(\mathrm{n}_{8} / 2000\right) 100\right]+\mathrm{W}_{5}\left[\left(\mathrm{p}_{9} / 1000\right) 100\right]
$$

Sujeito a:

$$
\begin{array}{ll}
550 X_{1}+400 X_{2} & \geq 15000 \\
750 X_{1}+575 X_{2} & \geq 22000 \\
1050 X_{1}+825 X_{2} & \geq 29000 \\
1375 X_{1}+1025 X_{2} & \geq 36000 \\
6250 X_{1}+5000 X_{2}+n_{1}-p_{1}=175600
\end{array}
$$




$$
\begin{array}{rr}
120 X_{1}+180 X_{2}+n_{6}-p_{6}= & 4000 \\
400 X_{1} \quad n_{7}-p_{7}= & 2000 \\
450 X_{2}+n_{8}-p_{8}= & 2000 \\
35 X_{1}+35 X_{2}+n_{9}-p_{9}= & 1000 \\
X_{1}, X_{2}, n_{j} \text { e } p_{j} \geq 0 &
\end{array}
$$

Onde,

$\mathrm{W}_{\mathrm{h}}=$ pesos atribuídos às variáveis de desvio, $\mathrm{h}=1, \ldots, 5$.

Esse problema pode ser resolvido usando o método Simplex de programação linear. Diferentes soluções são obtidas atribuindo diferentes valores aos parâmetros. Por exemplo, se $\mathrm{W}_{1}=\mathrm{W}_{2}=\mathrm{W}_{3}=\mathrm{W}_{4}=\mathrm{W}_{5}=1$, então a solução é a mesma do problema de Max VLP, do exemplo $1, X_{1}=5,0$ ha e $X_{2}=4,44$ ha. Se atribuir peso para $W_{1}$ de 6,5 vezes maior que os demais pesos atribuídos às outras variáveis de desvio, a solução ótima muda para $X_{1}=22,86869$ ha e $X_{2}=4,44$ ha.

\section{Críticas à Programacão por Metas}

(A) As soluções da Programação por Metas podem ser iguais às obtidas por Programação Linear.

(B) A Programação por Metas Lexicográficas pressupõe que haja trade-off apenas entre metas com mesmo nivel de prioridade.

(C) As soluções ótimas produzidas pela Programação por Metas podem ser inferiores ou seja soluções dominadas.

(D) A otimização da função de realização da PML não é o mesmo que otimizar a função de utilidade do tomador de decisão.

(E) Quando a quantidade de prioridades é grande, a Programação por Metas Lexicográficas pode levar à formulação de prioridades inoperantes. 


\section{A1 - 4.2 Programação Multi-objetivo}

A Programação Multi-objetivo - PMO -, também chamada de otimização vetorial, analisa o problema de otimizar, simultaneamente, vários objetivos sujeitos a satisfação de um conjunto de restrições que, usualmente, são lineares. A Programação Multiobjetivo se diferencia da Programação por Metas por trabalhar com objetivos ao invés de metas. Dado que é impossível definir um ótimo quando existem vários objetivos, a PMO ao invés de buscar um único ótimo, trata de gerar um conjunto de soluções eficientes, também chamadas de soluções não dominadas ou ótimo de Pareto. O conjunto eficiente é formado por soluções possiveis, as quais cumprem as restrições, de tal modo que não existe outra solução possível que proporcione melhoria num objetivo sem produzir piora em pelo menos um dos outros objetivos.

A programação Multi-objetivo apresenta a formulação matemática geral:

Eff $Z(X)=\left[Z_{1}(X), Z_{2}(X), \ldots, Z_{p}(X)\right]$

Sujeito a

$\mathbf{X} \in \mathbf{X}$

Onde,

Eff $Z(X)=$ significa a busca de soluções eficientes, quando "p" objetivos estão envolvidos na análise;

$\mathbf{X}=$ representa o vetor das variáveis de decisão;

$\mathbf{x}=$ conjunto de restrições básicas. 


\section{Técnicas para gerar o conjunto eficiente na PMO}

Existem quatro técnicas para gerar ou, ao menos, aproximar o conjunto eficiente na PMO: Método dos Coeficientes de Ponderação, Método das Restrições, Método NISE e Método Simplex com Múltiplos Objetivos. Uma explicação detalhada dos aspectos teóricos e operativos dessas técnicas é encontrada em Cohon (1978), Goicochea, Hansen \& Duckstein (1982), Zeleny (1982) e Haimes \& Chankong (1985).

\section{Exemplo 3. Formulação do Problema de PMO}

Usando os dados do Exemplo 1, supor que o agricultor tem dois objetivos: (a) maximizar o Valor Presente Líquido do Investimento e (b) minimizar a quantidade de horas de trabalho eventual usadas apenas na colheita. Acrescentar a restrição da área plantada $\operatorname{ser}^{3} 10$ ha. Incluir apenas a restrição de capital do ano 4, porque as restrições dos anos $1,2 \mathrm{e}$ 3 são redundantes.

\section{Estrutura do Modelo de PMO:}

$$
\begin{aligned}
& \operatorname{Eff} Z(X)=\left[Z_{1}(X), Z_{2}(X)\right] \\
& \text { Para, } \quad \begin{array}{l}
Z_{1}(X)=6250 X_{1}+5000 X_{2} \\
Z_{2}(X)=-400 X_{1}-450 X_{2}
\end{array}
\end{aligned}
$$

Sujeito a:

$$
\begin{aligned}
1375 X_{1}+1025 X_{2} & \leq 36000 \\
120 X_{1}+180 X_{2} & \leq 4000 \\
35 X_{1}+35 X_{2} & \leq 1000 \\
X_{1}+\quad X_{2} & \geq 10 \\
X_{i} & \geq 0
\end{aligned}
$$




\section{1) Resolução Gráfica do Exemplo 3}

Como neste exemplo temos apenas duas variáveis e dois objetivos, é possível obter graficamente um conjunto de soluções possíveis, cujos pontos extremos são apresentados na Tabela 2 .

Tabela 2 - Pontos Extremos do problema de PMO, para o exemplo 3

\begin{tabular}{lllll} 
Pontos & \multicolumn{2}{c}{ Variáveis de decisão } & \multicolumn{2}{c}{ Funções Objetivo } \\
Extremos & $\mathrm{X}_{1}$ & $\mathrm{X}_{2}$ & $\mathrm{Z}_{1}$ & $\mathrm{Z}_{2}$ \\
\hline & & & & \\
$\mathrm{A}$ & 10 & 0 & 62500 & 4000 \\
$\mathrm{~B}$ & 26,18182 & 0 & 163636,375 & 10472,728 \\
$\mathrm{C}$ & 19,18367 & 9,38776 & 166775,7375 & 11897,96 \\
$\mathrm{D}$ & 0 & 22,22 & 111111 & 10000 \\
E & 0 & 10 & 50000 & 4500 \\
\hline
\end{tabular}

Os pontos extremos formam um polígono $\mathrm{ABCDE}$ que representa o conjunto de soluções possíveis (F), Figura 1.

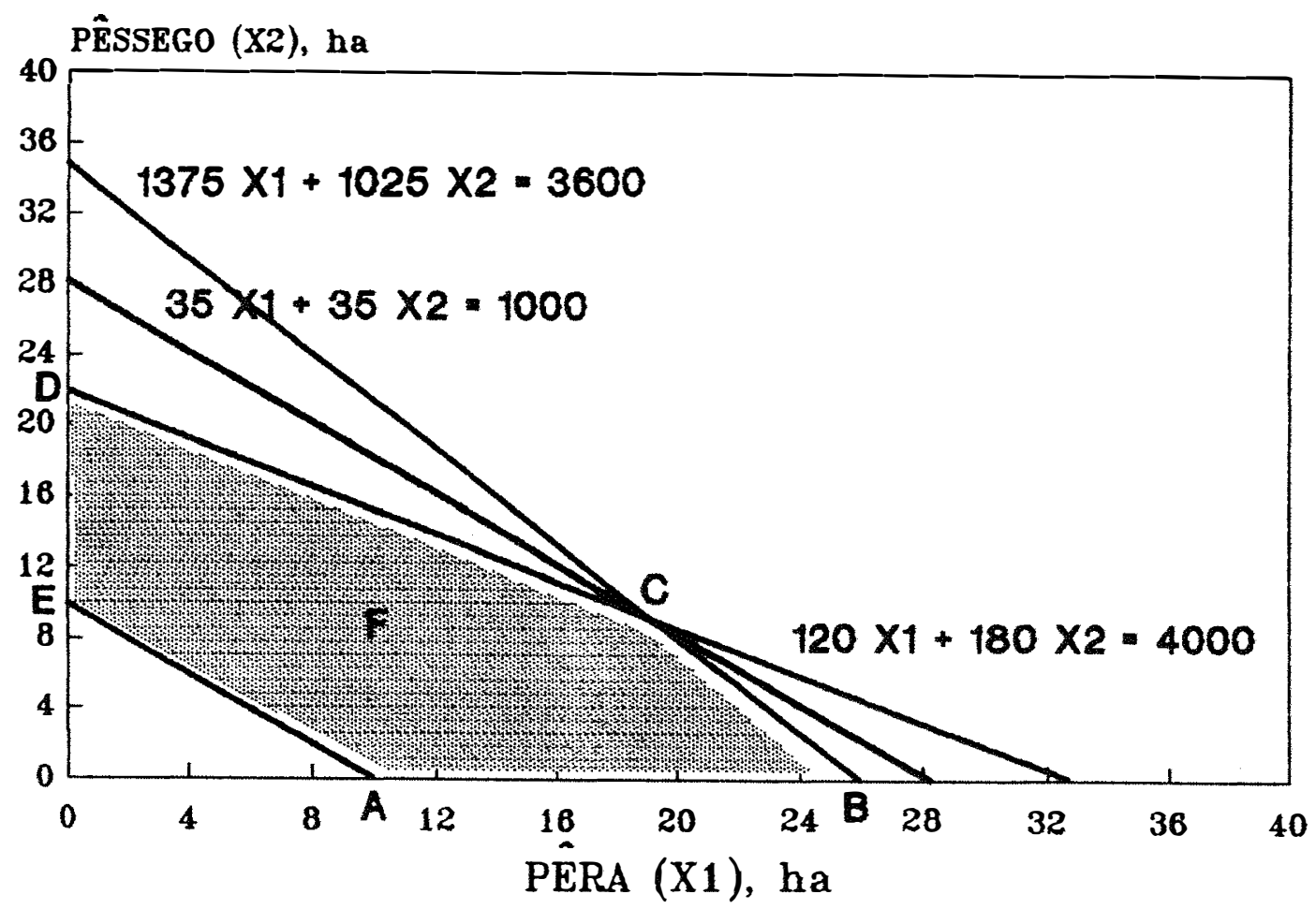

Figura 1 - Conjunto de soluções possível no espaço das variáveis de decisão do exemplo 3. 
A imagem algébrica dos pontos extremos é construída plotando os valores dos objetivos, correspondentes aos respectivos pontos extremos, no gráfico $Z_{1}$ versus $Z_{2}$ (espaço dos objetivos), Figura 2.

A Figura 2 mostra que os segmentos ligando $\mathrm{A}^{\prime}, \mathrm{B}^{\prime}$ e $\mathrm{C}^{\prime}$, representam o conjunto eficiente no espaço dos objetivos ( $\mathrm{F}^{\prime}$ ) para o problema analisado. De fato, os pontos contidos no espaço $\mathrm{F}^{\prime}$ e que não pertencem aos segmentos $\mathrm{A}^{\prime} \mathrm{B}^{\prime} \mathrm{C}^{\prime}$ são inferiores ou não eficientes porque estes propiciam menor VPL para um igual (ou maior) valor da mão-de-obra eventual para colheita ou propiciam igual (ou menor) VPL para maior valor de mão-de-obra eventual do que qualquer ponto contido no segmento $\mathrm{A}^{\mathrm{B}} \mathrm{B}^{\prime} \mathrm{C}^{\prime}$.

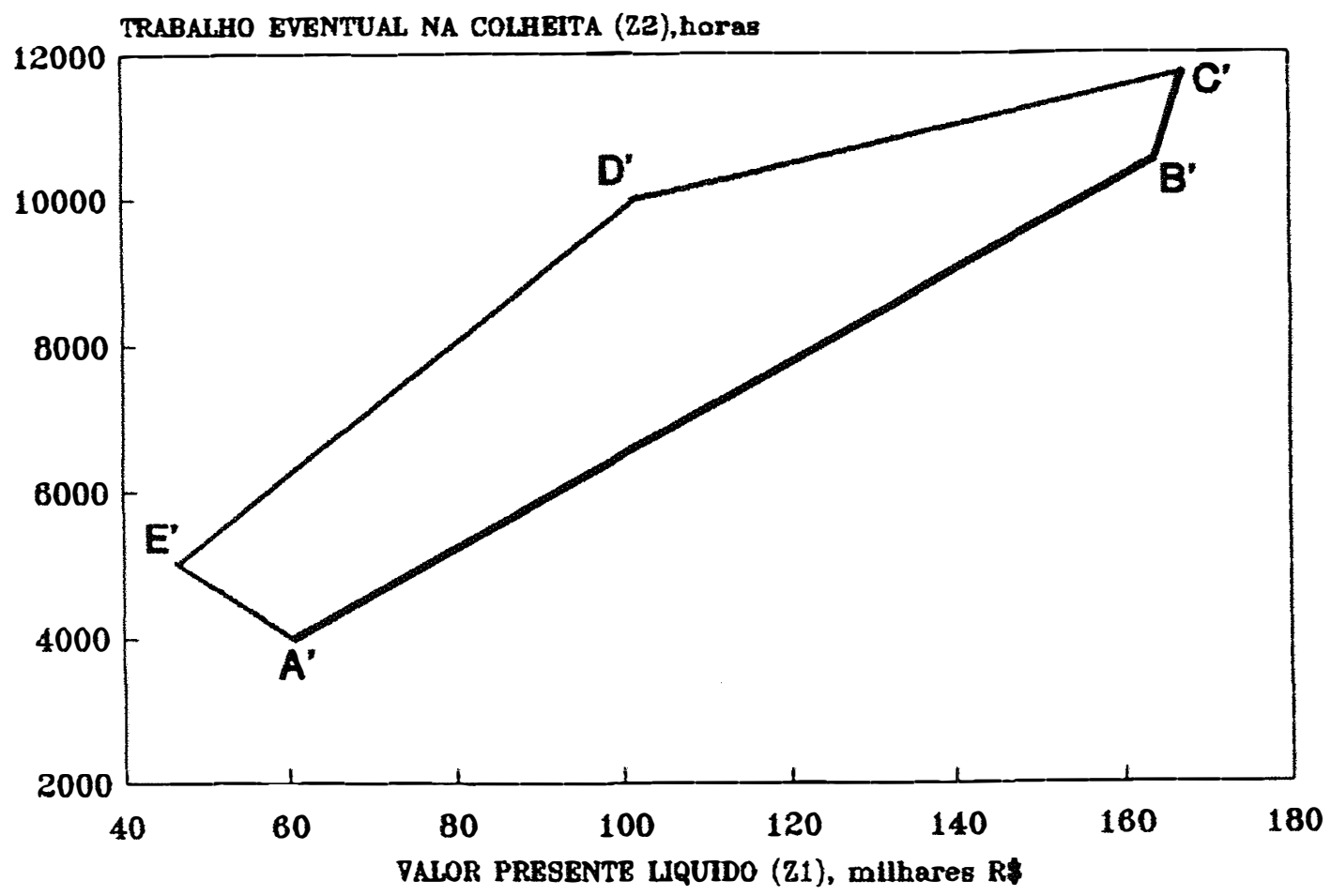

Figura 2 - Imagem do conjunto de soluções possível no espaço dos objetivos.

O conjunto eficiente pode ser interpretado como a curva de transformação que mede as relações entre os dois atributos. A inclinação dos dois segmentos $\mathrm{A}^{\prime} \mathrm{B}^{\prime}$ e $\mathrm{B}^{\prime} \mathrm{C}^{\prime}$ representa o "trade-off" ( ou custo de oportunidade) entre VPL $\left(Z_{1}\right)$ e Mão-de-obra eventual $\left(Z_{2}\right)$ 


\section{2) Cálculo do "trade-off" entre $Z_{1}$ e $Z_{0}$}

O conceito de solução ótima de Pareto leva a outro conceito importante na Programação Multi-objetivo: o valor do "trade-off" entre dois objetivos. O "trade-off" entre dois objetivos indica quanto do alcance de um objetivo deve ser sacrificado para se obter um acréscimo em uma unidade do outro objetivo. $\mathrm{O}$ valor do "trade-off' é um bom índice para medir o custo de oportunidade de um objetivo em relação a outro. Assim, para duas soluções eficientes $X$ ' e $X$ ", o valor do "trade-off" entre o j-ésimo $\left(Z_{j}\right)$ e o k-ésimo $\left(Z_{k}\right)$ objetivo é dado pela expressão:

$$
T_{j k}=\frac{Z_{j}\left(X^{\prime}\right)-Z_{j}\left(X^{\prime \prime}\right)}{Z_{k}\left(X^{\prime}\right)-Z_{k}\left(X^{\prime \prime}\right)}
$$

Neste exemplo, o “trade-off”' entre $Z_{1}$ e $Z_{2}$, no intervalo A'B', é dado por:

$$
\mathrm{TA}^{\prime}, \mathrm{B}^{\prime}=\frac{163636,375-62500}{10472,728-4000}=15,625 \mathrm{R} \$ / \text { hora }
$$

Isto implica que para cada hora de mão-de-obra eventual usada, tem-se um acréscimo no VPL de $\mathrm{R} \$ 15,625$. O inverso desse valor indica que para um acréscimo de $\mathrm{R} \$$ 1,0 do VPL, tem-se um acréscimo de 0,064 horas homem de trabalho eventual. Assim, se o "trade-off" é vantajoso para o tomador de decisão, então, o ponto B' é preferido, caso contrário, o ponto A' é preferido.

\section{3) Construcão da matriz de "Pay-off",}

Uma maneira de se obter informações úteis sobre o problema de PMO é otimizar cada objetivo separadamente obtendo o conjunto eficiente. E depois, calcular o valor 
de cada objetivo para cada solução ótima. A matriz obtida é denominada matriz de "pay-off", Tabela 3.

Tabela 3 - Matriz de "Pay-off" para o Exemplo 3.

\section{Valor Presente Líquido Mão-de-obra eventual} (horas)

$\begin{array}{lcc}\text { Valor Presente Líquido (R\$) } & \underline{\mathbf{1 6 6 8 3 6 , 7 3 7 5}} & 11897,96 \\ \text { Mão-de-obra eventual (horas) } & 62500 & \underline{\mathbf{4 0 0 0}}\end{array}$

OBS: A diagonal com pontos sublinhados contém os pontos ideais. A outra diagonal contém os pontos anti-ideais.

Os elementos da primeira linha indicam que os valores de $X_{1}$ e $X_{2}$, que proporcionam o máximo de VPL, geram um valor de mão-de-obra de 11897,96 horas. Os elementos da segunda linha indicam que um mínimo de mão-de-obra de 4000 horas corresponde a um valor do VPL de R\$62500. Na matriz de "pay-off" é fácil verificar o grau de conflito entre os objetivos. De fato, o máximo de VPL só é compatível com um nível três vezes maior do mínimo de mão-de-obra. E, o mínimo de mão-de-obra só é compatível com menos da metade do máximo VPL. Os elementos da diagonal, formada pelo vértice superior esquerdo até o inferior direito, são os "pontos ideais". Isto é, a solução onde todos os objetivos alcançam seus valores ótimos. Como os objetivos são conflitantes, é impossível obter o ponto ideal. A outra diagonal contêm os pontos anti-ideais, que são não-eficientes. Os pontos anti-ideais são importantes para normalizar as funções objetivos medidas em unidades diferentes e com valores absolutos diferentes. A diferença entre o ponto ideal e o anti-ideal define um intervalo de valores para cada função objetivo que é usado na técnica de restrições, mostrada a seguir. 


\section{A1 - 4.2.1 Programação Multi-objetivo com Restrições}

A técnica de Restrições, proposta por Marglin (1967) e formulada por Haimes \& Hall (1974), consiste em otimizar um dos objetivos, enquanto que os restantes "p1" são incluídos no conjunto das restrições do modelo. O conjunto eficiente é gerado por meio de variações paramétricas nos valores atribuídos aos termos independentes das restrições (RHS) nas quais se converteram os "p-1" objetivos. A substituição do objetivo inicialmente otimizado por outro dos incluídos nas restrições, possibilita a geração de novas soluções eficientes. O processamento do algoritmo finaliza quando alguma das soluções geradas satisfaz o tomador de decisão ou quando o conjunto de soluções geradas permite ao tomador de decisão a escolha de uma delas.

\section{Modelo matemático da Programação Multi-objetivo com Restrições:}

Opt $Z_{\mathrm{i}}(\mathrm{X})$

Sujeito a

$$
\begin{aligned}
& \mathbf{X} \in \mathbf{x} \\
& Z_{j}(X) \leq L_{j} \quad \forall j, \quad j \neq i, \quad j=1,2, \ldots, p
\end{aligned}
$$

Cohon (1978) propõe que $\mathrm{L}_{j}$ seja parametrizada pela expressão:

$$
\mathrm{L}_{j}=Z_{j}^{* *}(X)+\frac{\left[Z_{j}^{*}(X)-Z_{j}^{* *}(X)\right] t}{T}
$$

Onde,

$Z_{j}^{*}(X)=$ valores ideais, correspondem aos valores ótimos de cada objetivo considerado individualmente e que seria a solução na ausência de conflito entre os objetivos; $Z_{j}^{* *}(X)=$ valores anti-ideais, são os valores que um objetivo alcança quando o outro objetivo tem valor ideal;

$$
\mathrm{t}=1,2, \ldots, \mathrm{T}-1 \mathrm{e}
$$

$\mathrm{T}=$ valor que depende do número de soluções eficientes que o tomador de decisão deseja obter. 
Romero \& Rehman (1989) propõem que $\mathrm{L}_{\mathrm{j}}$ seja parametrizada considerando os valores ideais e anti-ideais como limites de $\mathrm{L}_{\mathrm{j}}$, como mostrado no Exemplo 4 .

A programação Multi-objetivo com Restrições requer $\mathrm{p}^{\mathrm{j}-1}$ rodadas do computador para o problema de PL correspondente, onde j é a quantidade de objetivos e p é quantidade de subintervalos de $\mathrm{L}_{\mathrm{j}}$. Por exemplo, para 4 objetivos e atribuindo 5 valores para $\mathrm{L}_{\mathrm{j}}$ tem-se 125 rodadas de PL no computador (em cada rodada é obtida uma solução possível). Esse trabalho computacional pode ser reduzido usando a Programação Linear Paramétrica.

\section{Exemplo 4 - Programação Multi-objetivo com Restrições}

Usando os mesmos dados do Exemplo 1 e escolhendo o VPL como objetivo a ser otimizado, a técnica de restrições conduz a seguinte formulação de Programação Linear Paramétrica.

$$
\begin{aligned}
\text { Maximizar } Z_{1}(X)=6250 X_{1}+5000 X_{2} \\
\text { Sujeito a: } \\
550 X_{1}+400 X_{2} \leq 15000 \\
750 X_{1}+575 X_{2} \leq 22000 \\
1050 X_{1}+825 X_{2} \leq 29000 \\
1375 X_{1}+1025 X_{2} \leq 36000 \\
120 X_{1}+180 X_{2} \leq 4000 \\
35 X_{1}+35 X_{2} \leq 1000 \\
X_{1}+\quad X_{2} \geq 10 \\
400 X_{1}+450 X_{2} \leq L_{1} \\
Z_{2}(X) \quad X_{i} \geq 0
\end{aligned}
$$

Os valores ideal e anti-ideal para o objetivo de minimizar a mão-de-obra eventual, mostrados na segunda linha da matriz de "pay-off", Tabela 3, podem ser considerados os limites superior e inferior que o intervalo do parâmetro $L_{1}$ pode variar.

Parametrizando $L_{1}$ para valores entre 4000 e 11897,728 horas, é obtida uma aproximação do conjunto eficiente, Tabela 4 . Observar que se obtêm os mesmos pontos 
extremos $\mathrm{A}, \mathrm{B}$ e $\mathrm{C}$, além de outros pontos contido nos segmentos $\mathrm{AB}$ e $\mathrm{BC}$. Consequentemente, também, são obtidos os pontos A', B' e C'e os segmentos A'B' e B'C'. Tabela 4 - Pontos extremos eficientes gerados pela PMO com Restrições, para 0 Exemplo 4.

\begin{tabular}{cllll}
\hline$X_{1}$ & $X_{2}$ & \multicolumn{1}{c}{$Z_{1}$} & \multicolumn{1}{c}{$Z_{2}$} & \multicolumn{1}{c}{$\mathrm{RHS}\left(\mathrm{L}_{1}\right)$} \\
\hline 19,18367 & 9,38776 & 166836,7375 & 11897,728 & 11897,728 \\
23,59281 & 3,47305 & 164820,3593 & 11000 & 11000 \\
26,04791 & 0,17964 & 163697,6047 & 10500 & 10500 \\
26,18 & 0 & 163625 & 10472 & 10472 \\
25,00 & 0 & 156250 & 10000 & 10000 \\
22,50 & 0 & 140625 & 9000 & 9000 \\
20,00 & 0 & 125000 & 8000 & 8000 \\
17,50 & 0 & 109375 & 7000 & 7000 \\
15,00 & 0 & 93750 & 6000 & 6000 \\
12,50 & 0 & 78125 & 5000 & 5000 \\
11,50 & 0 & 70312,5 & 4500 & 4500 \\
10,00 & 0 & 62500 & 4000 & 4000 \\
\hline
\end{tabular}

\section{A1 - 4.2.2 Programação Multi-objetivo com Coeficientes de Ponderação}

A idéia básica desta técnica, proposta por Zadeh (1963), consiste em combinar todos os "p" objetivos em uma única função composta. Com esse propósito, a cada objetivo associa-se um peso ou coeficiente de ponderação obtendo o somatório de todos os objetivos. Para gerar um conjunto de soluções eficientes, os diferentes pesos são submetidos a um tratamento paramétrico. 
Modelo matemático da Programação Multi-objetivo com Coeficientes de Ponderação:

$$
\text { Opt } F=\sum_{i=1}^{p} W_{i} \cdot Z_{i}(X)
$$

Sujeito a

$\mathbf{X} \in \mathbf{x}$

Onde,

$\mathbf{W}_{\mathrm{i}}$ é o coeficiente de ponderação do objetivo i, variando de $(0, x)$ e cuja parametrização possibilita a geração de pontos extremos do conjunto eficiente. A poligonal que une esses pontos constitui uma aproximação da curva de "trade-off".

Os pesos $\mathbf{W}_{\mathrm{i}}$ podem ser normalizados fazendo $\sum \mathbf{w}_{\mathrm{i}}=0$. Os pesos $\mathbf{W}_{\mathrm{i}}$, de modo geral, não podem ser interpretados como uma medida da importância relativa ou da preferência do tomador de decisão por cada objetivo. Esta interpretação seria correta somente se fosse aceito que a função de utilidade do TD fosse linear e aditiva, o que, geralmente, não é aceitável. Os $\mathbf{W}_{\mathrm{i}}$ devem ser considerados apenas como parâmetros que podem variar sistematicamente para gerarem o conjunto eficiente.

\section{Exemplo 5 - Formulação do problema de PMO com Coeficientes de Ponderação}

Usando os dados do Exemplo 4, o modelo de PMO com Coeficientes de Ponderação é formulado como um problema de Programação Linear Paramétrica:

$\operatorname{Max} Z=\mathbf{W}_{1}\left(6250 X_{1}+5000 X_{2}\right)+W_{2}\left(-400 X_{1}-450 X_{2}\right)$

Sujeito a:

$$
\begin{aligned}
& \mathbf{X} \in \mathbf{x} \\
& 0 \leq \mathbf{W}_{\mathrm{i}} \leq 1
\end{aligned}
$$

Parametrizando $\mathbf{W}_{\mathrm{i}}$, obtêm-se as soluções ótimas mostradas na Tabela 5. 
Tabela 5 - Soluções ótimas, para o exemplo 5 , obtidas com a parametrização de $\mathbf{W}_{\mathbf{i}}$

\begin{tabular}{rrr}
$\mathbf{W}_{1}$ & $\mathbf{W}_{\mathbf{2}}$ & Solução ótima (Ponto Extremo) \\
\hline & & \\
$0,4-1,0$ & $0-0,6$ & C ou C' \\
$0,1-0,4$ & $0,6-0,9$ & B ou B' \\
$0-0,1$ & $0,9-1,0$ & A ou A' \\
\hline
\end{tabular}

\section{A1 - 4.2.3 Método NISE}

O Método NISE ("Non-Inferior Set Estimation"), ou método de estimação do conjunto de soluções não inferiores, foi desenvolvido por Cohon (1978) como um método rápido para gerar, de forma aproximada, o conjunto de soluções eficientes. Esse método pode ser aplicado na resolução de problemas com mais de dois objetivos em conflitos, através da transformação do problema geral em casos particulares do enfoque bicritério.

O método NISE parte do suposto de que o conjunto de soluções possíveis é convexo e que as funções objetivos são lineares. O método opera gerando pontos extremos não dominados e avaliando a eficiência dos segmentos que unem os pontos eficientes adjacentes. Considera, ainda, que um segmento que une dois pontos extremos adjacentes é eficiente quando não é possível obter nenhum outro ponto eficiente que não pertença ao segmento. Utiliza o Método dos Coeficientes de Ponderação, para gerar os pontos eficientes e verificar a eficiência do segmento. Emprega a inclinação do segmento estudado, como coeficiente de ponderação. Se o segmento estudado não é eficiente, seu uso garante que um novo ponto extremo eficiente pode ser gerado. O novo ponto obtido é a solução possível com maior proximidade perpendicular ao segmento estudado. O processo algorítmico finaliza quando se gerar todos os pontos extremos, cujos segmentos são eficientes, ou quando se alcança o nível de aproximação considerado admissivel. A escolha por parte do tomador de decisão dos pontos da função de "trade-off" depende do valor que ele dê à relação marginal de substituição entre objetivos. 
Modelos matemáticos do Método NISE:

A) Para gera a Matriz de "Pay-off":

Opt $Z_{i}(X)$

Sujeito a

$\mathbf{X} \in \mathbf{x}$

B) Para gerar o conjunto eficiente:

Opt $Z_{1}(X)+W \cdot Z_{2}(X)$

Sujeito a

$\mathbf{X} \in \mathbf{x}$

Onde,

W é a inclinação do segmento de reta $\mathbf{Z}_{1} \mathbf{Z}_{2}$.

Exemplo 6 - Método NISE

Os pesos Wi são dados pela inclinação da reta $\mathrm{A}^{\prime} \mathrm{C}^{\prime}$, Figura 2. Usando os dados da matriz de 'Pay-off', Tabela 3, obtêm-se a inclinação da reta $\mathrm{A}^{\prime} \mathrm{C}^{\prime}$ :

$\frac{W_{1}}{W_{2}}=\frac{11897,96-4000}{166836,7375-62500}=0,07569$ (inclinação da reta $A^{\prime} C^{\prime}$ )

Fazendo, arbitrariamente, $\mathrm{W}_{2}=1$, tem-se: $\quad \mathrm{W}_{1}=0,07569$

O problema de otimização no Método NISE é formulado como:

$\operatorname{Max} Z(X)=0,07569 Z_{1}(X)+Z_{2}(X)$

Sujeito a

$\mathbf{X} \in \mathbf{x}$ 
Substituindo os $Z_{\mathrm{i}}(\mathrm{X})$ pelas respectivas equações, e simplificando a função objetivo, tem-se:

$\operatorname{Max} Z(X)=0,07569\left(6250 X_{1}+5000 X_{2}\right)+\left(-400 X_{1}-450 X_{2}\right)$

ou simplificando,

$\operatorname{Max} Z(X)=73,0625 X_{1}-71,55 X_{2}$

Sujeito a

$\mathbf{X} \in \mathbf{x}$

A solução, usando o simplex, é o ponto extremo B ou B' que é: $\mathrm{X}_{1}=$ 26,18182; $X_{2}=0 ; Z_{1}=163636,375$ e $Z_{2}=10472,728$.

$\mathrm{O}$ algoritmo segue usando as inclinações dos segmentos $\mathrm{A}^{\prime} \mathrm{B}^{\prime} \mathrm{e} \mathrm{B}^{\prime} \mathrm{C}^{\prime}$ como pesos para $Z_{\mathrm{i}}$.

\section{A1 - 4.2.4 Programação Multi-objetivo Simplex}

As primeiras técnicas Multi-objetivo Simplex, também denominadas de Programação Multicritério Simplex, foram propostas por Philip (1972) e Zeleny (1973). A idéia básica consiste em gerar o conjunto eficiente desprezando-se de um ponto extremo eficiente até os pontos extremos eficientes adjacentes. Esta técnica tem pouca utilidade prática porque só é aplicável em problemas muito pequenos. 


\section{TÉCNICAS PARA ESCOLHA DA SOLUCÃO ÓTIMA}

Através das Técnicas de Programação Multi-objetivo, acima descritas, estabelece-se o conjunto de soluções que Zeleny (1973) denomina ideal, Geoffrion et al. (1972) de solução perfeita e Yu (1973) de ponto ótimo. Entretanto, após a obtenção do conjunto eficiente, ainda permanece o problema de ajudar o tomador de decisão na escolha da solução ótima a ser implementada.

Existem dois enfoques para auxiliar o tomador de decisão na escolha dentre os elementos do conjunto eficiente da solução ótima: a Programação Compromisso e as Técnicas Interativas.

Do ponto de vista estritamente operativo, a Programação Compromisso apresenta uma clara superioridade quando comparadas com as Técnicas Interativas. Pois as Técnicas Interativas demandam do TD uma informação bastante complexas e de obtenção dificultosa, na maior parte dos casos (Wallenius, 1975).

\subsubsection{Programação Compromisso}

A Programação Compromisso foi formulada por Zeleny em uma série de trabalhos (1973, 1974a, 1974b, 1976a e 1982) e por Yu (1973).

A Programação Compromisso define a solução ótima como o ponto eficiente que se encontra mais próximo do ponto ideal. O ponto ideal é representado pelas soluções correspondentes à maximização do objetivo em questão, sujeito as restrições correspondentes, porém, sem levar em conta os outros objetivos durante o processo de otimização. Nesse método, são geradas unicamente as soluções não dominadas mais próximas do ponto ideal. As soluções assim obtidas são denominadas de soluções compromissos (compromisso deve ser entendido como: meio termo ou acordo). As coordenadas do ponto ideal são os valores ideais de cada um dos objetivos e, lógico, é uma solução não alcançável se os objetivos estão em conflito. Em outras palavras, as soluções compromissos chegam ao meio termo em relação à solução ótima. 
Com o objetivo de obter a distância entre cada ponto eficiente e a solução ótima, Zeleny propõe utilizar a seguinte família de funções de distância:

$$
L_{\alpha}=\left[\sum_{i=1}^{p}\left(W_{i}\left|Z_{i}^{*}(X)-Z_{i}(X)\right|\right)^{\alpha}\right]^{1 / \alpha}
$$

Onde,

$\alpha=1,2, \ldots, \infty$

$\mathrm{p}=$ número de objetivos considerados;

$\mathrm{W}_{\mathrm{i}}=$ coeficiente de ponderação do i-ésimo objetivo. Indica a importância relativa da discrepância entre o i-ésimo objetivo e o ponto ideal;

$Z_{\mathrm{i}}=$ solução eficiente; $\mathrm{e}$

$Z_{i}^{*}=$ solução ideal correspondente ao i-ésimo objetivo.

Quando os objetivos são quantificados em unidades diferentes, torna-se necessária a homogeneização de seus desvios absolutos. Assim, a distância métrica ao ponto ideal é obtida pela expressão:

$$
L=\left[\sum_{i=1}^{p} W_{i}\left|\frac{\mathrm{Zi}^{*}(X)-\mathrm{Zi}(\mathrm{X})}{\mathrm{Zi}^{*}(\mathrm{X})-\mathrm{Zi}^{* *}(\mathrm{X})}\right|^{\alpha}\right]^{1 / \alpha}
$$

Destas duas equações infere-se que quando aumenta o valor de a, diminui o de $L_{a}$, porque $L_{1}$ é a maior distância métrica e $L \infty$ é a menor. Por isto, definindo-se apenas $L_{1}$ e L $\infty$ obtêm-se o segmento da curva de "trade-off" em que estão compreendidas todas as soluções compromissos. Assim, para valores de a entre 1 e $\infty$, a solução compromisso está compreendida entre $L_{1}$ e $L \infty$. 
Na Programação Compromisso, a família de funções de distância, L e L $\alpha$, usa $\alpha=1$ para a distância mais longa, $\alpha=2$ para a distância mais curta, no sentido geométrico, isto é distância euclidiana, e $\alpha=\infty$ para a distância TChebycheff. É interessante observar que conforme o parâmetro $\alpha$ vai aumentando, é atribuído um peso maior ao $\mathrm{Z}_{\mathrm{i}}$ com desvio maior. Desta forma, para $\alpha=\infty$, a Programação Compromisso limita-se a minimizar o desvio máximo. Diferentes soluções compromissos podem ser geradas para diferentes valores de $\alpha \mathrm{e}$ p.

\section{Modelo matemático da Programação Compromisso:}

$\operatorname{Min} \mathrm{L}_{1}=\sum_{\mathrm{i}=1}^{\mathrm{p}} \mathrm{W}_{\mathrm{i}}\left|\mathrm{Z}_{\mathrm{i}}^{*}(\mathrm{X})-\mathrm{Z}_{\mathrm{i}}(\mathrm{X})\right|$

Sujeito a

$\mathbf{X} \in \mathbf{x}$

$\operatorname{Min} L_{\infty}$

Sujeito a

$\mathbf{X} \in \mathbf{x}$

$\mathrm{W}_{\mathrm{i}}\left|\mathrm{Z}_{\mathrm{i}}^{*}(\mathrm{X})-\mathrm{Z}_{\mathrm{i}}(\mathrm{X})\right| \leq \mathrm{L} \infty$

$\mathrm{i}=1,2, \ldots, \mathrm{p}$

Exemplo 7 - Programação Compromisso

Usando os dados da matriz de "Pay-off", Tabela 3, calcula-se a melhor solução compromisso para as distâncias métricas $L_{1}$ e $L \infty$, formulando os problemas de Programação Linear:

A) Métrica $\mathrm{L}_{1}$

$$
\operatorname{Min} L_{1}=W_{1} \frac{166836,7375-Z_{1}(X)}{166836,7375-62500}+W_{2} \frac{Z_{2}(X)-4000}{11897,96-4000}
$$

Simplificando a equação da função objetivo, tem-se:

$\operatorname{Min} L_{1}=0,1105479 X_{1}+0,104898 X_{2}$ 
Sujeito a

$\mathbf{X} \in \mathbf{X}$

A solução para $W_{1}=W_{2}$ é o ponto $B\left(X_{1}=26,18\right.$ e $\left.X_{2}=0\right)$ ou B'.

B) Métrica $L \infty$

$\operatorname{Min} \mathrm{L}_{\infty}=\mathrm{d}$

Sujeito a

$\mathbf{X} \in \mathbf{x}$

$W_{1} \frac{166836,7375-Z_{1}(X)}{166836,7375-62500} \leq d$

$\mathrm{W}_{2} \frac{\mathrm{Z}_{2}(\mathrm{X})-4000}{11987,96-4000} \leq \mathrm{d}$

Simplificando as equações, tem-se:

$\operatorname{Min} \mathrm{L}_{\infty}=0,059902 \mathrm{X}_{1}+0,04792 \mathrm{X}_{2}$

Sujeito a

$\mathbf{X} \in \mathbf{X}$

$0,110548 X_{1}+0,104898 X_{2}=2,105022$

Onde,

$\mathrm{d}=$ maior desvio $\left(\mathrm{Z}_{\mathrm{i}}^{*}-\mathrm{Z}_{\mathrm{i}}^{* *}(\mathrm{X})\right)$.

Neste exemplo, $d=166836,7375-62500=104336,7375$

A solução para $\mathrm{W}_{1}=\mathrm{W}_{2}$ é o ponto $Z^{\prime}$, onde $\mathrm{VPL}=119000$ e Mão-de-obra eventual $=7616$ horas, que corresponde ao ponto $X_{1}=19,04$ e $X_{2}=0$. Portanto, a melhor solução compromisso está no intervalo Z'B'. Parametrizando $\mathrm{W}_{\mathrm{i}}$, obtêm-se informações sobre a estabilidade desta solução e o intervalo que a solução compromisso pode ser definida. 


\section{A1 - 4.2.6 Técnicas Interativas}

Outra forma de escolher a solução ótima, entre os elementos do conjunto eficiente, consiste nas chamadas Técnicas Interativas. Essas técnicas se apoiam numa definição progressiva das preferências do tomador de decisão. Desta forma, se estabelece uma interação entre o modelo e tomador de decisão. A idéia básica destas técnicas consiste em conseguir que o analista se converta num mero intermediário entre o modelo (computador) e o tomador de decisão, de maneira que o primeiro "calcule" e o segundo "decida". A interação se concretiza numa espécie de conversação em que o TD se pergunta a cerca de suas preferências ou intercâmbios. Os Métodos Interativos mais conhecidos se devem a Benayoun et al. (1971), Geoffrion et al. (1972), Grauer \& Wierzbicki (1984), Zionts \& Wallenius (1976), Steuer (1986) e Arias (1989).

\section{A1 - 4.2.6.1 Método STEP (STEM)}

A aplicação deste método, proposto por Benayoun et al. (1971), permite obter soluções eficientes de maneira interativa com o tomador de decisão de acordo com suas indicações. Esse método usa o conceito de distância geométrica, sendo a menor distância a melhor solução para um problema multicritério. Portanto, a $L_{\sharp}$ é usada como medida da distância ao ponto ideal. Os objetivos são normalizados previamente, segundo um coeficiente de ponderação baseado na diferença do ideal menos o anti-ideal. E, deve ser considerado que o conjunto de soluções possíveis pode ser modificado em cada interação do programa.

As fases do algoritmo do método STEM para obter soluções eficientes são:

(1) Construção da matriz de "pay-off', resolvendo os problemas de Programação Linear dado pelo modelo matemático:

Opt $Z_{\mathrm{i}}(\mathrm{X})$

Sujeito a

$\mathbf{X} \in \mathbf{x}$

(2) Determinação dos pesos relativos de cada objetivo a partir da matriz de "pay-off". 
A importância relativa de cada objetivo, $\mathrm{h}_{\mathrm{i}}$, é função da variação frente ao seu ideal.

$$
\eta_{i}=\frac{\alpha_{i}}{\sum_{i=1}^{p} \alpha_{i}}
$$

Para,

$$
\alpha_{i}=\left|\frac{\mathrm{Zi}^{*}(\mathrm{X})-\mathrm{Zi}^{* *}(\mathrm{X})}{\mathrm{Zi}^{*}(\mathrm{X})}\right|\left|\sum_{\mathrm{j}=1}^{\eta} \mathrm{C}_{\mathrm{ij}}^{2}\right|^{-1 / 2}
$$

Onde,

$Z_{i}^{*}(X)=$ ideal do i-ésimo objetivo obtido resolvendo o problema de Programação Linear da primeira fase

$Z_{i}^{* *}(X)=$ anti-ideal do i-ésimo objetivo quando se otimizam os objetivos restantes.

$\mathrm{C}_{\mathrm{ij}}=$ coeficiente da variável $\mathrm{j}$ no i-ésimo objetivo.

(3) Obtenção da primeira solução eficiente. A primeira solução não dominada que se gera é a mais próxima do ideal, considerando o peso relativo de cada objetivo, resolvendo o problema:

Min d

Sujeito a

$\mathbf{X} \in \mathbf{x}$

$\eta_{\mathrm{i}}\left|\mathrm{Z}_{\mathrm{i}}^{*}(\mathrm{X})-\mathrm{Z}_{\mathrm{i}}(\mathrm{X})\right| \leq \mathrm{d}$

$\mathrm{i}=1,2, \ldots, \mathrm{p}$

As soluções geradas, nesta fase, são analisadas pelo tomador de decisão que as comparam com sua solução ideal e obtém um dos três resultados: 
(a) os objetivos alcançam valores não satisfatórios. Neste caso, o problema carece de solução ou deve-se aplicar outro método para gerar soluções não dominadas;

(b) todos os objetivos são atingidos em níveis satisfatórios. Neste caso, a solução obtida é a ótima;

(c) apenas alguns objetivos alcançam níveis satisfatórios. Neste caso, deve se obter novas soluções eficientes. O tomador de decisão escolhe o nível de sacrificio dos objetivos satisfatórios para melhorar os valores dos que não o foram. Em conseqüência, o conjunto de objetivos se particiona em dois subconjuntos: $\mathbf{O}_{\mathrm{S}}$ (formado pelos objetivos que alcançam um nivel satisfatório) e $\mathbf{O}_{\mathrm{I}}$ (formado pelos objetivos que não alcançam níveis satisfatórios).

O novo problema a resolver, tem o modelo matemático:

Min d

Sujeito a

$\mathbf{X} \in \mathbf{x}$

$\forall \eta_{\mathrm{i}}\left|\mathrm{Z}_{\mathrm{i}}^{*}(\mathrm{X})-\mathrm{Z}_{\mathrm{i}}(\mathrm{X})\right| \leq \mathrm{d} ; \forall \mathrm{Z}_{\mathrm{i}} \in \mathrm{O}_{\mathrm{I}}$

$\forall \mathrm{Z}_{\mathrm{k}}(\mathrm{X}) \geq \mathrm{C}_{\mathrm{k}} ; \forall \mathrm{Z}_{\mathrm{k}} \in \mathbf{O}_{\mathrm{S}}$

$\forall \mathrm{Z}_{\mathrm{i}}(\mathrm{X}) \geq \mathrm{C}_{\mathrm{i}} ; \forall \mathrm{Z}_{\mathrm{i}} \in \mathbf{O}_{\mathrm{I}}$

$\mathrm{i}=1,2, \ldots, \mathrm{p}$

Onde,

$\mathrm{C}_{\mathrm{k}}=$ valor mínimo exigido pelo $\mathrm{k}$-ésimo objetivo.

$\mathrm{C}_{\mathrm{i}}=$ valor alcançado pelo i-ésimo objetivo na última integração.

A solução assim obtida é novamente analisada pelo tomador de decisão que pode, outra vez, encontrar-se na situações (a), (b) ou (c) acima descritas. 


\section{A1 - 4.2.6.2 Método "Surrogate Worth Trade-off” (SWT)}

O Método "Surrogate Worth Trade-off" - SWT - é interativo por necessitar da intervenção do tomador de decisão. O SWT foi desenvolvido por Haimes \& Hall (1974) e seu propósito é a determinação da solução compromisso ótima na qual o tomador de decisão é indiferente a melhoria de um objetivo (i) a custa da piora de outro objetivo (j), para todo i diferente de j. Para que isso ocorra, todas as "funções surrogate" são nulas.

Seu algoritmo parte da matriz de "pay-off" e tem as seguintes fases:

(1) Geração de soluções. Aplica-se o método das restrições que, para o caso de minimização de objetivos, apresenta o modelo matemático:

$\operatorname{Min} Z_{i}(X)$

Sujeito a

$\mathbf{X} \in \mathbf{x}$

$Z_{j}(X)=L_{j} ; j \neq i, \quad j=1,2, \ldots, p$

$\mathrm{Z}_{\mathrm{k}}(\mathrm{X}) \leq \mathrm{L}_{\mathrm{k}} ; \mathrm{k} \neq \mathrm{i} \mathrm{j} ; \mathrm{k}=1,2, \ldots, \mathrm{p}$

O problema geral se reduz a um problema bicritério, onde:

$$
\begin{aligned}
& L_{j}=Z_{j}^{*}(X)+I_{j}, \quad I_{j} \in\left[0,\left|Z^{* *}(X)-Z_{j}^{*}(X)\right|\right] \\
& L_{k} \in\left[Z^{*}{ }_{k}(X)-Z^{* *}{ }_{k}(X) \mid\right]
\end{aligned}
$$

Fazendo a parametrização de $\mathrm{I}_{\mathrm{j}}$ e mantendo constantes os $\mathrm{L}_{\mathrm{k}}$, são obtidas as relações de "trade-off" entre $Z_{i}(X)$ e $Z_{j}(X)$, ou seja, $U_{i j}$.

(2) Determinação de soluções eficientes.

Em virtude do teorema da complementaridade dos problemas duais, $\mathrm{U}_{\mathrm{ij}}$ será diferente de zero na medida em que se verifique $Z_{j}(X)=L_{j}$. Isto implica que a melhora de $U_{i j}$ unidades em $Z_{\mathrm{i}}(X)$ pode ser obtida mediante o sacrificio de uma unidade de $Z_{\mathrm{j}}(X)$. Se, pelo contrário, $\mathrm{U}_{\mathrm{ij}}=0$, então não é possível melhorar o valor do objetivo (i) a custa de sacrificar o valor de 
$Z_{j}(X)$. Conseqüentemente, são soluções ativas ou não dominadas aquelas que satisfazem $\mathrm{U}_{\mathrm{ij}}{ }^{1} 0$, para um valor dado de $\mathrm{L}_{\mathrm{j}}$. Os valores de $\mathrm{U}_{\mathrm{ij}}{ }^{1} 0$, obtidos por parametrização de $\mathrm{I}_{\mathrm{j}}$, podem ser interpretados como taxas de "trade-off" entre os objetivos, ao indicar em quanto pode ser melhorado o objetivo (i) a custa da piora em uma unidade de valor do objetivo $\mathrm{j}$.

A partir das taxas de "trade-off" $\left(\mathrm{U}_{\mathrm{ij}}\right)$, usando a análise de regressão linear, pode-se ajustar funções de "trade-off", do tipo:

$$
\begin{aligned}
& \mathrm{U}_{\mathrm{ij}}=\mathrm{F}\left[\mathrm{Z}_{\mathrm{j}}(X)\right] \\
& \mathrm{U}_{\mathrm{ij}}=\mathrm{f}\left[\mathrm{Z}_{1}(X), Z_{2}(X), \ldots, Z_{\mathrm{i}+1}(X), \ldots Z_{\mathrm{p}}(X)\right] \\
& \forall \mathrm{i} \neq \mathrm{j}
\end{aligned}
$$

Estas funções refletem as relações de "trade-off' entre cada par de objetivos $(i, j)$, sendo úteis para conhecer os subconjuntos de curvas de "trade-offs" e para generalizar a atitude do tomador de decisão frente à relação de intercâmbio entre objetivos.

(4) Determinação da função de "Surrogate Worth".

A comparação dos valores dos objetivos, obtidos na fase de determinação de soluções eficientes, com as funções de "trade-off', permite ao tomador de decisão decidir ou não pelo sacrificio de uma unidade de $Z_{j}(X)$ em troca da melhora de $Z_{i}(X)$ em $U_{i j}$ unidades, permanecendo constantes os valores dos demais objetivos. As respostas do tomador de decisão são quantificadas numa escala de valores que varia de -10 e +10 . Se o tomador de decisão está disposto a sacrificar mais de uma unidade de $Z_{\mathrm{j}}$ para melhorar em $\mathrm{U}_{\mathrm{ij}}$ unidades o valor de $Z_{\mathrm{i}}$, sua resposta será positiva e, caso contrário será negativa. A quantificação do valor atribuído à resposta depende da maior ou menor disposição ao sacrificio de $Z_{\mathrm{j}}$ em troca de uma melhora em $Z_{\mathrm{i}}$. Estando mais próxima de +10 quanto maior a disposição e mais próxima de -10 quanto menor for a disposição do TD.

$\mathrm{O}$ valor atribuído à cada resposta, $\mathrm{W}_{\mathrm{ij}}$, é denominado de "Surrogate Worth" e é uma função de $Z_{j}$, já que $U_{i j}$ varia com $Z_{j}$. A função $W_{i j}\left(Z_{j}\right)$ é chamada de Função de "Surrogate Worth" e permite determinar o intervalo de indiferença e, Conseqüentemente, a solução ótima. O intervalo de indiferença é dado pelos valores dos objetivos que anulam as 
Funções de "Surrogate". Conhecendo-se tais valores, a solução ótima é obtida resolvendo o problema:

$\operatorname{Min} Z_{i}(X)$

Sujeito a

$\mathbf{X} \in \mathbf{x}$

$Z_{j}(X) \leq Z_{j}^{+}(X) ; \forall i \neq j ; j=1,2, \ldots, p$

Onde, $Z_{j}^{+}(X)=$ valor do objetivo j que anula a função de "surrogate", ou seja, $W_{i j}\left(Z_{j}\right)=0$.

\section{A1 - 4.2.6.3 Método de Ponderações Recursivas}

O Método de Ponderações Recursivas de Programação Multicritério foi proposto por Arias (1989) com o propósito da informação requerida do tomador de decisão ser o mais elementar possível e o processo algorítmico de soluções usar um tempo computacional reduzido. O método baseia-se na ponderação de objetivos normalizados, correlacionando esta ponderação com a distância geométrica entre o valor obtido de cada objetivo em cada interação e o valor ideal segundo as preferências do tomador de decisão, ou seja, atribui significado geométrico ao vetor de ponderações.

$\mathrm{O}$ algoritmo se estrutura nas seguintes fases:

(1) Determinação da matriz de "pay-offs" conforme o modelo matemático:

Opt $Z_{k}(X)$

Sujeito a

$\mathbf{X} \in \mathbf{x}$

$\forall \mathrm{k} \in \mathbf{J}$ 
Onde,

$Z_{\mathrm{k}}=$ Função do $k$-ésimo objetivo

$\mathbf{J}=$ Conjunto de objetivos que em cada interação se divide em dois subconjuntos: $\mathbf{J}_{\mathbf{s}}^{\mathrm{i}}$ constituído pelos objetivos cujos níveis alcançados o tomador de decisão não pretende melhorar e $\mathbf{J}_{\mathbf{n}}{ }^{\mathrm{i}}$ constituído pelos objetivos cujos níveis são insatisfatórios.

(2) Se não existe nenhum vetor de soluções considerado satisfatório, então, determina-se nova solução eficiente atribuindo aos objetivos ponderações iguais, tal que $\mathrm{W}_{\mathrm{j}}^{\mathrm{o}}=1$, e resolvendo o modelo matemático:

Opt $\sum_{j=1}^{p} W_{j}^{o} \cdot Z_{j}(X)$

Sujeito a

$\mathbf{X} \in \mathbf{x}$

(3) A valoração da solução anterior que, no caso de ser considerada não satisfatória pelo TD, origina uma divisão do conjunto de objetivos (J) em conjunto de objetivos não melhoráveis $\left(\mathbf{J}_{\mathbf{s}}{ }^{\mathrm{i}}\right)$ e conjunto de objetivos insatisfatórios $\left(\mathbf{J}_{\mathbf{n}}{ }^{\mathrm{i}}\right)$.

Considera-se que um objetivo é não melhorável quando o tomador de decisão está de acordo com o nível alcançado ou não está disposto a piorá-lo a custa de melhora em outros objetivos. Esse nível alcançado se denomina valor ou nível de conformidade e se caracteriza por ser subjetivo e dinâmico, já que é estabelecido pelo tomador de decisão e pode ser modificado em cada interação, produzindo a translação do valor ideal para o valor de conformidade.

(4) Cálculo do valor $D^{i}$. Em função dos valores ideal $\left(Z_{j}^{*}\right)$, anti-ideal $\left(Z_{j}^{* *}\right)$ e de conformidade ( $Z_{j}^{s}$ ) são gerados um valor $\mathbf{D}_{j}^{i}$ para cada objetivo, que indica a distância normalizada entre o ideal e o nível de conformidade. Assim, para os objetivos contidos no conjunto $\mathrm{J}_{\mathrm{s}}^{\mathrm{i}}$, são definidos os valores de $\mathbf{D}_{\mathrm{j}}{ }^{i}$, conforme o modelo matemático: 


$$
\mathbf{D}_{j}^{i}=\frac{Z_{j}^{*}-\left(Z_{j}^{s}\right)^{i-h}}{Z_{j}^{*}-Z^{* *}{ }_{j}}
$$

Onde,

(i - h) é a interação em que o tomador de decisão manifestou seu último nível de conformidade para o objetivo j. Para os objetivos contidos em $\mathbf{J}_{j}{ }^{i}$, implica em $\mathbf{D}_{j}^{i}=0$, já que o valor de conformidade coincide com o ideal.

(5) No cálculo do grau de proximidade $\mathbf{R}_{j}^{i}$ da solução obtida para o objetivo $\mathbf{j}$ na interação ( $\mathrm{i}$ - 1) com respeito ao seu valor de conformidade ao ideal, usa-se a expressão:

$$
\begin{aligned}
& \mathbf{R}_{j}^{i}=\frac{Z_{j}^{*}-Z_{j}^{i-1}}{Z_{j}^{*}-Z_{j}^{* *}}-\mathbf{D}_{j}^{i} \\
& \forall j \in J ; \quad \mathbf{R}_{j}^{i} \in \mathfrak{R}
\end{aligned}
$$

(6) Determinação das ponderações dos objetivos $\left(W_{j}^{i}\right)$. Tendo em conta os graus de proximidade $\left(\mathbf{R}_{\mathbf{j}}{ }^{j}\right)$ de interações anteriores, definem-se as ponderações para i-ésima interação, usando:

$$
\mathrm{Wij}_{\mathrm{ij}}=\sum_{\mathrm{i}=0}^{\mathrm{n}} \mathbf{R}_{\mathrm{j}}^{\mathrm{i}} \quad \forall \mathrm{j} \in \mathbf{J}
$$

Desta forma, o objetivo $\mathrm{j}$ terá maior ponderação quanto maior for sua distância do ideal ao valor de conformidade, atribuindo-se, assim, mais importância na melhora deste objetivo. Este método não exige que a soma dos pesos seja igual a 1 , devido à normalização ser equivalente a dividir a função objetivo por uma constante, o que não afeta as soluções. 
(7) A resolução do problema correspondente a i-ésima interação é feita com o modelo matemático:

$$
\operatorname{Opt} \sum_{j=1}^{p} W_{j}^{i} X Z_{j}(X)
$$

Sujeito a

$\mathbf{X} \in \mathbf{x}$

(8) Apresentação ao tomador de decisão da solução gerada. No caso da solução não ser considerada satisfatória, então:

(a) O tomador de decisão não quer modificar seus valores de conformidade nem adicionar objetivos ao subconjunto $\mathbf{J}_{\mathbf{s}}{ }^{\mathrm{i}}$. Portanto, não existe solução satisfatória.

(b) $\mathrm{O}$ tomador de decisão quer modificar o subconjunto $\mathbf{J}_{\mathbf{s}}{ }^{\mathrm{i}}$. Então, aplica-se novamente o algoritmo a partir da fase 3 .

Esse método converge para uma solução final quando a solução é satisfatória, ou seja, o TD manifesta sua conformidade com os valores obtidos:

$$
\mathbf{R}_{\mathrm{j}}^{\mathrm{i}+1}=0, \forall \mathrm{j}, \mathrm{j} \in \mathbf{J}_{\mathrm{s}}^{\mathrm{i}+1} \text { e } \mathbf{J}=\mathbf{J}_{\mathrm{s}}^{\mathrm{i}+1}
$$

Portanto, verifica-se que a partir desta interação todas ponderações posteriores são iguais, isto é:

$$
\mathrm{W}_{\mathrm{j}}^{\mathrm{i}}=\mathrm{W}_{\mathrm{j}}^{\mathrm{i}+1}=\mathrm{W}_{\mathrm{j}}^{\mathrm{i}+2}
$$




\section{A1 - 5 REFERÊNCIAS BIBLIOGRÁFICAS}

ARIAS, P. El método de ponderaciones recursivas de programación multicriterio y sua aplicación a la planificacion agraria. Madri. Investigacion Agraria: Economia, v.4, n.2, p.175-190, 1989.

BENAYOUN, R.J.; DE MONTGOLFIER, J.T.; TERGNY, J. \& LARITCHEV O. Linear programming with multiple objective functions: Step Method (STEM). Mathematical Programming, v.1, n.3, p.366-375, 1971.

CHARNES, A. \& COOPER, W.W. Management models and industrial applications of linear programming. New York, Ed. John Wiley \& Sons, 1961. v.I, 467p. e v.II (Apêndice B).

CHARNES, A.; COOPER, W.W. \& FERGUSON, R. Optimal estimation of executive compensation by linear programming. Management Science, v.1, p. 138-151, 1955.

COHON, J. L. Multiobjective programming and planning. New York, Ed. Academic Press, 1978. 333p.

GEOFFRION, A.M.; DYER, J.S. \& FEINBERG, A. An interactive approach for multicriterion optimization, with an application to the operation of an academic department. Management Science, v. 19, n.4, p.357-368, 1972.

GOICOCHEA, A.; HANSEN, D.R. \& DUCKSTEIN, L., Multiobjective decision analysis with engineering bussiness applications. New York, Ed. John Wiley \& Sons, 1982.

GRAUER, M. \& WIERZBICKI, A.P. (Ed.) Interactive decision analysis. Berlin, Ed. Springer-Verlag, 1984. 
HAIMES, Y.Y. \& HALL, W.A. Multiobjectives in water resources systems analysis: The Surrogate Worth Trade-off Method. Water Resources Research, v.10, p.615-623, 1974.

HAIMES, Y.Y. \& CHANKONG, V. (Ed.) Decision making with multiple objectives, Lecture Notes in Economics and Mathematical Systems, Berlin, Springer, v.242, 1985.

HEADY, E.O. Economics of agricultural production and resource use. Englewood Cliffs, N.J.: Prentice-Hall, 1970.

HWANG, C. \& MASUD, A. Multiple objective decision making, methods and applications. Berlin, Ed. Springer-Verlag, 1979. 182p.

IGNIZIO, J.P. Goal programming and Extensions. Massachusetts, Ed. Lexington Books, 1976. 216p.

IJIRI Y. Management goals and accounting for control. Holanda, North-Holland Publishing Company, 1965, 19lp.

KUHN, H. \& TUCKER, A. Nonlinear programming. Proc. Berkeley Symp. Math. Statist. Probability. Berkeley, Univ. of California Press, p.481-492, 1951.

LEE, SANG M. Goal programming for decision analysis. Philadelphia, Ed. Auerbach Publishers, 1972. 387p.

MARGLIN, S.A. Public investiment criteria. Cambridge, Massachusetts, MIT Press, 1967.

OLSON, D.L. Comparison for four goal programming algorithms. Journal of the Operational Research Society, v.35, p.347-354, 1984. 
PHILIP J., Algorithms for the vector maximization problem. Mathematical Programming, v.2, n.2, p.207-229, 1972.

REHMAN, T. \& ROMERO, C. The application of the MCDM paradigm to the management of agricultural systems: Some basic considerations. Agricultural Systems, v.41, n.3, p.239-255, 1993.

ROMERO, C. \& REHMAN, T. Goal programming via multidimensional scaling applied to Senegalese subsistence farming: Comment. American Journal of Agricultural Economics. v.65, n.4, p.829-831, 1983.

ROMERO, C. \& REHMAN, T. Agricultural decisions analysis with multiple criteria. Developments in Agricultural Economics N.5, Amsterdam, Elsevier Science Publishers, 1989. $257 \mathrm{p}$.

SIMON, H.A. A behavioural model of rational choice. Quarterly Journal of Economics, v.69, p.99-118, 1955.

SIMON, H.A. Models of Man. New York: John Wiley \& Sons, 1957.

STEUER, R. E. Multiple criteria optimization: theory, computation and application. New York, Ed. John Wiley and Sons, 1986.

WALLENIUS J. Comparative evaluation of some interactive approaches to multicriterion optimization. Managment. Science, v.21, p.1387-1396, 1975.

YU, P. L. A class of solutions for group decision problems. Management Science, v.19, n.8, p.936-946, 1973. 
ZADEH, L.A. Optimality and non-scalar-valued performance criteria. IEEE Transactions on Automatic Control, AC-8, p.56-60, 1963.

ZELENY, M. Compromise programming. In: Eds. COCHRANE, J.L e ZELENY, M. Multiple Criteria Decision Making. University of South Carolina Press, 1973. p.262301.

ZELENY, M. A concept of compromise solutions and the method of the displaced ideal. Computers and Operations Research, v.1, p.479-496, 1974.

ZELENY, M. Linear multiobjective programming. Lectures Notes in Economics and Mathematical Systems, 95. Springer-Verlag, 1974.

ZELENY, M., Multiple criteria decision making. Kyoto - 1975. Lectures Notes in Economics and Mathematical Systems, 123, Springer-Verlag. 1976, 345p.

ZELENY, M. Multiple criteria decision making. New York, McGraw $\quad$ HILL, 1982. Cap. 9.

ZIONTS, S. Multiple criteria problem solving. Berlin, Springer-Verlag, 1978. 481p.

ZIONTS, S. \& WALLENIUS, J. An interactive programming method for solving the multiple criteria problem. Management Science, v.22, n.6, p.652-663, 1976. 
APÊNDICE 2

EQUAÇÕES DAS FUNÇÕES OBJETIVOS, METAS E RESTRIÇÕES 


\section{Legenda das siglas das equacões}

\section{Funcões Objetivos:}

MIN LEX $Z_{\mathrm{h}}=$ processo de minimização lexicográfica dos desvios (n, p);

$\mathrm{h}=$ nível de prioridade para cada objetivo, $\mathrm{h}=1, \ldots, 6$;

$\mathrm{n}_{1}, \ldots, \mathrm{n}_{6}=$ desvios negativos;

$\mathrm{p}_{1}, \ldots, \mathrm{p}_{6}=$ desvios positivos.

\section{$\underline{\text { Metas: }}$}

$\mathrm{MB}$ = valor presente da margem bruta anualizada, para cada atividade (j), em US\$;

$\mathrm{VV}=$ valor de venda, em US\$;

$\mathrm{VC}=$ valor de compra, em US\$;

$\mathrm{BCI}_{\mathrm{g}}=$ balanço de mata ciliar na gleba g (classes V, VII e VIII);

$\mathrm{BTR}_{\mathrm{t}}=$ balanço de uso do trator no mês t;

$\mathrm{X}_{\text {gej }}=$ atividades (j), na gleba (g), época (e) das águas ou seca: culturas anuais (milho, feijão e amendoim nas épocas das águas e seca e arroz, época das águas, com tecnologias mecânica, manual e tração animal); culturas perenes (abacate, goiaba, mamão, manga, maracujá, limão taiti, tangerina, acerola, café, seringueira e eucalipto); pastagens (pasto de braquiária e capineira de Naipe); pecuária (corte e leite); matas (ciliar e de reserva) e atividades com tecnologia em uso na propriedade para a pecuária, pasto, culturas e florestas; $\mathrm{X}_{\mathrm{vt}}=$ atividades de venda: milho (épocas das águas e seca); animais (pecuária de corte e leite); leite (pecuária de leite); aluguel de trator para terceiros; prestação de serviços da mão-de-obra familiar para terceiros;

$X_{\mathrm{ct}}=$ atividades de compra: milho (nos meses 1 a 12); aluguel de trator de terceiros (nos meses 1 a 12); contratação de mão-de-obra residente (nos meses 1 a 12); contratação de mão-de-obra eventual (nos meses 1 a 12); 
$\mathrm{X}_{\mathrm{rt}}=$ atividades de transferência de excesso de caixa de um mês ( $\mathrm{t}$ ) para o mês seguinte $(\mathrm{t}+1)$

$\mathrm{J}_{\mathrm{t}}=$ taxa de juros mensal;

$\mathrm{X}_{\mathrm{k}}=$ variáveis de desvios positivo e negativo da mão-de-obra fixa;

$\mathrm{X}_{1}=$ variáveis de desvio positivo e negativo do fluxo de caixa;

$\mathrm{X}_{\mathrm{m}}=$ atividades de produção de alimentos básicos (arroz, milho, feijão, amendoim, carne e leite);

$\mathrm{VP}_{\mathrm{m}}=$ valor da produção dos alimentos básicos, em US\$;

$\mathrm{MOR}_{\mathrm{t}}=$ atividade de uso da mão-de-obra residente;

$\mathrm{MOF}_{\mathrm{t}}=$ atividade de uso da mão-de-obra familiar;

MAXMB = meta do objetivo de maximizar o lucro;

MINEMO = meta do objetivo de minimizar a estacionalidade do uso da mão-de-obra;

MINEFC = meta do objetivo de minimizar a estacionalidade do fluxo de caixa;

MAXVP = meta do objetivo de maximizar a produção de alimentos básicos;

MINDQ = meta do objetivo de minimizar o uso de defensivos químicos;

MAXMOP = meta do objetivo de maximizar o uso da mão-de-obra permanente (residente e familiar).

\section{Restricões:}

$\mathrm{X}_{\mathrm{gej}}=$ atividades ( $\mathrm{j}$ ) nas glebas ( $\mathrm{g}$ ) e nas épocas (e);

$\mathrm{b}_{\mathrm{g}}=$ disponibilidade de área nas glebas $(\mathrm{g})$;

$\mathrm{BCI}_{\mathrm{g}}$, = Balanço da Mata Ciliar e de Reserva, nas glebas (g' ');

$\mathrm{X}_{\mathrm{tj}}=\operatorname{atividades}(\mathrm{j})$ no mês $\mathrm{t}$;

$a_{t j}=$ coeficientes técnicos de uso de trator na atividade (j), no mês t;

$\mathrm{UTR}_{\mathrm{t}}=$ atividade de uso de trator, no mês $\mathrm{t}$;

$\mathrm{CTR}_{\mathrm{t}}=$ atividade de aluguel de trator de terceiros, no mês $\mathrm{t}$;

$a_{t \mathfrak{t j}}=$ coeficientes técnicos de uso de mão-de-obra na atividade $(j)$, no mês t; $\mathrm{VMOF}_{\mathrm{t}}=$ prestação de serviços da mão-de-obra familiar para terceiros, no mês $\mathrm{t}$; $\mathrm{CMOR}_{\mathrm{t}}=$ contratação de mão-de-obra residente, no mês $\mathrm{t}$; 
$\mathrm{CMOE}_{\mathrm{t}}=$ contratação de mão-de-obra eventual, no mês t; $\mathrm{MOF}_{\mathrm{t}}=$ atividade de mão-de-obra familiar, no mês $\mathrm{t}$;

$\mathrm{VTR}_{\mathrm{t}}=$ aluguel de trator para terceiros, com uso de mão-de-obra permanente, no mês t; $\mathrm{CMI}_{\mathrm{t}}=$ atividade de compra de milho, no mês $\mathrm{t}$;

$\mathrm{CTR}_{\mathrm{t}}=$ atividade de aluguel de trator de terceiros, no mês $\mathrm{t}$; $\mathrm{TFC}_{\mathrm{t}}=$ atividade de transferência de excesso de caixa, no mês $\mathrm{t}$; $\mathrm{TFMI}_{\mathrm{t}}=$ atividade de transferência de excesso de milho, no mês t; $\mathrm{VMI}_{\mathrm{t}}=$ atividade de venda de milho, no mês $\mathrm{t}$; $\mathrm{X}_{\mathrm{p}}=$ atividade de criação de gado de leite; VLT = atividade de venda de leite produzido; $\mathrm{dm}_{\mathrm{tj}}=$ desvio da mão-de-obra, na atividade (j), no mês t;

$\mathrm{BEMO}_{\mathrm{t}}=$ atividade de balanço da estacionalidade do uso da mão-de-obra, no mês $\mathrm{t}$; $\mathrm{df}_{\mathrm{tj}}=$ desvio do fluxo de caixa, na atividade (j), no mês $\mathrm{t}$; $\mathrm{BEFC}_{\mathrm{t}}=$ atividade de balanço da estacionalidade do fluxo de caixa, no mês $\mathrm{t}$. 


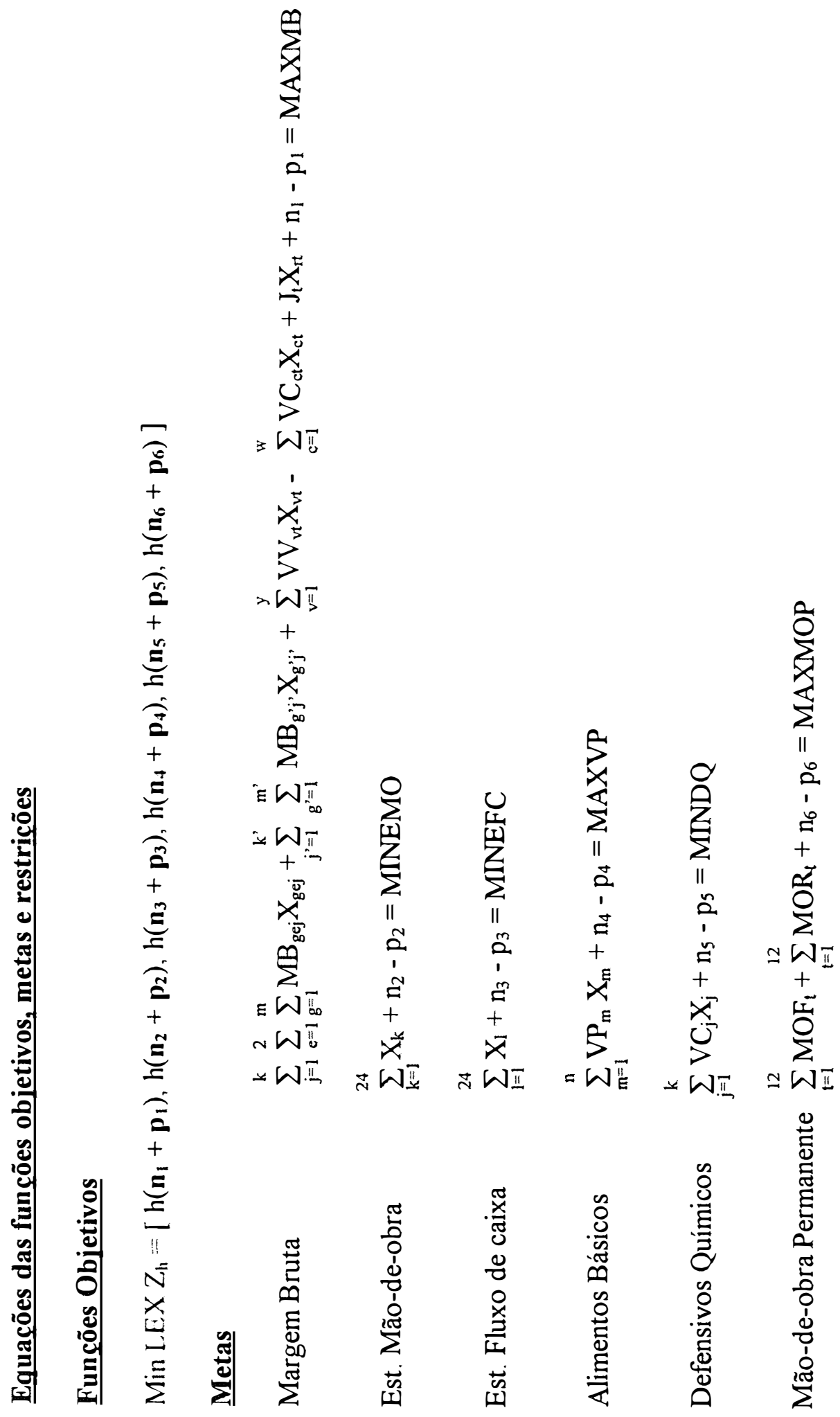



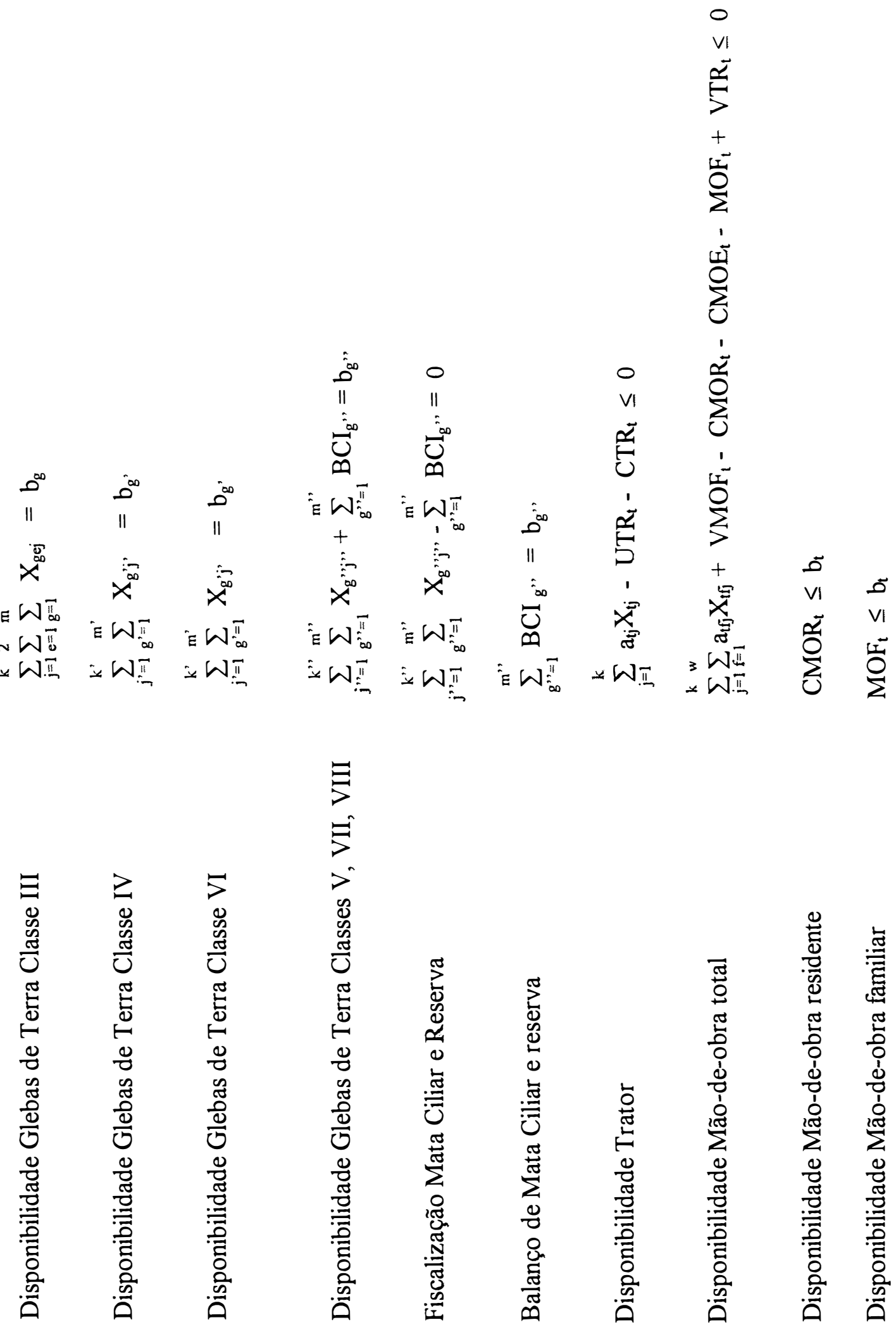


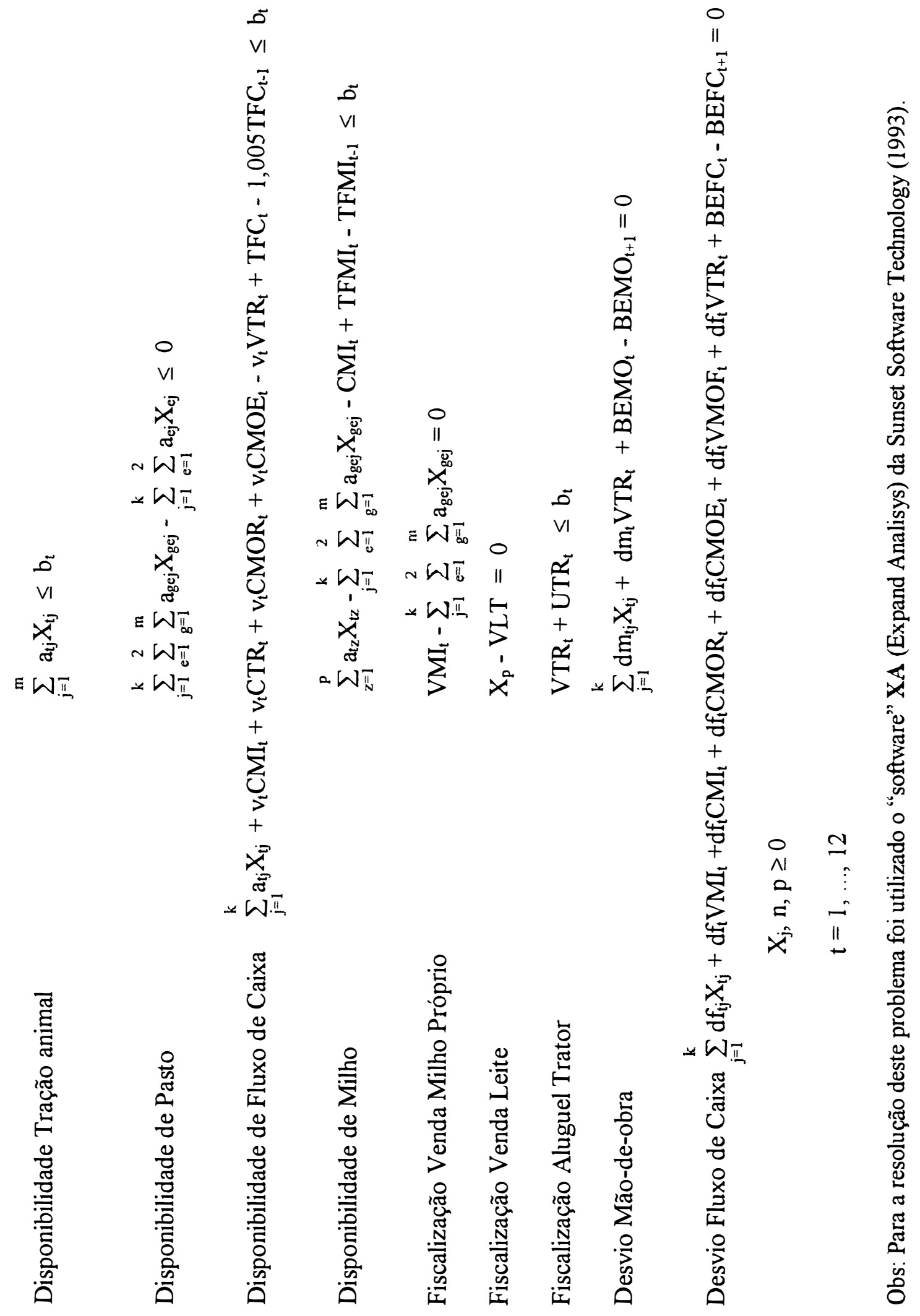


APÊNDICE 3

CARTÕES REPRESENTATIVOS DOS OBJETIVOS 
Objetivo considerado na escolha do que plantar e do que criar em cada gleba de terra de minha propriedade:

\section{AGROTÓXICOS, QUANTO MENOS MELHOR!}

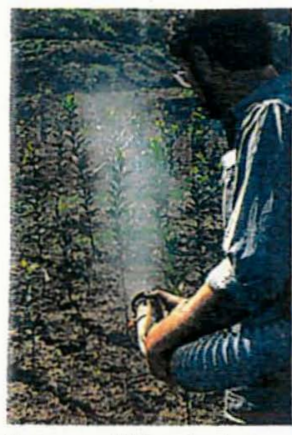

Lixões e pesticidas sảo alguns dos agentes poluidores.
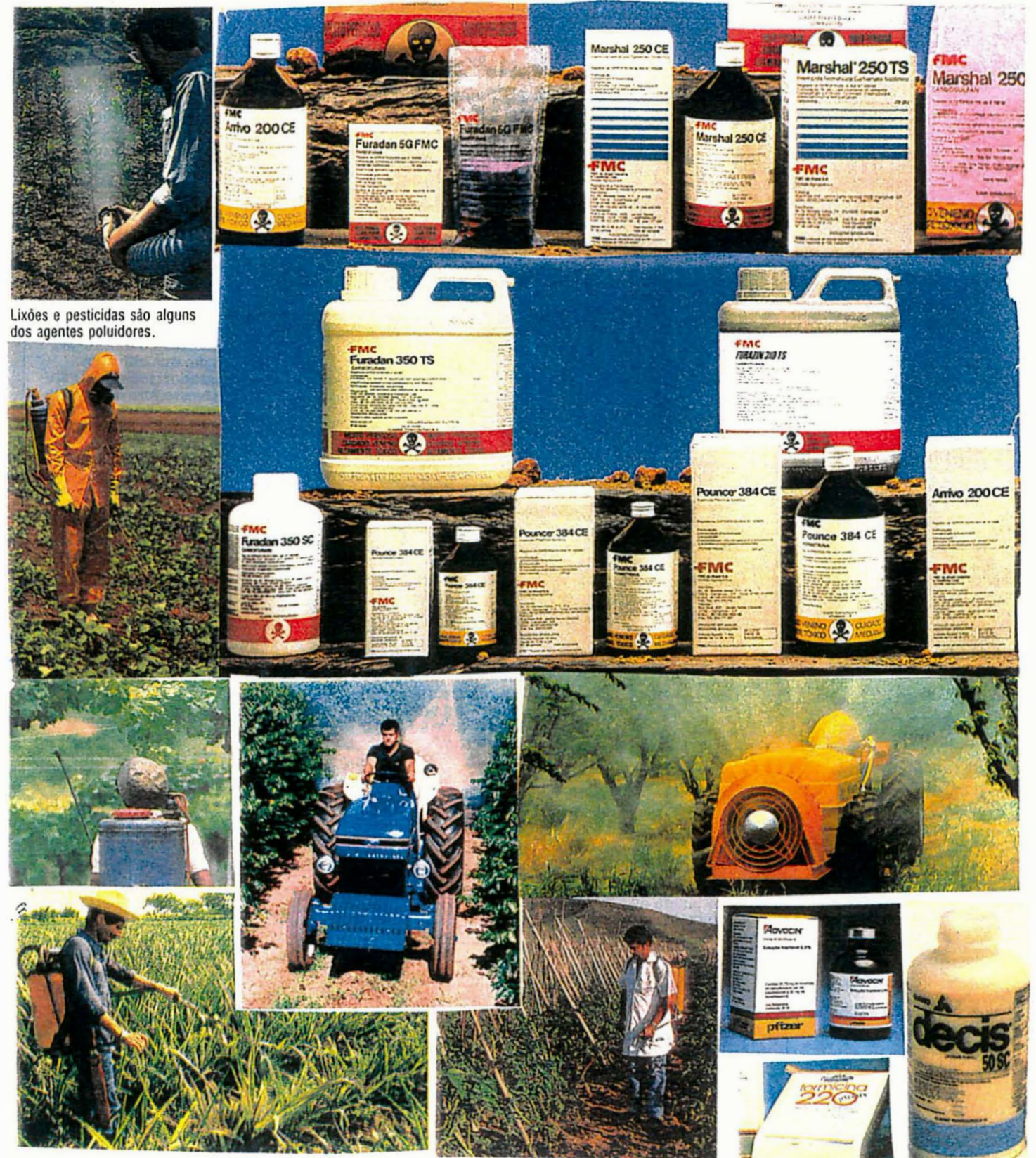

.
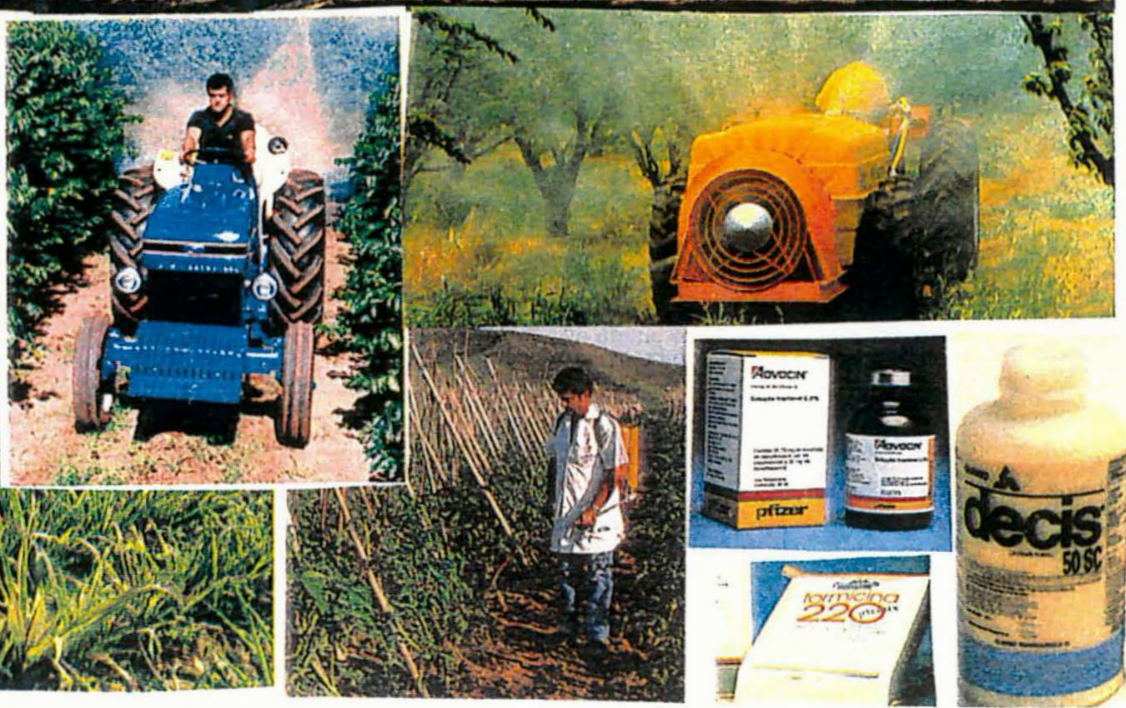

Figura 6- Cartão que ilustra o objetivo de minimizar o uso de defensivos agrícolas. 
Objetivo considerado na escolha do que plantar e do que criar em cada gleba de terra de minha propriedade:

\section{LUCRO, QUANTO MAIS MELHOR!}

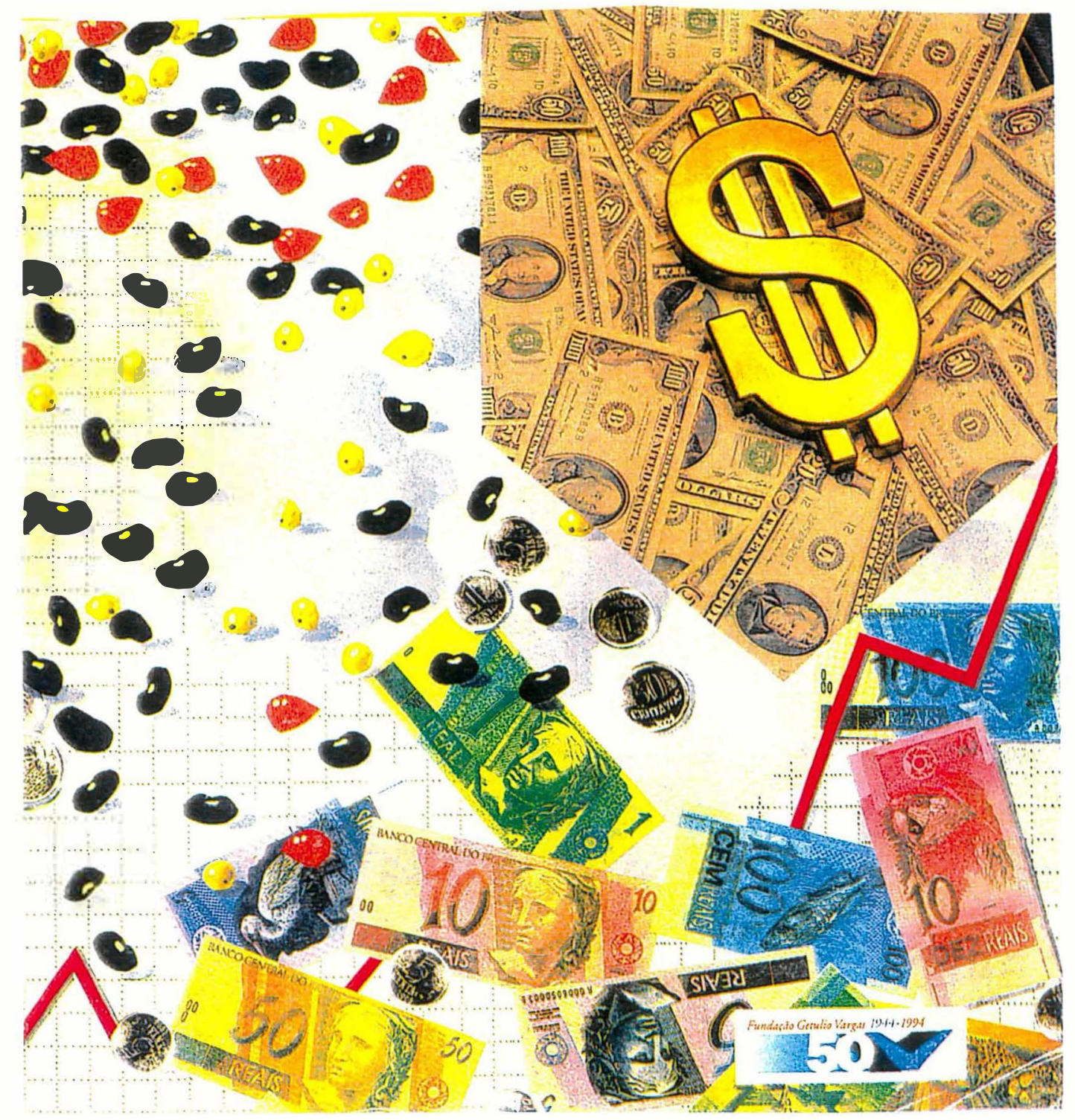

Figura 7- Cartão que ilustra o objetivo de maximizar o lucro. 
Objetivo considerado na escolha do que plantar e do que criar em cada gleba de terra de minha propriedade:

\section{ESTABILIDADE DA RENDA, QUANTO MAIS MELHOR!}

É MELHOR GANHAR TOQDO MES A MESMA QUUANTIA.

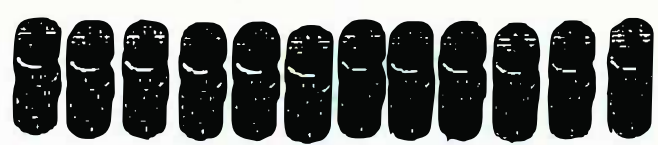

JAN FEV MAR ABR MAI JUN JUL AGO SET OUT NOV DEZ
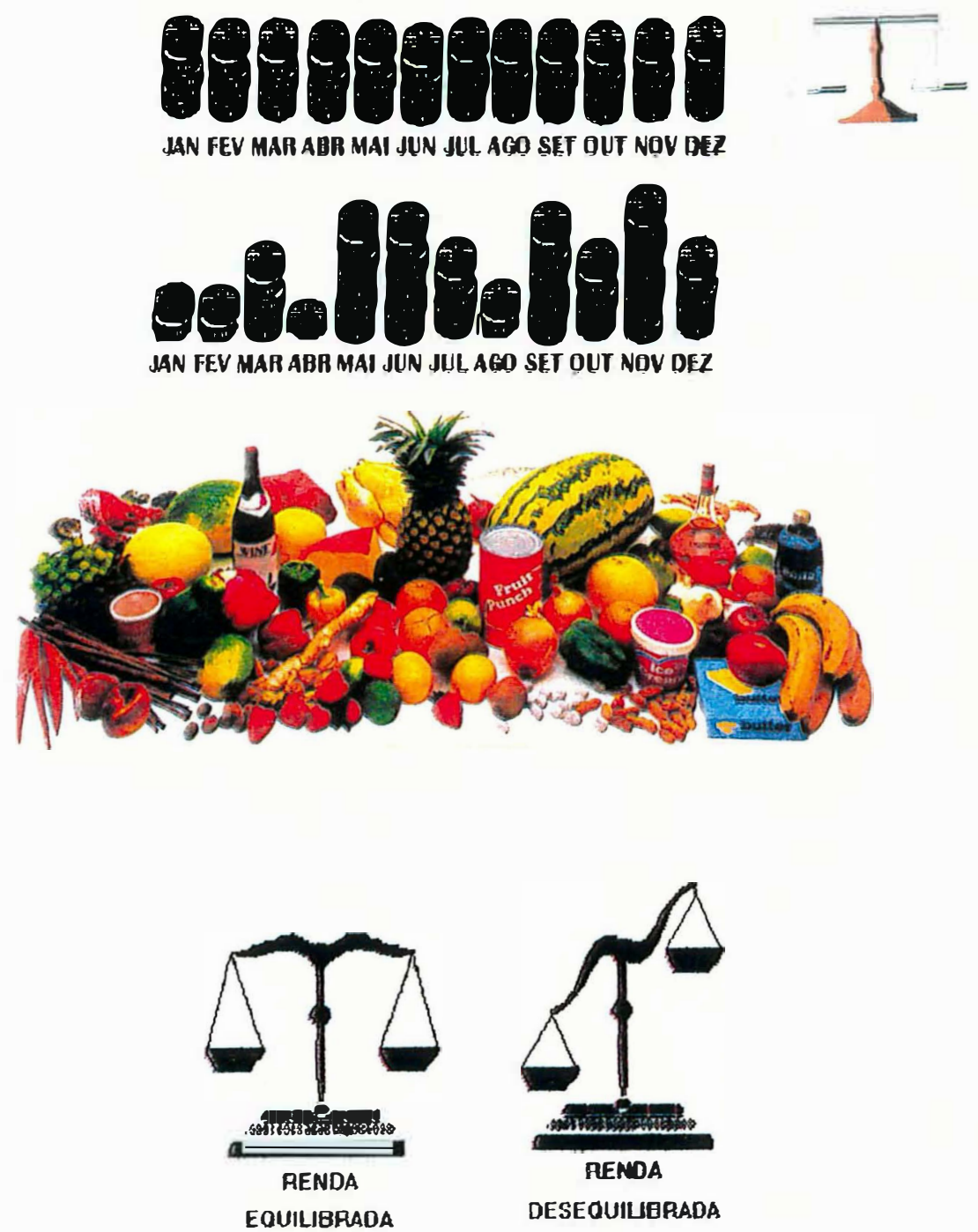

TODO ANO RENDA BOA É MELHOR

TER ANO MAUTO BOM ERUIM

É PIOR

Figura 8- Cartão que ilustra o objetivo de minimizar a estacionalidade do fluxo de caixa. 
Objetivo considerado na escolha do que plantar e do que criar em cada gleba de terra de minha propriedade:

\section{TER TRABALHO PARA A FAMÍLIA, QUANTO MAIS MELHOR!}
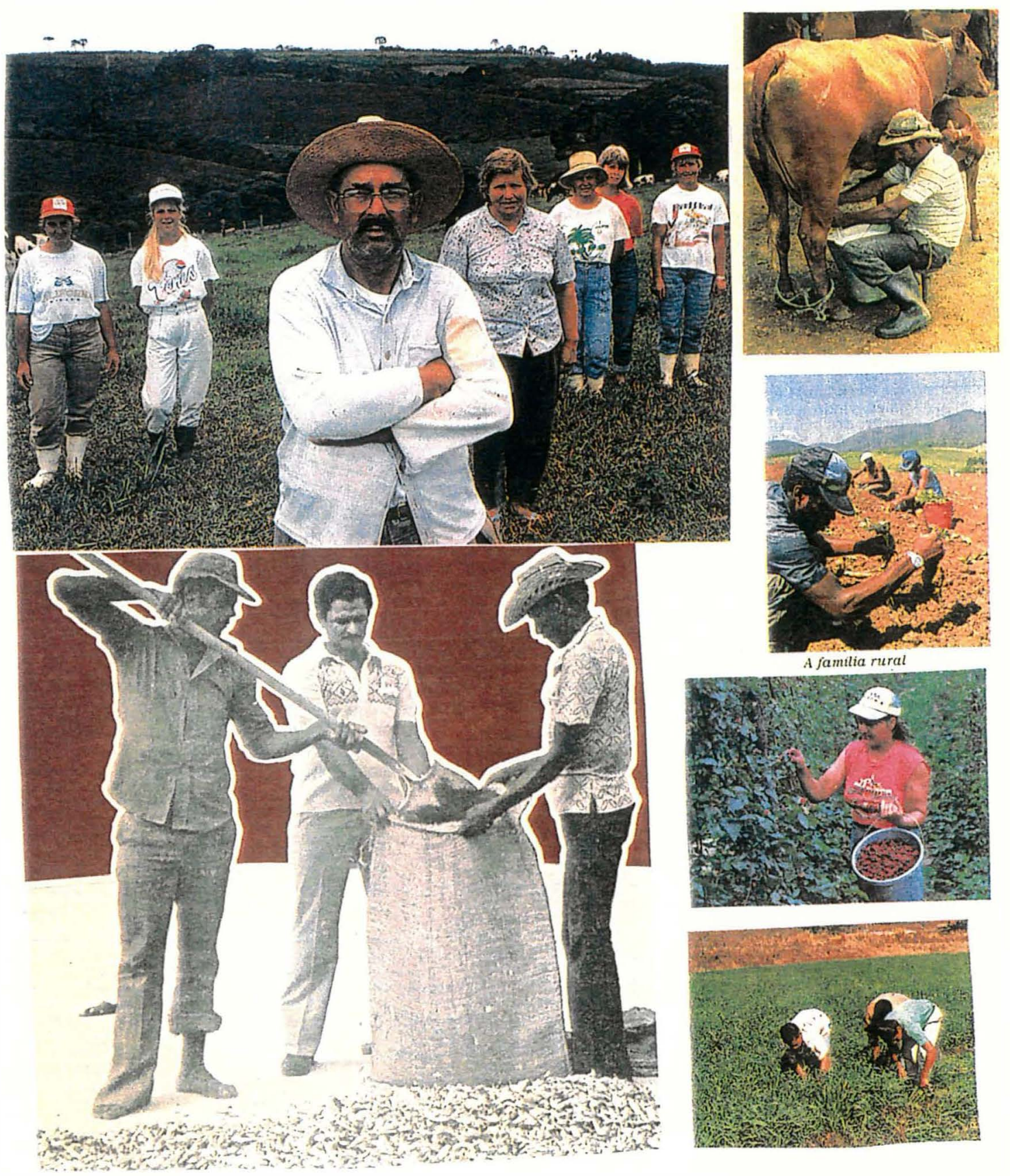

Figura 9- Cartão que ilustra o objetivo de maximizar o uso da mão-de-obra permanente. 
Objetivo considerado na escolha do que plantar e do que criar em cada gleba de terra de minha propriedade:

\section{ALIMENTOS BÁSICOS, QUANTO MAIS MELHOR!}

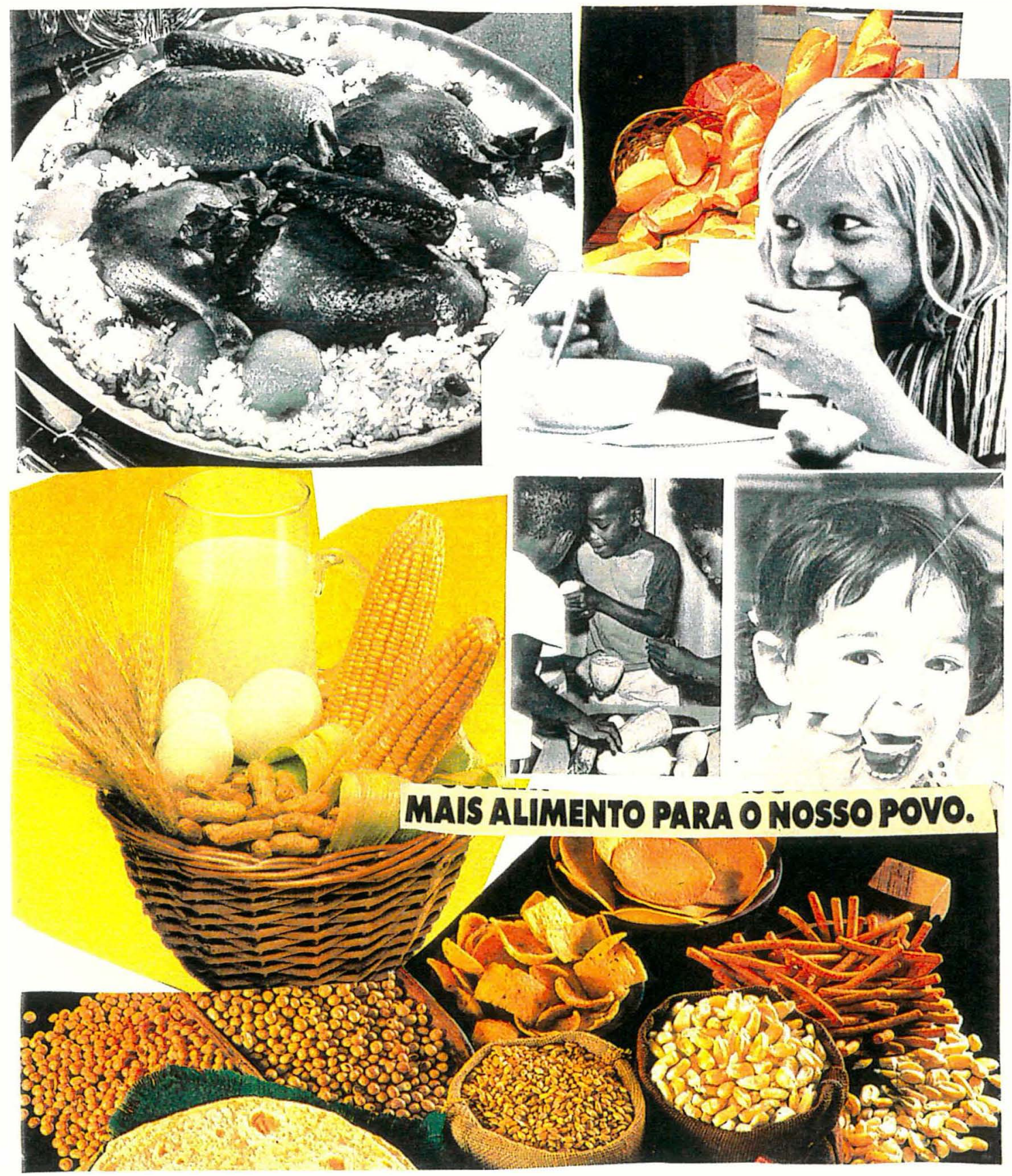

Figura 10- Cartão que ilustra o objetivo de maximizar a produção de alimentos básicos. 
Objetivo considerado na escolha do que plantar e do que criar em cda gleba de minha propriedade:

\section{estabilidade no uso da mão-de-obra quanto mais estável melhor}
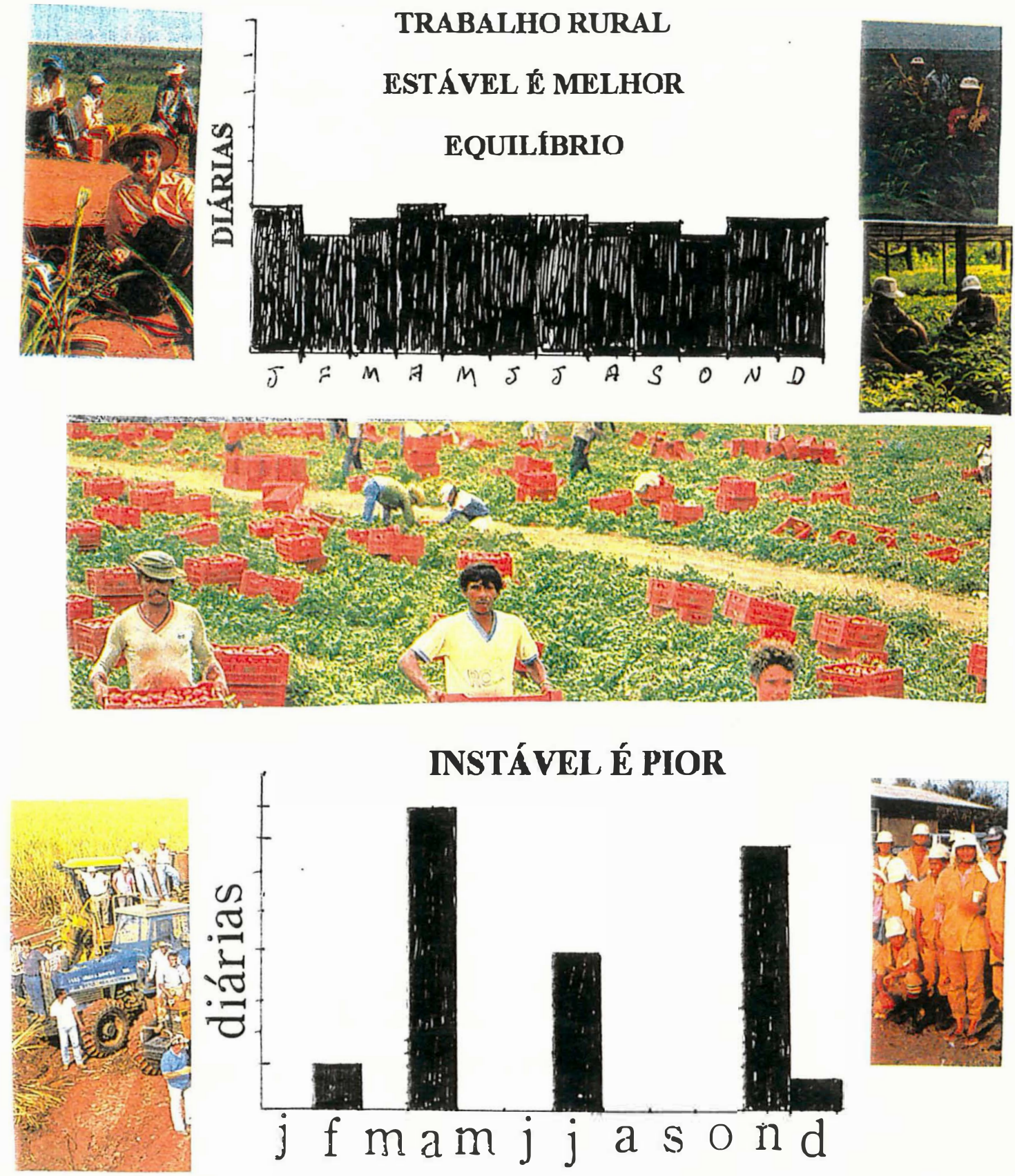

Figura 11- Cartão que ilustra o objetivo de minimizar a estacionalidade do uso da mão-de-obra. 